\title{
Scary warnings and rational precautions : a study into fear arousal and its contribution to precautionary motivation
}

Citation for published version (APA):

Ruiter, R. A. C. (2000). Scary warnings and rational precautions : a study into fear arousal and its contribution to precautionary motivation. [Doctoral Thesis, Maastricht University]. Universiteit Maastricht. https://doi.org/10.26481/dis.20001215rr

Document status and date:

Published: 01/01/2000

DOI:

10.26481/dis.20001215rr

Document Version:

Publisher's PDF, also known as Version of record

Please check the document version of this publication:

- A submitted manuscript is the version of the article upon submission and before peer-review. There can be important differences between the submitted version and the official published version of record.

People interested in the research are advised to contact the author for the final version of the publication, or visit the DOI to the publisher's website.

- The final author version and the galley proof are versions of the publication after peer review.

- The final published version features the final layout of the paper including the volume, issue and page numbers.

Link to publication

\footnotetext{
General rights rights.

- You may freely distribute the URL identifying the publication in the public portal. please follow below link for the End User Agreement:

www.umlib.nl/taverne-license

Take down policy

If you believe that this document breaches copyright please contact us at:

repository@maastrichtuniversity.nl

providing details and we will investigate your claim.
}

Copyright and moral rights for the publications made accessible in the public portal are retained by the authors and/or other copyright owners and it is a condition of accessing publications that users recognise and abide by the legal requirements associated with these

- Users may download and print one copy of any publication from the public portal for the purpose of private study or research.

- You may not further distribute the material or use it for any profit-making activity or commercial gain

If the publication is distributed under the terms of Article $25 \mathrm{fa}$ of the Dutch Copyright Act, indicated by the "Taverne" license above, 


\section{SCARY WARNINGS AND RATIONAL PRECAUTIONS}

A STUDY INTO FEAR AROUSAL AND ITS CONTRIBUTION

TO PRECAUTIONARY MOTIVATION 



\title{
SCARY WARNINGS AND RATIONAL PRECAUTIONS
}

\author{
A STUDY INTO FEAR AROUSAL \\ AND ITS CONTRIBUTION \\ TO PRECAUTIONARY MOTIVATION
}

\section{PROEFSCHRIFT}

ter verkrijging van de graad van doctor aan de Universiteit Maastricht, op gezag van de Rector Magnificus, Prof. Dr. A.C. Nieuwenhuijzen Kruseman, volgens het besluit van het College van Decanen, in het openbaar te verdedigen op vrijdag I5 december 2000 om 10.00 uur

door

Robert Antonie Christiaan Ruiter 


\section{promotores}

Prof. dr. G.J. Kok

Prof. dr. B. Verplanken (University of Tromsø, Norway)

beoordielingscommissie

Prof. dr. N.K. de Vries (voorzitter)

Dr. R.M. Meertens

Prof. dr. H.L.G.J. Merckelbach

Prof. dr. W. Stroebe (Universiteit Utrecht)

Prof. dr. K. Witte (Michigan State University, USA)

\section{colofon}

Lay-out: NORA OOSTING [grafische vormgeving], Maastricht Cover design: Jeroen Ruiter

Printing: Unigraphic, Maastricht

Painting on cover: (C) The Munch Museum, Dedalus Foundation, 2000c/o Beeldrecht, Amstelveen

ISBN 90-5681-090-1

The studies presented in this dissertation were conducted under the auspices of The Maastricht Health Research Institute for Prevention and Care (HEALTH) at Maastricht University, The Netherlands. HEALTH is part of the Netherlands School of Primary Care Research (CaRe), which has been acknowledged since 1995 by the Royal Dutch Academy of Art and. Sciences (KNAW). 


\section{ACKNOWLEDGEMENTS}

I express my gratitude to Gerjo Kok and my parents for their initiatives, advices and support during my work on the present thesis. They gave me the right motivation and made this thesis possible.

I thank the following people for making it all a lot easier through providing good advices, support, and a lot of fun: Charles Abraham, Theo van Achterberg (and Billie), Mauriçe Alberts, Hans Brug, Matt Commers, David De Cremer, Anton Dijker, Gerdien van Eersel, Pepijn van Empelen, Adrian Faupel, Marja Hortulanus, Harm Hospers, René Lion, Ree Meertens, Miranda van Reisen, Selma en Jeroen Ruiter, Bas Verplanken, Mark van Vugt, Marieke Werrij, colleagues Department of Health Education and Promotion (1995-1999), colleagues Department of Experimental Psychology (1999-present).

Rob Ruiter 



\section{CONTENTS}

ChAPTER 1 Overview

CHAPTER 2 Scary warnings and rational precautions: A review of the psychology of fear appeals

ChAPTER 3 Evoked fear and effects of appeals on attitudes to performing breast self-examination: An information processing perspective

CHAPTER 4 The effects of severity and susceptibility information on the systematic processing of persuasive messages

CHAPTER 5 The effects of fear-arousing health information on processes of fear control and danger control: The (presumed) moderating role of individual differences in efficacy expectancies

CHAPTER 6 Strengthening the persuasive impact of fear appeals: The role of action framing

CHAPTER 7 The effects of threatening information and fear arousal on action planning

REFERENCES

SUMMARY

SAMENVATtING

CURriculum VItAE 145 



\section{CHAPTER I}

\section{OVERVIEW}




\section{INTRODUCTION}

The doctoral thesis presented here describes a research project into the effects of fear appeals on precautionary motivation. A fear appeal is a persuasive communication that attempts to motivate recipients into safer behaviour by arousing fear (Rogers, 1983). Fear is an unpleasant emotional state that is triggered by the perception of threatening stimuli. This state is accompanied by physiological arousal and, importantly, motivates cognitive, affective and behavioural action to realise conditions that are perceived as safe (cf. Frijda, 1986). Being a motivator to action, fear could thus serve an important role in increasing the effectiveness of health campaigns. Indeed, examples of fear-arousing health campaigns are numerous. The most famous ones worldwide are probably those in the area of AIDS prevention, for example campaigns portraying death-referring images such as tombstones in the UK and the grim reaper in Australia. In the Netherlands, the annual fireworks campaigns and, in smoking prevention, the young girl that changes into an old woman while lighting a cigarette are well-known examples. From a scientific but also a practical point of view, the important question to ask, however, is to what extent the use of fear arousal may motivate people to safer behaviour? This question also served as the starting point for the studies described in the present thesis. It is a relevant question because the few evaluation studies of fear-arousing public campaigns and many laboratory studies that tested this question cast doubt on the effectiveness of fear appeals in motivating self-protective action.

Before we started in 1995, the effects of fear arousal on attitude and behaviour change had attracted the interest of researchers, in particularly those in the field of experimental social psychology, for more than four decades. This long-lasting interest could not prevent that empirical research suffered from a lack of consistent findings. Although relevant components of effective fear appeals had been successfully identified - that is, information about, on the one hand, the severity of the threat and the recipient's susceptibility to it and, on the other hand, the effectiveness and feosibility of the recommended action - it was not clear how both groups of variables, threat and efficacy variables respectively, relate to each other in influencing precautionary motivation and action. In other words, the effects of fear appeals on measures of attitude and behaviour change were still not fully understood.

Thus, there continued to be a strong scholarly need for theorising on the effects of fear appeals supported by empirical studies in controlled settings. The present research started with reviewing the fear appeal literature, which is presented in chapter 2, followed by six experimental studies that are reported in the chapters 3 to 7 . The current chapter provides an overview 
of these chapters by summarising the main findings and conclusions and discusses their implications for future research and for the use of fear appeals in health education practice.

\section{OVERVIEW OF THE STUDIES}

\section{Literature review}

The literature study presented in chapter 2 starts with a review of past and current research into the effects of fear appeals on precautionary motivation, and discusses related theoretical frameworks. Past research has mainly been based on the assumptions that (i) fear-arousing information motivates people to behaviour change and (ii) efficacy beliefs have a central role in this process. Protection motivation theory by Rogers $(1975,1983)$ is the most popular theoretical framework that models these assumptions. It suggests that fear-arousing (or threatening) information motivates people to undertake self-protective action, which is operationalised as the intention to perform the recommended action, but only if threatened and fearful people believe that the recommended action is effective in averting the threat (response efficacy) and they feel capable to perform it (self-efficacy). If response efficacy or self-efficacy is low, successful persuasion of fearful message receivers will be unlikely. In short, an interaction effect between threat and efficacy variables on protection motivation is assumed. However, the empirical support for this interaction effect has been weak, or at best inconsistent (Eagly \& Chaiken, 1993; Rogers \& Prentice-Dunn, 1997).

Current research has tried to explain this inconsistency along two lines of research. The first line of research assumes that a better understanding of mediating cognitive processes may explain the inconsistency regarding the interaction effect of threat and efficacy variables on protection motivation (cf. Eagly \& Chaiken, 1993). Several studies examined the effects of threatening information on the cognitive processing of threat-relevant persuasive information (e.g., Baron, Logan, Lilly, Inman, \& Brennan, 1994), among which also two studies in the present thesis that are reported in, respectively, the chapters 3 and 4 (see also below). The second line of research is based on the notion that for a full understanding of the effects of fear appeals research attention should not be restricted to identifying relevant belief determinants of message acceptance (cf. Leventhal, 1970; Rogers, 1975). It should also be directed to the emotion of fear and its effects on defensive processes, because the latter may interfere with the adoption of 
the recommended response ( $\mathrm{cf}$. Witte, 1992a). In the present thesis, two experimental studies that are reported in chapter 5 addressed this research line.

On the basis of our review of past and current research, however, we concluded that current models that explain the effects of fear appeals do not adequately distinguish between emotional (i.e., fear arousal) and cognitive (i.e., threat perception) responses to fear appeals and, in general, were not well supported. Therefore, a process model has been formulated (see Figure 2.1) that should guide future research into the effects of fear appeals. The model suggests a complex pattern of relationships between fear arousal and self-protective action, and argues for a re-conceptualisation of fear arousal and its relationship to processes that may interfere with (e.g., denial) or facilitate (e.g., positive attitude) the acceptance of recommended precautions. As such, the model identifies important questions for future research, some of which have been addressed in the empirical studies we have carried out and that are summarised next.

\section{Fear arousal and information processing}

A first research question that is addressed by two empirical studies concerns the extent to which. fear arousal and threat perceptions prompt precautionary motivation through enhanced systematic processing of relevant persuasive information. In response to the inconsistency of empirical findings in fear appeal research, Eagly and Chaiken (1993, p. 446) suggested to link fear appeal research with research derived from dual process theories of attitude change. The latter especially focus on identifying cognitive processes that mediate the effects of presented information on attitude change. Relevant models in this area are the Elaboration Likelihood Model (Petty \& Cacioppo, 1986) and the Heuristic-Systematic Model (Chaiken, 1980; Chaiken, Liberman, \& Eagly, 1989). These models suggest that attitude change does not have to result from central route or systematic information processing, that is on the basis of a critical evaluation of presented arguments. Attitude change may also result from less cognitively demanding processes that base the attitude on simple peripheral cues such as the lay-out of the message, or on "rule-of thumb" (heuristic) reasoning such as "the source looks trustworthy so she might be right". It is further assumed that attitudes that result from systematic processing, are more stable over time, more resistant to counter-argumentation, and, important for health education practice, better predictors of behaviour (for a recent discussion of dual process models and empirical findings, see Chaiken \& Trope, 1999).

Based on the notion that fear is a motivator to (cognitive) action (Frijda, 1986) and some earlier research that examined the effects of threat information on systematic processing (Baron et al., 1994; Gleicher \& Petty, 1992; Meijnders, 1998; Pointer \& Rogers, 1993), it was hypothesised that mild 
fear arousal results in more systematic processing of persuasive precautionary information than low fear arousal. The first study, which is reported in chapter 3, found partial support for this hypothesis. Female first-year undergraduates first read information in which fear of breast cancer was manipulated. After measuring fear arousal, respondents read a persuasive message about performing breast self-examination (BSE). Analyses revealed no support for more argument-based processing after reading the mild fear-arousing message than after reading the low fear-arousing message. Inclusion of reported fear instead of manipulated fear, however, revealed that respondents who expressed greater fear more strongly based their attitude toward BSE performance on the arguments provided. These findings did not replicate those of earlier studies (Baron et al., 1994; Gleicher and Petty, 1992) in which the fear (threat) manipulation successfully induced systematic processing. These latter studies, however, missed a measure of fear arousal that preceded the persuasive message while, as in our study, fear was manipulated by combining severity and susceptibility information. This confounding of, respectively, fear arousal, severity perceptions and susceptibility perceptions made it impossible to disentangle the effects of these three variables on the systematic processing of persuasive information. Our findings suggest that fear arousal, rather than perceptions of severity and susceptibility, may be related to the careful processing of persuasive information.

After studying the effects of fear arousal, our second empirical study, which is reported in chapter 4, examined the independent effects of severity and susceptibility information on the systematic processing of threat-relevant persuasive information. First-year female undergraduates came to the laboratory and read information about breast cancer and BSE performance. The first study was extended by including measures of cognitive responses, which served as an extra indicator of systematic processing, and performance of BSE within the next three months. Despite the fact that severity and susceptibility information successfully manipulated severity and susceptibility perceptions, respectively, no empirical support was found for the hypothesised independent effects of these two information components on the systematic processing of persuasive information about BSE performance. Additional analyses with reported fear could not be carried out because fear arousal was deliberately measured after the dependent variables to not interfere with ongoing cognitive processes, thus leaving it unclear what residual level of fear was measured and making causal interpretations impossible. The manipulations also did not affect BSE performance.

In combination, our two studies suggest that fear arousal, rather than threat perceptions may prompt systematic processing. This conclusion could, however, be premature for three reasons. First, inclusion of reported fear in the first study does not exclude the possibility that unknown varia- 
bles may have been responsible for the reported findings (e.g., trait anxiety). Second, susceptibility information successfully increased perceptions of personal relevance, but in contrast to dual process research that consistently identifies perceived personal relevance as an important motivator of systematic processing (cf. Johnson \& Eagly, 1989), variations in susceptibility information did not influence systematic processing. Third, the relevance of breast cancer in the life of women - in the Western world breast cancer is the most common form of cancer among women - may necessitate more implicit experimental procedures to study the effects of fear-arousing information on systematic processing (see also chapter 2). In conclusion, the effects of fear arousal and threat perception on the likelihood of systematic processing of persuasive information are still not fully understood. More research is needed to examine how emotional and cognitive components may contribute independently or in combination with each other to establish precautionary motivation.

\section{The moderating role of efficocy perceptions}

A second research question that is addressed by two experimental studies presented in chapter 5 concerns the moderating role of efficacy perceptions in processes of danger control and fear control. Danger control processes have the intention to avert the presented threat, while fear control processes focus on reducing or eliminating the experienced fear (cf. Leventhal, 1970). More recent studies have operationalised the former by measures of attitude, intention and behaviour change, while the latter are indexed by measures of avoidance and denial (e.g., Rippetoe \& Rogers, 1987; Witte, Berkowitz, Cameron, \& McKeon, 1998). The latest theoretical framework of fear appeals, the extended parallel process model (EPPM; Witte, 1992a), suggests that efficacy perceptions have a moderating role in both danger control processes and fear control processes. Specifically, EPPM assumes that, in response to accepting risk information, threat perceivers, first evaluate the effectiveness and feasibility of the recommended protective action. If the recommended action is thought to be effective and possible, then the motivation to accept the recommendation will increase, resulting in more positive attitude and intention to avert the threat (i.e., danger control). Conversely if the recommended action is evaluated as ineffective or impossible to undertake, then continuing threat perception will result in fear arousal. At this point fear control processes are instigated that may result in denial and avoidance coping.

To test this hypothesis, we focused on the role of individual differences in efficacy perceptions and thus did not manipulate efficacy perceptions. Our focus better relates to everyday practice in which fear appeals are mainly used in mass media campaigns. These campaigns result in limited exposure 
and therefore are not likely to influence efficacy perceptions. Thus, in accordance with EPPM, only those in the target population that already have high efficacy perceptions might profit from these campaigns. To test EPPM, two experimental studies were carried out that manipulated fear of breast cancer and measured existing efficacy perceptions toward BSE performance, either after the dependent variables (experiment 3 ) or well in advance of the actual study (experiment 4). The findings on measures of attitude and intention confirmed the earlier reported inconsistency concerning the interaction of threat and efficacy variables in processes of danger control (cf. Eagly \& Chaiken, 1993, see also chapter 2). Experiment 3 supported the prediction of EPPM that the positive effect of threatening information on attitude and intention is restricted to respondents who expressed high efficacy expectancies, while experiment 4 did not find support for this interaction effect between threat and efficacy variables on indices of danger control. With regard to the role of efficacy perceptions in processes of fear control the findings were more consistent, although they also did not support EPPM predictions. Both experiments reported main effects of fear arousal on measures of defensive avoidance, issue derogation and perceived manipulation that were not moderated by efficacy expectancies. The latter thus do not seem to play an important role in processes of fear control.

In conclusion, the experiments reported in chapter 5 tested the assumptions of a leading theoretical framework in explaining the effects of fear appeals. However, rather than confirming EPPM's predictions, the findings confirmed the conclusion in chapter 2 that another model is implicit in the fear appeal literature. The findings indeed may suggest that (i) fear control responses are less dependent on efficacy beliefs than danger control responses and (ii) the effects of threat perception on precautionary motivation are not moderated, but may be mediated by efficacy expectancies (see chapter 2, for more detail).

\section{Strengthening precautionary information}

Finally, a third research question was based on the model presented in. chapter 2 and concerned the presentation of precautionary information. Empirical findings in attitude-behaviour research, in general, and fear appeal research, in particular, suggest that efficacy perceptions are more proximal to the formation of protection motivation than threat perceptions. For example, Rippetoe and Rogers (1987) report evidence that threat perceptions motivate action contemplation. but that the kind of action that will be undertaken is dependent on response efficacy and self-efficacy perceptions. Precautionary information thus should highlight the efficacy and feasibility of recommended actions, next to other variables that may be important such as concerns over response costs and the approval of important others 
(i.e., normative perceptions). Two recent innovations in persuasion research may help in optimising the presentation of precautionary information: the valence of wording (Rothman \& Salovey, 1997) and the use of volitional prompts (Gollwitzer \& Schaal, 1998). Both were tested under conditions of fear arousal in two experimental studies that are reported in chapters 6 and 7 . respectively.

To start with valence of wording, research drawing upon the work of Kahneman and Tversky $(1979,1984)$ and Meyerowitz and Chaiken (1987) has indicated that formulating what is objectively the same information in terms of either gains or losses (i.e., action framing) systematically influences decision making. In a review of this literature, Rothman and Salovey (1997) suggested that the type of behaviour that is promoted determines which action frame will be most effective. Findings suggest that behaviours focussing on early detection of health problems (e.g., BSE performance, medical screening) are best promoted by frames that present the negative consequences of not performing the safer behaviour (e.g., "Failing to use a disclosing rinse before brushing limits your ability to detect areas of plaque accumulation": Rothman et al., 1999. p. 1361), whereas primary prevention behaviours (e.g., condom use, not smoking) are best promoted by frames that emphasise the positive consequences of performing the safer behaviour (e.g., "People who use a mouth rinse daily are taking advantage of a safe and effective way to reduce plaque accumulation"; Rothman et al., 1999, p. 1361). Rothman and Salovey (1997) explain these findings in terms of the greater perceived risk associated with detection behaviours and Kahneman and Tversky's (1984) prospect theory. The latter predicts that people prefer risky options when considering losses (i.e., negative consequences), while preferring certain options when considering gains (i.e., positive consequences).

In, to our knowledge, the first study that examined the effects of action framing under conditions of fear arousal, we hypothesised that the persuasive impact of fear appeals may increase by tailoring the valence of the persuasive information to the characteristics of the targeted behaviour. More specifically, it was predicted that more fear of breast cancer results in a more positive attitude toward performing BSE after reading persuasive information that stresses the negative consequences of not performing BSE (i.e., loss frame) compared to reading information that stresses the positive consequences of performing BSE (i.e., gain frame). Our findings among female undergraduates provided some evidence for the hypothesis on a relative measure of BSE importance. Among respondents who reported mild fear arousal, those who read the loss frame gave higher importance to BSE performance when comparing this behaviour with five other health behaviours than those who read the gain frame. No framing effects were found among 
respondents who reported low fear arousal. It is concluded that the findings are promising and thus may stimulate future research. This research should then give special attention to cognitive and affective processes that mediate the effects of action framing under conditions of fear.

Regarding the use of volitional prompts, recent work suggests that postdecisional or volitional processes explain why some intenders act while others do not. Largely based on the work of Gollwitzer it has been demonstrated, for example in a study by Orbell, Hodgkins, and Sheeran (1997) that forming "implementation intentions", that is, specifying when and where an intention is to be enacted, can distinguish between intenders who do and those who do not act. Gollwitzer argues that such detailed plans create cues to action in relevant environments, which prompt intenders to act automatically when encountered. Drawing upon early work of Leventhal and colleagues who studied the relationship between frightening information and action instructions (e.g., Leventhal, Singer, \& Jones, 1965), we tested the effects of fear arousal on postdecisional processes - in particular, on action planning. It was hypothesised that fear of breast cancer will motivate female undergraduates to think about actions that can avert the presented threat such as BSE performance. It was further predicted that this hypothesis would be especially true among respondents who stated positive intentions toward performing BSE. The findings supported the first hypothesis but not the second hypothesis. Fear arousal thus seems to result in more planning of precautionary action. The prediction that this effect is stronger among high intenders compared to low intenders may be better tested by including a measure of BSE performance in future research. However, because debriefing procedures with the participants still in the laboratory are limited, other precautions should be taken that prevent any long-term negative effects of the fear manipulation. One might think of developing more immediate measures of behaviour such as enlisting for an instruction session about BSE performance led by a physician.

\section{IMPLICATIONS FOR RESEARCH}

The theoretical and empirical studies summarised above describe a mixed pattern of findings. in fact, they confirm other reviewers' conclusions that existing theoretical frameworks fail to explain the effects of fear appeals on the establishment of precautionary motivation and self-protective action (e.g., Eagly \& Chaiken, 1993; Sutton, 1992). As argued more extensively in chapter 2 , a change in our thinking about the structure of fear arousal and 
its relationship to threat perception, fear control, and precautionary motivation is therefore justified.

With regard to the structure of fear arousal, our threat manipulations successfully aroused fear in all studies, but threatening information and selfreports of fear had different effects on measures of information processing, fear control, danger control, and action planning. This suggests that there is more that contributes to fear arousal than just threat perception. Individual difference variables such as trait anxiety and previous experiences may play a role, but have hardly received empirical support in fear appeal studies (Witte \& Allen, in press). Furthermore, it is possible that reported fear is a conscious reflection of threat and efficacy appraisals (and possibly a third variable) and thus does not reflect true fear arousal, which is conceptualised by emotion theories as the product of automatic, preconscious processing (cf. Frijda, 1986). Therefore, to capture the true effects of fear arousal independent, continuous measures are needed such as the galvanic skin response and the startle reflex that measure fear arousal on-line (Lang, 1995).

Our findings further suggest that fear arousal, rather than threat perceptions, mediates the effects of threat information on indices of systematic processing. Future research is needed to provide further support for this conclusion. However, whether existing procedures that make use of argument strength manipulations are sufficiently sensitive to identify different modes of attention and information processing may be doubted. Especially if the topic (and thus most arguments) is well known to the target audience, levels of attention to the message may decrease rapidly. More implicit measures of, for example, eye movements and fixation durations may yield more reliable conclusions about the kind of attention fearful participants spend to relevant persuiasive information (cf. Groner, McConkie, \& Menz, 1985). On the other hand, one may wonder whether respondents who are confronted with frightening messages give high priority to careful evaluation of the arguments presented. We found clear effects of threat information on fear arousal, main effects of fear arousal on precautionary motivation (mainly on attitude), but hardly any effects on measures of systematic information processing, and strong effects of fear arousal on measures of fear control such as message derogation.

Another important line for future research is to determine whether fear control processes have a more automatic nature than danger control processes " and how both control processes are related to each other. The absence of a moderating role of efficacy perceptions in the relationships between fear arousal and fear control responses (see chapter 5) and research on affective processes in general (see Wegner \& Bargh, 1998) suggest that fear control processes occur automatically and pre-consciously. The attitudebehaviour literature, on the other hand, suggests that danger control proces- 
ses are strongly guided by efficacy perceptions; in fact, more strongly by efficacy perceptions than by threat perceptions, which implies that efficacy perceptions mediate instead of moderate the effects of threat information on precautionary motivation. In addition, it is not clear whether both control processes run parallel to each other or have a sequential relationship. If fear control processes are indeed automatically instigated, they may precede danger control processes. Fear control processes may then bolster intention formation while surpassing efficacy considerations, or their outcomes (e.g., denial) may interfere with the establishment of precautionary motivation and action (see also chapter 2).

Our last two studies provide some indications that the effectiveness of fear appeals may increase significantly from incorporating recent innovations in persuasion research in their reassuring parts, such as accurate valence of wording and use of postdecisional prompts. However, more research is needed that identifies relevant variables that mediate the effects of action framing and action planning under conditions of fear, next to providing information that is tailored to individual needs (see Brug \& De Vries, 1999).

Finally, the experimental studies reported in the chapters 3 to 7 all covered the area of early detection of breast cancer by performing breast self-examination and included young female undergraduates as research participants. This may severely limit the generalisability of our findings. Future research is therefore needed that should extend our studies to other risk behavioūs and populations.

\section{CONCLUSION AND IMPLICATIONS FOR PRACTICE}

The present research tried to bring more clarity to the area of health-related fear appeals, but instead identified a number of important research questions that await further tests. Our empirical findings, nevertheless, suggest that fear arousal may prompt precautionary motivation through enhanced systematic processing, but at the same time may instigate responses that deny or avoid the presented threat and thus hinder adaptive coping. A review of the fear appeal literature additionally suggested that precautionary information more effectively promotes a positive attitude toward safer behaviour than threatening information. Health messages may thus profit from information that (i) is tailored to the needs of its recipients and the characteristics of the promoted behaviour and (ii) provides specific action instructions and prompts, rather than from information that stresses the negative consequences of not performing the safer behaviour. If the use of fear arous- 
al in health campaigns is found necessary, then this should be accomparied by serious reservations. It should only be approved if extensive pilot tesing has proven the effectiveness of its use and guarantees the absence of iny harmful side effects. 


\section{CHAPTER 2}

SCARY WARNINGS AND RATIONAL PRECAUTIONS: A REVIEW OF THE PSYCHOLOGY OF FEAR APPEALS

Submitted for publication as:

Ruiter, R. A. C., Abraham, C., \& Kok, G. (2000).

Scary warnings and rational precautions: A review of the psychology of fear appeals. Manuscript under revision. 


\section{INTRODUCTION}

Public health campaigns frequently combine messages highlighting threats to well-being with recommendations to take protective action. This practice is founded on implicit assumptions about the effects of fear arousal and perceived threat on decision making and action regulation. Considerable research efforts have been devoted to investigating these processes, but it is questionable whether health-related fear appeals are evidence-based in the sense that they reflect research findings.

Fear-inducing HIV-preventive campaigns in 1980's and 1990's used images of death such as tombstones (in the UK) or the grim reaper (in Australia), but evaluations have cast doubt on the effectiveness of such campaigns (e.g., Rigby, Brown, Anagnostou, Ross, \& Rosser, 1989; Ross, Rigby, Rosser, Anagnostou, \& Brown, 1990; Sherr, 1990). Moreover, reviews of intervention effectiveness have not identified fear arousal as a feature that distinguishes between effective and ineffective interventions (Fisher \& Fisher, 1992; Kirby et al., 1994). Yet fear-arousing messages continue to be employed in health promotion. This is illustrated by recent smoking prevention campaigns designed in Australia, the Netherlands and Canada, including plans to illustrate warning messages on cigarette packets with pictures of diseased lungs (Stivoro, 1997; Research and Evaluation Committee of the National Expert Advisory Committee on Tobacco, 1999; http://www.hcsc.gc.ca/english/archives/releases/2000_07e. htm).

Clarification of research findings in this area and their implications for practice as well as identification of unanswered questions would provide a foundation for developing evidence-based practice. This paper reviews theoretical models and empirical findings pertinent to the relationship between fear arousal, motivation and self-protective action. It highlights the sometimes blurred distinction between fear arousal and threat perception and links research on fear arousal to that on deliberative and volitional processes underpinning precautionary motivation and action. Unanswered questions are identified but it is suggested that, on the basis of available evidence, fear arousal should be used with greater caution in health promotion.

\section{WHAT IS A FEAR APPEAL?}

A fear appeal is a persuasive communication attempting to arouse fear in order to promote precautionary motivation and self-protective action (cf. Rogers, 1983; Rogers \& Deckner, 1975). Fear arousal is an unpleasant emo- 
tional state triggered by the perception of threatening stimuli. It is assumed that such states involve physiological arousal and motivate cognitive, affective, and behavioural responses directed toward alleviation of threat and reduction or elimination of fear (cf. Dijker, Koomen, \& Kok, 1997; Frijda, 1986). This definition distinguishes fear arousal from cognitive processes involved in attitude change, including cognitive dissonance (e.g., Cooper \& Fazio, 1984: Harmon-Jones, Brehm, Greenberg, Simon, \& Nelson, 1996), as well as from the concept of negative mood (Forgas, 1992). Thus while threat perception may be inherent to fear arousal (Frijda, 1986; Lazarus, 1991a; Lazarus, 1991b; Lazarus \& Folkman, 1984: Zajonc, 1980; Zajonc, 1984) the former does not necessitate the latter (Leventhal, 1970; Rogers. 1983).

Fear appeals typically provide two types of information. First, an attempt is made to arouse fear by presenting a threat (e.g. "HIV infection") to which the recipient is susceptible (e.g., "having unprotected sex puts you at risk for acquiring AIDS") and which is severe (e.g." "AIDS is a deadly disease"). Secondly, a search for "safety conditions" is prompted by recommending protective action (e.g., "by using condoms you can prevent HIV infection"). Such action may be presented as effective in neutralising the threat (e.g." "condoms prevent HIV infection during sexual intercourse") and easy to execute (e.g., "condoms can be bought everywhere and are easy to use"). This ideal structure has changed little during more than 45 years of research into fear appeals (Eagly \& Chaiken, 1993; Witte, 1992a).

\section{FEAR AS A LEARNING-ENHANCING DRIVE}

The systematic analysis of the processes mediating the effects of fear appeais on persuasion began with the development of the Drive Reduction Model of persuasion by Carl Hovland and colleagues (Hovland, Janis, \& Kelley, 1953). This model and its extensions, as formulated by Janis (1967) and McGuire (1968, 1969), highlighted motivational processes (or drives), such as attitudes, goals, needs and especially emotional arousal, that explain the effects of communication on action (Eagly \& Chaiken, 1993). Fear was portrayed as a drive state motivating trial-and-error behaviour that may reduce the drive. Drawing upon learning theory principles, it was proposed that fear arousal enhances message acceptance when the message also prompts mental rehearsal of the recommended precaution that reduces fear. Consequently, high levels of fear arousal may fail to prompt change because rehearsal of recommended precautions may result in inadequate fear reduction; hence 
the assumption of a curvilinear relationship between fear arousal and persuasion. Janis (1967) and McGuire $(1968,1969)$ predicted an inverted Ushaped relationship, with moderate levels of fear arousal (defined by personal and contextual factors) resulting in maximum persuasion. Their models postulated (albeit supposing different underlying processes) that moderate fear motivates precautionary action (i.e., acceptance of recommended behaviour), whereas high fear may instigate defensive processes that interfere with message acceptance (e.g., derogation of the message content, denying the threat). In the latter case risk behaviour will either remain unchanged or may be intensified (see Rogers, 1983, on boomerang effects).

Empirical support for drive reduction models is weak. The hypothesized curvilinear relationship has only rarely been observed (Boster \& Mongeau, 1984; Eagly \& Chaiken, 1993; Janis \& Leventhal, 1968; Leventhal, 1970; Sutton, 1982). Janis and Leventhal (1968) concluded that most studies found a positive linear relationship in which greater message acceptance was more likely in high fear-arousing conditions (e.g., Berkowitz \& Cottingham, 1960; Leventhal \& Niles, 1965; Leventhal, Singer, \& Jones, 1965). Janis and Feshbach (1953) reported greater change in attitudes and dental hygiene behaviours after presenting groups of high school students mild rather than strong fear appeals but this finding has not been replicated. Indeed an attempted replication by Leventhal and Singer (1966) found the reverse effect: greater attitude and behaviour change after a strong fear appeal than after moderate or weak fear appeals. It should be noted, however, that practical and ethical restrictions mean that laboratory experiments rarely generate intense fear (cf. Boster \& Mongeau, 1984; Janis \& Leventhal, 1968). It remains possible, therefore, that high fear arousal may prompt avoidance responses due to, for instance, feelings of hopelessness (see Greenberg, Solomon, \& Pyszczynski, 1997, for a recent review).

Empirical tests have also failed to confirm the postulated mediating role of fear reduction in fear arousal-persuasion relationships. Hendrick, Giesen, and Borden (1975), L.eventhal and Singer (1966), and Mewborn and Rogers (1979) found that lower fear, following fear appeals and the presentation of precautionary recommendations, was not predictive of precautionary motivation or action. Overall then, empirical findings have not confirmed predictions derived from drive reduction models and, in particular, there is little support for the fear reduction hypothesis (Beck \& Lund, 1981: Eagly \& Chaiken, 1993; Leventhal, 1970). 


\section{THE COGNITIVE BASIS OF PRECAUTIONARY MOTIVATION}

Leventhal $(1970,1971)$ reviewed this literature and argued for greater research emphasis on the cognitive antecedents of self-protective action. His Parallel Response Model (PRM, Leventhal, 1970) suggests that fear appeals incorporate different stimuli that trigger distinct motivational and coping responses, particularly fear control and danger control. Fear control can be thought of as involving emotion-focussed coping (Lazarus \& Folkman, 1984) that generates reassurance through denial of the threat or derogation of the message. It is maladaptive because it does not avert the perceived threat (Leventhal, 1971; Witte, 1992a). Danger control, on the other hand, refers to cognitive processes orientated toward the presented threat, rather than the evoked fear. Danger control responses may prompt protective action. Leventhal $(1970,1971)$ argued that fear and danger control responses may operate independently but that one may dominate the other. For example, people with low self-esteem seem to be primarily concerned with fear control and to turn to danger control only when fear has been reduced. In contrast, people high in self-esteem may act directly on controlling presented threats through adaptive action (see Leventhal, 1971). In summary then, the PRM suggests that fear arousal need not precede the danger control processes that underpin precautionary motivation and that fear can also precipitate emotion-focussed processes that may undermine precautionary motivation.

Rogers elaborated Leventhal's work by developing Protection Motivation Theory (PMT; Rogers, 1975). Based on expectancy-value theory (Edwards, 1954), this social cognitive model and its revision (see Maddux \& Rogers, 1983; Rogers, 1983) have become the predominant theoretical frameworks within which fear appeals have been studied. Similar models have been suggested by Beck and Frankel (1981) and Sutton (1982) but attracted fewer empirical tests. PMT suggests that fear appeals instigate two mediating cognitive processes that, together, constitute danger control responses. Threat appratsal (including assessments of threat seriousness and personal suscepribility) and coping appraisal (including assessments of the effectiveness of potential responses and one's ability to undertake these successfully) generate protection motivation defined as "an intervening variable that has the typical characteristics of a motive: it arouses, sustains, and directs activity" (Rogers, 1975 , p. 98). In practice, protection motivation is operationalised as an intention measure (i.e., "the intent to adopt the comminnicator's recommendation"; Rogers, 1983, p. 158).

The revised theory incorporates two additional constructs: rewards associated with maladaptive responses (e.g., smoking and relaxation), and costs assaciated with adaptive responses (e.g., non-smoking and gaining weight). By adding these two belief components. Rogers (1983) redefined PMT as 
an attitude-based model (i.e., attitude = outcome expectations $\mathrm{x}$ evaluations; Fishbein \& Ajzen, 1975), rather than a derivative of the health belief model (see Becker, 1974; Janz \& Becker, 1984; Strecher \& Rosenstock, 1997). In this form, PMT strongly resembles the theory of planned behaviour (Ajzen, 1988) and social cognitive theory (Bandura, 1986), including outcome expectations (specified as beliefs about seriousness, susceptibility, rewards, costs, and response efficacy) and self-efficacy expectations as the main determinants of intention to take self-protective action (cf. Milne, Sheeran, \& Orbell, 2000).

The internal structure of PMT has been extensively tested (for reviews, see Boster \& Mongeau, 1984; Eagly \& Chaiken, 1993; Floyd, Prentice-Dunn, \& Rogers, 2000; Milne et al., 2000). In general, experimental and non-experimental studies have found considerable support for the postulated relationships between threat appraisal (i.e., severity, susceptibility) and coping appraisal (response efficacy, self-efficacy) measures and precautionary intentions, across a wide variety of behavioural domains. However, while the independent associations with intention are relatively strong and consistent for response efficacy and especially for self-efficacy, they are weaker and less consistent for perceived susceptibility and especially perceived severity (Bandura, 1997; Eagly \& Chaiken, 1993; Floyd et al., 2000; Milne et al., 2000; Schwarzer, 1992; Sutton, 1982).

Fewer tests of PMT's capacity to predict behaviour are available. A recent meta-analysis (Milne et al., 2000) indicates that threat appraisal (i.e., severity and susceptibility) and response efficacy measures have small associations with concurrent behaviour, and do not predict future behaviour. By contrast, self-efficacy, response costs and intention were found to be strong predictors of concurrent and future behaviour. Thus, consistent with the larger domain of attitude-behaviour research, efficacy components are stronger determinants of protective action than threat perceptions (see also Floyd et al., 2000; Godin \& Kok, 1996). In other words, it is perceptions of the precautions themselves that appear to be the strongest determinants of protective action.

Research also suggests that threat perception, in the absence of high selfefficacy and response efficacy, may prompt maladaptive fear control coping rather than danger control in the form of preparation for action (Abraham, Sheeran, Abrams, \& Spears, 1994; Rippetoe \& Rogers, 1987; Witte, Berkowitz, Cameron, \& McKeon, 1998). For example, Rippetoe and Rogers (1987) found that perceptions of threat concerning breast cancer prompted both adaptive (e.g., intentions to perform breast self-examination) and maladaptive (e.g., avoid thinking about breast cancer) action. However, the critical factor in determining whether threat perceivers had a preference for adaptive or maladaptive responses were perceptions of response efficacy and 
self-efficacy. Under conditions of high threat, when both efficacy perceptions were high, adaptive responses were preferred over maladaptive ones. Conversely, when both efficacy perceptions were low maladaptive responses were preferred.

The potentially negative effects of threat perception on protective motivation are recognised by PMT. The theory proposes that becoming conscious of the severity of a threat that one is susceptible to will instigate protection motivation but that the nature of this motivation will depend on coping appraisal (i.e., response efficacy and self-efficacy). When recommended protective action is judged to be ineffective in averting the threat or impossible to undertake then no intention to act will result. Consequently, risk behaviour generating the threat will be maintained or even intensified (Rogers, 1983). However, empirical findings are mixed in relation to this proposed interaction effect (Eagly \& Chaiken, 1993; Rogers \& PrenticeDunn, 1997). Some studies report support (e.g., Kleinot \& Rogers, 1982; Maddux \& Rogers, 1983; Rogers \& Mewborn, 1976; Self \& Rogers, 1990) while others do not (e.g., Griffeth \& Rogers, 1976; Mulilis \& Lippa, 1990; Rippetoe \& Rogers, 1987; Rogers \& Thistlethwaite, 1970; Shelton \& Rogers, 1981; Wolf, Gregory, \& Stephan, 1986; Wurtele \& Maddux, 1987). In their review of 15 years of empirical research into PMT, Rogers and PrenticeDunn (1997) stated: "Threat and coping appraisal variables have been found to interact in about one half of the studies in which both classes of variables have been tested" (p. 119, italics added). Thus, while threat appraisal measures have been found to be poor predictors of protective action compared to coping appraisal measures, it is unclear that this can be explained in terms of the proposed interaction between these processes.

PMT served to elaborate what might be meant by danger control processes but focused on threat perception rather than fear arousal. The theory explicitly acknowledges that fear arousal can be the source and the product of threat perception (Rogers, 1983; Rogers \& Prentice-Dunn, 1997), but does not specify a process model implying sequential measurement of fear over time. This cognitive focus has led some authors to replace the term fear appeals with threat appeals (e.g., Beck \& Frankel, 1981), thereby effectively removing questions concerning fear arousal from research into fear appeals. This cognitive focus has also indicated that efficacy perceptions are more powerful predictors of preventive action than threat perception, suggesting that other models such as the theory of planned behaviour may provide equally valid models of the relevant cognitive prerequisites (Godin \& Kok, 1996). 


\section{A RETURN TO FEAR CONTROL PROCESSES}

Witte (1992a) argues that fear control processes need to be understood because they may interfere with the establishment of cognitive antecedents of precautionary intentions (cf. Dillard, 1994). Witte notes that Leventhal's (1970) PRM did not specify how fear control and danger control process are related (cf. Beck \& Frankel, 1981) and that Rogers' (1983) PMT focuses exclusively on danger control processes. To resolve these shortcomings she has proposed her own Extended Parallel Process Model (EPPM; Witte, 1992a) and presented evidence supporting hypotheses generated by EPPM (Witte, 1992b; Witte, 1994; Witte et al., 1998; Witte \& Allen, in press). EPPM proposes that threat perception initially instigates danger control processes. Threat perceivers evaluate recommended action on its effectiveness and feasibility and their psychological response depends on the outcome of this coping appraisal. If the recommended action is thought to be ineffective or impossible then continuing threat perception will result in emotional and, in particular, fear arousal. At this point fear control processes are promoted resulting in denial and avoidance coping. Thus EPPM has the advantage of incorporating both fear and danger control processes. Nevertheless, certain questions remain unanswered. For example, the model does not clarify how these processes operate in parallel. Indeed it tends to imply sequential processing. We return to such questions below.

\section{FEAR AROUSAL AS AN INFORMATION-PROCESSING MODERATOR}

PMT, like other social cognitive models (Conner \& Norman, 1996), assumes rational and deliberative information processing. People perceiving a threat to their health are portrayed as attending carefully to information about recommended action and basing coping appraisals of efficacy and feasibility on the arguments provided. Yet research into dual process models of attitude change (e.g, Chaiken, Giner-Sorolla, \& Chen, 1996; Chaiken, Liberman, \& Eagly, 1989: Petty \& Cacioppo, 1986) suggests that attitudes can be formed and changed through less rational processes, especially when the motivation or cognitive capacities to process information are low. The Elaboration Likelihood Model (ELM; Petty \& Cacioppo, 1986), for example, distinguishes between central and peripheral information processing. The former evokes cognitive change based on consideration of presented arguments but peripheral route processing can result in cognitive change due to other characteristics of the message, such as the expertise of the source. In 
general, central route attitude changes have been found to be more stable and predictive of behaviour and more resistant to counter-argumentation (for useful reviews, see Chaiken \& Trope, 1999; Eagly \& Chaiken, 1993).

The processing of fear-relevant information after the presentation of threatening information has been investigated by several studies (e.g., Baron, Logan, Lilly, Inman, \& Brennan, 1994; Gleicher \& Petty, 1992; Meijnders, 1998; Pointer \& Rogers, 1993). In general, these studies have hypothesised that fear arousal will heighten the relevance of fear-relevant information and, therefore, result in systematic processing, especially if fearful respondents are not reassured in advance about the efficacy of the recommended. action (Gleicher \& Petty, 1992). There is some evidence to support this hypothesis (Baron et al., 1994; Gleicher \& Petty, 1992). For example, Baron and colleagues reported that under conditions of high threat attitudes toward dental hygiene were more positive after reading a strongly argued persuasive message than after reading the weak persuasive message. This effect of argument strength on attitude was not found in the low threat conditions, supporting the hypothesis that fear, or at least perceived threat, promotes systematic processing of potentially reassuring information. The overall picture is not conclusive, however, because unpublished studies have reported inconsistent support for this hypothesis (Meijnders, 1998; Pointer \& Rogers, 1993).

One reason for inconsistency may be a lack of clarification concerning the relationship between threat, usually manipulated by presenting high/high. or low/low severity and susceptibility information, and fear arousal. Since threat manipulations prompt fear arousal, it is difficult to ascertain whether threat perceptions or the emotion of fear are responsible for the observed effects on message processing. Our own studies suggest, however, that fear arousal may have stronger effects on systematic processing of fear-relevant persuasive messages than perceptions of severity, susceptibility, or threat (see chapters 3 and 4). For example, Ruiter, Kok, Verplanken, \& Brug (in press, reported in chapter 3 ) followed a threat manipulation concerning breast cancer with a measurement of fear arousal. Female participants then read persuasive information about performing monthly breast self-examination (BSE). Analyses revealed no support for more systematic processing of the BSE message under conditions of high threat compared to low threat. but when fear arousal was included, results indicated that argument strength influenced attitude toward BSE to a greater extent amongst those who expressed greatest fear. These findings suggest that it may be fear arousal, rather than threat perception that prompts systematic processing. This conclusion could, however, be premature because, since threat manipulations were used to generate fear arousal but fear arousal and not threat perception. appear to influence processing, it is possible that a third variable affected 
fear of breast cancer. Individual differences such as chronic anxiety relating to breast cancer (e.g., induced by experience of breast cancer in the respondent's family) and general responsiveness to threatening information (e.g., trait anxiety) could account for these results (cf. Jepson \& Chaiken, 1990), although a recent meta-analysis of the effects of fear appeals (Witte \& Allen, in press) casts doubt on the importance of individual difference variables in explaining the effects of fear appeals.

Two other methodological issues arise from this research. First, the relationship between personal relevance and perceived susceptibility. These constructs have been used interchangeably by fear appeal researchers (e.g., Baron et di., 1994), but it is possible for people to acknowledge a threat as relevant (e.g., "lung cancer is a risk because I smoke") without accepting their own susceptibility (e.g., "I will not contract lung cancer because neither my mother or grandfather have it and both have smoked all their lives"). Theoretical and operational separation of these constructs would be desirable (see also chapter 4). Secondly, the operational definition of systematic processing as the impact of strong (versus weak) arguments on attitude change may be problematic when applied to health promotion. Strong arguments must be relevant, valid and supportive of the recommended protective action, but strong arguments may also be those that have not been previously considered (Vinokur \& Burnstein, 1978). This is often problematic in health promotion research because key arguments are already in the public domain. For example, the argument, "If you perform regular selfexamination you are likely to detect any cancer early and it is likely to be more easily treated" provides the strongest reason for performing BSE but it is not new to most women. A new argument should perhaps read "You probably know ... but did you know that ...".

In summary, the effects of fear arousal and threat perception on the likelihood of systematic processing of persuasive information are still not fully understood. Experimental procedures have not distinguished adequately between the effects of threat perception and fear arousal on information processing. Fear may promote the cognitive antecedents of precautionary intentions by activating systematic, rather than peripheral, processing but individual characteristics may also be involved in determining the extent of systematic processing. 


\section{RE-CONCEPTUALISING FEAR AROUSAL AND ITS RELATIONSHIP TO THREAT PERCEPTION, FEAR CONTROL AND PRECAUTIO- NARY MOTIVATION}

It is clear that research into fear appeals has yet to answer some important questions. In particular, is there something more to fear arousal than threat perception and, if so, how does this affect the processing of information on risk and precautionary action? We believe that a more sophisticated model is implicit in the literature and have outlined this below. In doing so we highlight a number of hypotheses arising out of the existing literature.

We propose first that risk information generates the experience of fear before or in parallel to conscious perception of threat as is suggested by PRM and EPPM. This emotional response may generate fear control processes and affect precautionary motivation independently of threat perception. This proposal corresponds to theories of emotion that portray emotional experiences as the products of automatic, preconscious processing of perceptual cues in which physiological arousal and action readiness are combined (Frijda, 1986; Lazarus, 1991a; Lazarus, 1991b; Wegner \& Bargh, 1998; Zajonc, 1980; Zajonc, 1984). Frijda (1986), for example, argues that emotions such as fear, arise as the result of rapid, preconscious information processing in which the stimuli are categorised (what is it?), compared (is it important to me?), diagnosed (what can I do?), and evaluated (what is the urgency, difficulty and severity of the situation?), followed by action orientation that lays the foundation for subsequent planned action (e.g., establishing a flight tendency). Dependent on the nature of the resulting action tendency, physiological changes are instigated (e.g., fear arousal). Fear is, therefore, viewed as an automatic and primary response that may contribute to but is not the product of more conscious, deliberative danger control processes that regulate action.

In discussing the relationship between fear arousal and attitude change, Rogers (1983) concluded that, "fear arousal does not facilitate attitude change unless this arousal directly affects the cognitive appraisal of the severity of that threat" (p165) but, in their review, Eagly and Chaiken (1993) noted that this path has not been well supported by empirical findings. They argued that there is more support for a path in which efficacy perceptions influence the level of fear, which then influence fear control processes (such as defensive avoidance) (Eagly \& Chaiken, 1993, p. 444). There is, however, an incompatibility between the emotional experience of fear arousal as described above and the measures of self-reported fear employed in the studies reviewed by Eagly and Chaiken (1993). It is possible, therefore, that reported fear is a reflection of threat and coping appraisals rather than an index of fear arousal. This would account for observations of 
high reported fear when perceived threat is high and adaptive coping possibilities are expected to be low (see Rippetoe \& Rogers, 1987; Witte, 1992a).

In order to test the proposal that fear arousal precedes threat perception and Rogers' suggestion that threat perception may mediate the effect of fear on danger control processes, independent measures of fear arousal are required. Psychophysiological measures such as the galvanic skin response (measuring automatic nervous system arousal) or the starle reflex (measuring fear arousal) could be used on-line to determine levels of fear arousal. Similarly, procedures within neuropsychology to measure the brain activity (e.g., electroencephalography analysis [EEG], functional magnetic resonance imaging [f-MRI]) could be employed to identify the onset of threat appraisal processes (Berntson \& Cacioppo, 2000; Cacioppo, Tassinary, \& Bernts, 2000).

Witte (1992a, e.g., p. 116) draws upon research into affective processes to argue that fear control responses are more automatic and less conscious than danger control responses (Bargh \& Chartrand, 1999; Lazarus, 1984; Lazarus, 1991a; Lazarus, 1991b; Murphy \& Zajonc, 1993; Wegner \& Bargh, 1998; Zajonc, 1980; Zajonc, 1984). For example, Wegner and Bargh (1998) suggest that negative emotions may automatically activate defence mechanisms to control the emotion. Such fear control processes may result in conscious responses such as avoiding situations that would evoke the emotion, but they may also prompt automatic, unconscious responses such as suppression of the emotional response. Thus fear may be a primary response that leads to automatic fear control processes that could interfere with the formation of precautionary motivation because attention may be distracted from subsequent reassuring messages (Witte, 1992a; see Witte \& Allen, in press, for empirical evidence). This could be tested by measuring attention independently of self-reported cognitive measures. On-line eyemovernent registration (in case of exposure to video fragments), reading time and unanticipated post-hoc recall tasks could be employed. Such research would also bave the advantage of observing study participants as active information seekers who have the opportunity to re-direct their attention from presented information, thereby better reflecting the reality of reallife responses to fear-arousing messages such as those presented on television (Jacoby;, Jaccard, Kuss, Troutman, \& Mazursky, 1987; Lion \& Meertens, in press).

Witte (1992a) argued that fear control and danger control responses are determined by efficacy beliefs. Yet, Witte et al. (1998, p.574) found only' partial support for the hypothesis that "Individuals exposed to the fear appeal campaign message with low-efficacy perceptions should have a greater degree of defensive avoidance, perceived manipulation, and issue derogation than those with high-efficacy perceptions." However, Witte (1994, 
pp. 117-118) reported support for the hypotheses that, "There is a direct relationship between fear and message rejection outcomes, such as defensive avoidance and reactance" and that "Perceived efficacy .... is unrelated to message rejection outcomes such as defensive avoidance or reactance." This pattern of results could indicate that fear control processes are less influenced by efficacy perceptions because they are automatic in nature, but that the more deliberative action planning involved in danger control is more dependent on efficacy perceptions. Two studies that are reported in chapter 5 studied the role of existing efficacy perceptions in processes of fear control and danger control. The findings suggest that fear control processes that are directed to the presented threat information (e.g., message derogation) are not influenced by efficacy perceptions, while the role of efficacy perceptions in processes of danger control are further unclear.

PMT and EPPM propose an interactive model in which the effects of threat recognition on intention formation are moderated by efficacy perceptions (Rogers, 1983; Witte, 1992a). An alternative view derived from the social cognitive literature is that the effects of threat perception on intention are largely mediated by coping appraisals. Perceptions of severity and susceptibility have, in some cases, been found to have direct effects on intention formation when controlling for theory of planned behaviour and PMT variables. However, in general, threat perception appears to have a more distal effect on motivation than response efficacy and self-efficacy (e.g., Abraham et al., 1994; Plotnikoff \& Higginbotham, 1995; Plotnikoff \& Higginbotham, 1998). Consequently, a number of authors have suggested that threat recognition prompts action contemplation, whereas perceptions of efficacy and feasibility determine the kind of action that will be undertaken and are, therefore, more proximal determinants of action (Rippetoe \& Rogers, 1987; Schwarzer, 1992; Witte et al., 1998). Thus while threat perception may contribute to precautionary motivation by prompting consideration of outcome expectancies, perceptions of response efficacy, response costs and self-efficacy may determine intention. formation and subsequent action. Bandura $(1986,1997)$ has argued that actions thought to be effective in reducing a threat may not be performed because people do not feel able to execute them but that ineffective actions do not need further consideration regarding their feasibility. This suggests that response efficacy expectancies have priority over self-efficacy appraisals/expectancies. Finally, it is worth noting that if the danger control process is unresolved due to unsatisfactory coping appraisals this is likely to generate feedback that enhances perceived threat and fear arousal and, thereby, amplifies fear controll processes.

The relationships described above (apart from the potential feedback effects of unsatisfactory coping appraisals) are represented in Figure 2.1. 


\section{THE PRESENTATION OF PRECAUTIONARY INFORMATION}

The model sketched above implies that precautionary information should ideally highlight the effectiveness of recommended action, address concerns over costs and bolster self-efficacy. Research based on the theory of planned behaviour suggests that normative perceptions may also be important (Ajzen, 1991; Trafimow \& Fishbein, 1995), at least for some people and some actions (Trafinnow \& Finlay, 1996). Taking account of these findings it is possible to tailor health promotion messages so that they address the cognitions highlighted by social cognitive models. There is, however, a considerable body of research on persuasion that provides additional guidelines on the preparation of arguments and messages. Important features include argument strength, source expertise and action instructions (for a healthrelated overview, see Maibach \& Parrott, 1995). Further improvements may be possible by carefully tailoring the contents (Brug \& de Vries, 1999), valence of wording (Rothman \& Salovey, 1997), and use of volitional prompts (Gollwitzer \& Schaal, 1998).

More recent research drawing upon the work of Kahneman and Trersky (1979, 1984) and Meyerowitz and Chaiken (1987) has indicated that formulating what is objectively the same information in terms of either gains or losses (i.e., message framing) systematically influences decision making. Several studies have investigated the extent to which people are sensitive to message framing in the context of health decisions (Detweiler, Bedell, Salovey, Pronin, \& Rothman, 1999; Rothman, Martino, Bedell, Detweiler, \& Salovey, 1999; Rothman, Salovey, Antone, Keough, \& Martin, 1993). The persuasive effects of presenting the negative consequences of not performing the healthy behaviour (loss frame) have been compared to the effects of presenting the positive consequences of performing the healthy behaviour (gain frame) on measures of attitudes and behaviour (e.g., Meyerowitz \& Chaiken, 1987).

Levin, Schneider, and Gaeth (1998) defined this form of message framing as action framing and in a review of this literature, Rothman and Salovey (1997) suggested that the type of behaviour that is promoted determines which action frame will be most effective. Findings suggest that behaviours focussed on early detection of health problems are best promoted by loss frames (e.g.. "Failing to use a disclosing rinse before brushing limits your ability to detect areas of plaque accumulation"; Rothman et al., 1999, p. 1361), whereas prevention behaviours are best promoted by gain frames (e.g., "People who use a mouth rinse daily are taking advantage of a safe and effective way to reduce plaque accumulation"; Rothman et al., 1999, p. 1361). Rotbman and Salovey (1997) explain these findings in terms of the greater perceived risk associated with detection behaviours. Although the 
long-term importance of, for example, performing BSE is generally acknowledged the short-term negative consequences (e.g., worry due to finding, a lump in the breast) may be especially important to intention formation and implementation (Weinstein, 1988). Prevention behaviours, in contrast, typically result in relatively certain, desirable outcomes so that not performing the behaviour becomes the risky option. Kahneman and Tversky (1979, 1984) have shown that people prefer risky options when confronted with losses but prefer certainty when considering gains. Consequently, the more risky detection actions will be most attractive when potential losses are highlighted whereas the less risky preventive behaviours will be promoted best by emphasising potential gains. A first study that investigated the effects of action framing within the domain of fear appeals is described in chapter 6. It provides some empirical support for the hypothesis that appropriate action framing increases the persuasive impact of fear appeals.

Leventhal and colleagues studied the relation between fear arousal and the provision of specific instructions on how to take precautionary action iiseventhal.. Iones. \& Trembly, 1966; Leventhal et al., 1965; Leventhal, Watts " \& Pagano, 1967). In one well known study (Leventhal et al., 1965) participants read a potentially high or low fear-arousing message about the negative consequences of tetanus and were advised to have a vaccination injection at the local hospital. Half the respondents received a map highlighting the location of the hospital and were instructed to think about their daily schedule in order to arrange classes so that they would have time to visit the hospital. Results showed that those in the high fear condition had more positive attitudes and intentions toward tetanus injections than those in the low fear conditions, whereas the provision of action instructions had no influence on attitudes and intentions. Action instructions did, however, influence action: $30 \%$ of the students receiving action instructions had an injection while only $3 \%$ did so in the absence of action instructions. Thus fear arousal had a positive effect on the antecedents of precautionary motivation (i.e., attitudes) and on precautionary intention formation. This effect did not, however, translate into a greater likelihood of action. Motivation was nonetheless crucial to action. None of those in the control condition (with no fear message) went for an injection, irrespective of whether or not they received specific instructions. Thus fear and threat perception created a motivational basis for action while specific instructions facilitated the translation of good intentions into action.

These findings foreshadow those of more recent work suggesting that postdecisional or volitional processes explain why some intenders act while others do not. A number of theorists have distinguished between two stages of action control: (i) a decisional or motivational stage which culminates in intention formation and (ii) a postclecisional or volitional stage which 
involves self-regulatory activities directed toward the enactment of intentions (Gollwitzer, 1993; Gollwitzer \& Moskowitz, 1996; Kuhl, 1992; Schwarzer, 1992). This work suggests that social cognitive models of motivation do not adequately represent key aspects of action control. Gollwitzer (1993), for example, has demonstrated that forming "implementation intentions", that is, specifying when and where an intention is to be enacted can distinguish between intenders who do and do not act. He argues that such detailed plans create cues to action in relevant environments, which prompt intenders to act automatically when encountered (see also Abraham, Sheeran, Norman, Conner, De Vries, \& Otten, 1999; Orbell, Hodgkins, \& Sheeran, 1997). This research emphasises the importance of combining fear appeals with specific instructions and prompts to action planning. It also raises interesting questions about the relationship between the emotion of fear and postdecisional processes. For example, the question whether fear arousal inhibits or enhances action planning, which was addressed by a study reported in chapter 7. The findings of that study suggest that fear arousal may prompt thinking about where and when to perform the recommended action.

\section{CONCLUSIONS AND IMPLICATIONS}

This review indicates that the contribution of fear appeals to the adoption of self-protective behaviour is in doubt. Fear arousal may render information concerning response efficacy and self-efficacy more salient, for example, through enhancing systematic processing (e.g., Baron et al., 1994), but it is the impact of these messages on attitude and intention formation and action planning that determine the effect of a fear appeal on precautionary action (e.g., Rippetoe \& Rogers, 1987; Witte et al., 1998). Measures of threat perception have weaker relationships with intention and behaviour (e.g., Milne et al., 2000). This implies that it is the precautionary information or reassurance included in the message, not the capacity to arouse fear, that is likely to have greatest impact on behaviour, especially since fear may inhibit the establishment of precautionary motivation through the instigation of fear control processes (cf. Leventhal, 1970; Witte, 1992a; Witte \& Allen, in press).

We have suggested a re-conceptualisation of the psychological responses to fear appeals and recommended that future research invest in sequential measures of fear arousal other than self-report measures. We would also echo Eagly and Chaiken's (1993) call for more research into the effects of fear arousal on attention to precautionary information and the impact this 
has on the development of precautionary motivation. In addition we have highlighted the importance of tailoring precautionary information so that it addresses key cognitive antecedents of action (particularly response efficacy and self-efficacy), uses appropriate action framing and includes specific action instructions.

Although some key questions remain unanswered in this field, these findings have clear implications for the use of fear appeals. It seems likely that fear arousal may have inhibiting as well as facilitating effects on assimilation of protection motivation and can lead to avoidant coping. Consequently, cautious use of fear arousal techniques seems advisable. A greater focus on precautionary information and the promotion of action at the expense of prompting fear arousal is likely to be more consistently effective than attempts to frighten people about health risks with images of death and injury. Campaigns should continue to highlight the personal relevance of health threats but the severity of outcomes following health-risk behaviour may be much less important to establish than the feasibility of preventive action. 


\title{
CHAPTER 3
}

\author{
EVOKED FEAR AND EFFECTS OF APPEALS \\ ON ATTITUDES TO PERFORMING BREAST \\ SELF-EXAMINATION: AN INFORMATION \\ PROCESSING PERSPECTIVE
}

Accepted for publication as:

Ruiter, R. A. C., Kok, G., Verplanken, B., \& Brug, J.

(in press). Evoked fear and effects of appeals on attitudes

to performing breast self-examination: An information processing perspective. Health Education Research. 


\section{INTRODUCTION}

One of the remaining questions in health education practice is whether an effective persuasive message should evoke fear of the negative consequences of unhealthy behaviour. Yet, public health campaigns frequently employ potentially frightening messages that highlight threats to well-being (e.g., HIV infection, lung cancer or car accidents) and recommend protective action (such as the use of condoms, to stop smoking, or no drinking when you are driving). For instance, recent smoking prevention campaigns targeted at young people in The Netherlands and Australia vividly display the negative consequences of smoking, followed by a briefly formulated recommendation not to start smoking or to give up smoking (National Expert Advisory Committee on Tobacco, 1999: Stivoro, 1997). These campaigns have not been appropriately tested, but evaluations of comparable campaigns on HIV prevention in Australia (e.g., the "grim reaper" campaign) and the United Kingdom (e.g., the "tombstones" campaign) have cast doubt on the effectiveness of evoking fear in health education practice (Rigby, Brown, Anagnostou, Ross, \& Rosser, 1989; Ross, Rigby, Rosser, Anagnostou, \& Brown, 1990; Sherr, 1990). The present study was aimed to provide theoretical and practical implications for the role of fear arousal in health messages. It specifically examined the effects of evoked fear on argument-based processing of fear-relevant persuasive information. First we will briefly review the literature on fear arousal in health education, after which we will describe and discuss the rationale, methods, and results of our study.

A fear appeal is a persuasive communication that arouses fear to promote self-protective action (Witte, 1992a). Fear appeals have mainly been designed and studied from the perspective of Rogers' protection motivation theory (Rogers, 1975, 1983). This expectancy-value model postulates that the appraisal of a severe threat to which the recipient is susceptible will instigate protection motivation but that the nature of this motivation will depend on coping appraisal. When the recommended precaution is evaluated as sufficient regarding its efficacy in averting the threat (response efficacy) and its feasibility (self-efficacy), it will be adopted. The result is a reduction in threat. When the recommendation is judged as not being helpful in coping with the threat, action will be focused on reducing experienced levels of fear (fear reduction or control, instead of threat reduction or danger control). The message may then be denied or avoided, while risk behaviour generating the health threat will be maintained or even intensified (e.g., Leventhal, 1970; Mulilis \& Lippa, 1990; Rippetoe \& Rogers, 1987; Rogers, 1983; Witte, 1992a).

Fear appeal theory therefore supposes that the kind of action undertaken in response to fear-arousing information varies with the interaction of the per- 
ceived threat of the health problem and the perceived efficacy of the recommended precaution. However, in a recent empirical review of protection motivation theory, Rogers and Prentice-Dunn (1997, p. 119) concluded that in almost $50 \%$ of the studies the predicted interaction effect of threat and efficacy variables on precautionary motivation was not found. Thus, despite the long-standing interest in the effects of fear appeals within social psychology and health education research (for reviews, see Higbee, 1969; Sutton, 1982; Eagly \& Chaiken, 1993; Ruiter, Abraham, \& Kok, 2000 [reported in chapter 2]), empirical findings do not provide clear evidence of their effectiveness. In fact, recent meta-analyses of protection motivation theory indicate that threat appraisal measures are poor predictors of protective action compared to coping appraisal measures (Floyd, Prentice-Dunn, \& Rogers, 2000; Milne, Sheeran, \& Orbell, 2000). Severity and susceptibility perceptions seem to have a more distal effect on precautionary motivation than response efficacy and self-efficacy beliefs (e.g., Abraham, Sheeran, Abrams, \& Spears, 1994; Rippetoe \& Rogers, 1987; see also Ruiter et al., 2000).

Certain mediating cognitive processes may be the reason for the inconsistencies regarding the interaction effect of threat and efficacy variables (cf. Eagly \& Chaiken, 1993). For instance, fearful respondents may become more critical and as a result easily reject recommended actions that are sustained with weak arguments (cf. Baron, Logan, Lilly, Inman, \& Brennan, 1994). Dual process models of attitude formation and change, such as Petty \& Cacioppo's (1986) elaboration likelihood model (ELM) and Chaiken's heuristic systematic model (HSM; see Chaiken, Liberman, \& Eagly, 1989), may be helpful in studying the cognitive processes that mediate the effects of evoked fear on persuasion (i.e., attitude change). Both models suggest that attitude change after exposure to a persuasive message is not always the result of careful consideration of the quality of presented arguments as assumed by the cognitive response model (Greenwald, 1968). If the receiver is not motivated to carefully read the contents of the message, or does not have the cognitive abilities for the task, attitude change may sooner be based on other characteristics of the message (i.e., peripheral cues), for example, the layout of the message or the perceived credibility of the source of the message. Such peripheral or heuristic ("rule-of-thumb") processing of persuasive information results in relatively less stable attitudes, which predict behaviour less well, compared to argument-based attitudes (for a recent overview of dual-process theories in attitudes, see Chaiken \& Trope, 1999).

Factors such as perceived personal relevance and distraction have been studied quite extensively as possible determinants of an individual's motivation and ability to systematically process persuasive information (Eagly \& Chaiken, 1993; Petty \& Wegener, 1998). Studies into the effects of fear arousal on argument-based message processing have only recently been reported (Baron. 
et al., 1994; Gleicher \& Petty, 1992; Meijnders, 1998; Pointer \& Rogers, 1993). In general, these studies suggest that an increase in fear arousal is accompanied by more argument-based processing. This is especially true if recipients are not reassured in advance about the effectiveness of the recommended action to avoid a threat. In such a case, processing may undermine this reassurance (Gleicher \& Petty, 1992). The direction of these findings is in contrast with results reported by Jepson and Chaiken (Jepson \& Chaiken, 1990). They concluded that fear of cancer impedes systematic processing of issue-specific persuasive messages. However, they studied the role of chronic issue-specific fear and argued that, in contrast to evoked fear, chronic fear may have resulted in well-learned defensive responses to fear-relevant material such as defensive avoidance.

The present study builds on research that examined the effects of evoked fear on argument-based processing of fear-relevant persuasive messages (e.g., Baron et al., 1994). Our study extends this line of research by studying the effects of fear of breast cancer on attitudes toward performing breast self-examination (BSE). Breast cancer is a highly prevalent type of cancer among women, which can be treated successfully if detected in an early stage. Performing BSE regularly is therefore an important self-protective behaviour. In an experimental design, fear was evoked by providing participants with either low risk or high risk information about breast cancer. After the measurement of fear arousal, a persuasive message about performing BSE was presented. The main dependent variable was the attitude toward performing BSE. Consistent with the notion that fear arousal is a motivational construct that urges people to seek safety conditions (cf. Dijker, Koomen, \& Kok, 1997; Ditto, Jemmot, \& Darley, 1988; Frijda, 1986) and the little research that studied the persuasive effects of messageinduced fear from an information processing perspective (Baron et al., 1994; Gleicher \& Petty, 1992; Meijnders, 1998; Pointer \& Rogers, 1993), we hypothesised that fear of breast cancer will increase argument-based processing of subsequent fear-relevant persuasive information.

Evidence for this hypothesis was sought by using two analytical procedures. First, argument-based processing implies that the strength of the provided arguments is supposed to influence attitudes (Petty \& Cacioppo, 1986: Chaiken et al., 1989). Therefore, we expected the effects of argument strength on attitude toward BSE to be stronger in the mild fear conditions than in the low fear conditions. Second, most fear appeal studies measured fear only after presenting the persuasive information and administering the dependent measures (e.g. Baron et al., 1994; Gleicher \& Petty, 1992). This excludes the possibility to study the effects of evoked fear, as it leaves it unclear whether the fear reported was the actual level of fear while reading the threat information or some residual level that remained after reading the 
persuasive information ( $\mathrm{cf}$. Sutton, 1982). We therefore measured fear arousal directly after participants read the threat information about breast cancer, and before they read the persuasive information about BSE. This also made it possible to test the effects of reported fear on argument-based processing. We expected the effects of argument strength on attitude toward BSE to be stronger among participants who reported mild fear arousal than among participants who reported low fear arousal.

\section{METHOD}

\section{Participants and experimental design}

The participants were eighty-eight female first-year undergraduates at Maastricht University. Their mean age was 20 years. The participants were contacted by means of registration forms that asked for first-year students to participate in several behavioural science studies. After leaving their name and telephone number, they were invited by telephone to come to the laboratory. They were not given any information in advance about the topic and objectives of the study other than that they have to read some educational materials and answer some questions. They were randomly assigned to the conditions of a 2 (Fear: low vs. mild) $\times 2$ (Argument Strength: weak vs. strong) between-participants design.

\section{Procedure}

Participants were invited to the laboratory in groups of at most four persons and were placed in separate cubicles. They started with completing a questionnaire provided to them on paper, which measured their pre-experimental attitude toward BSE. They were then told that they would evaluate the effectiveness of several educational messages about breast cancer developed by the department of health education and promotion of Maastricht. University. The experiment was completely computer-controlled. Participants first read a message about the threat of breast cancer, which contained the manipulation of fear. The threat message was followed by a self-report measure of fear arousal. Next, participants read a persuasive message about performing a monthly BSE, supported by either eight weak or eight strong arguments, which constituted the manipulation of argument strength. Finally, a questionnaire was administered with the post-experimental attitude toward BSE as dependent measure. 


\section{Manipulations}

\section{Fear}

A common way to induce different levels of fear arousal is that in the mild fear condition the threat is presented as very severe and as personally relevant, because the person is told to be susceptible to it. Conversely, in the low fear condition the threat is presented as not severe and not personally relevant (e.g., Baron et al., 1994; Gleicher \& Petty, 1992; Meijnders, 1998). Thus in many studies, severity and susceptibility are confounded, and their independent effects on precautionary motivation cannot be studied (cf. Eagly \& Chaiken, 1993)

For several reasons we decided to manipulate fear of breast cancer by varying information about the severity of breast cancer, while keeping constant information that stressed the perceiver's susceptibility to breast cancer. Firstly, 71 female first-year undergraduates of the University of Leiden participated in a pilot test of the fear manipulation in which severity and susceptibility information were varied. A 2 (Severity: low vs. high) x 2 (Susceptibility: low vs. high) between participants design showed that Severity significantly interacted with Susceptibility on a 4-point scale of fear arousal, $F(1,67)=4.10, p<.05$. More specific analyses revealed that the largest difference between the means was the result of a main effect of Severity among conditions of high susceptibility ( $\mathrm{M}_{\text {high severity, high susceptibility) }}$ $=2.87$ vs. $M_{\text {low severity, high susceptibility }}=1.87$ ). In other words, severity seems only important in fear arousal among women who believed to be susceptible to the threat of breast cancer. Secondly, it may ease the interpretation of the effects of threat information if only one fear component (i.e., severity) is varied. Thirdly, perceptions of severity are assumed to be more strongly related to the emotion of fear than perceptions of susceptibility (see Rogers, 1983).

To stress recipients' susceptibility to breast cancer, both the low and the mild fear message emphasized that breast cancer is a relevant topic even for women younger than 30 years of age. Information about the severity of breast cancer was varied. In the mild fear condition it was explained that most of the women with breast cancer die from their disease, whereas in the low fear condition the text read that women with breast cancer have a good chance to fully recover from their disease. Furthermore, the mild fear condition described a "radical mastectomy" (breast removal) as a common treatment for breast cancer and was accompanied by two photos showing the serious physical consequences of this treatment. The low fear condition described a less radical treament called "lumpectomy" which removes the tumour without affecting the breast itself, accompanied by two photos that showed no visible physical consequences except for a small scar. 


\section{Argument strength}

The manipulation of argument strength was developed and pilot tested along the guidelines proposed by Petty and Cacioppo (1986, pp. 31-33). Either eight strong arguments or eight weak arguments persuaded respondents to perform monthly breast self-examination. Both persuasive messages were equal in length (694 words). An example of a weak argument that was used was: "Performing BSE is a nice way to be intimate with yourself". An example of a strong argument was: "By performing BSE you are able to detect breast cancer in an earlier and therefore more treatable stage" (see Appendix, p.54, for the complete persuasive messages).

\section{Measures}

\section{Pre-experimental attitude}

In the first questionnaire, three semantic-differentials assessed respondents' attitude toward BSE on 7-point scales (unimportant - important, undesirable - desirable, ineffective - effective; Cronbach's alpha $=.71$ ). This measure was used as a covariate to control for existing differences in attitude toward BSE between participants upon entering the experiment. Our interest in these questions was concealed by including similar questions concerning other health topics (i.e., AIDS and condom use, skin cancer and self-examination, and heart disease and low fat diet).

\section{Fear arousal}

The level of evoked fear of breast cancer was measured between the fear arousal message and the persuasive message through 10 mood adjectives (relaxed, nervous, tense, jittery, restful, anxious, calm, uncomfortable, worried, frightened) on a 4 -point scale $(1=$ not at all, $2=$ a little, $3=$ rather much, $4=$ very much). The adjectives were presented in random order. The adjectives and answering scale were derived from earlier social psychological research into the effects of fear appeals (e.g., Leventhal, Singer, \& Jones, 1965; Rippetoe \& Rogers, 1987; Mewborn \& Rogers, 1979), the "tense. arousal scale" of the UWIST mood adjective checklist (Matthews, Jones, \& Chamberlain, 1990), and the Dutch version of the Spielberger's (Spielberger, Gorsuch, \& Lushene, 1970) state and trait anxiety index (Van der Ploeg, Defares, \& Spielberger, 1979). After proper recoding, the scores on 10 items were averaged into one index of fear arousal (Cronbach's alpha $=.92$ ).

\section{Post-experimental attitude}

The attitude toward performing a monthly BSE was assessed directly after reading the persuasive message by four 7-point semantic differentials 
(unimportant - important, undesirable - desirable, bad - good, negative positive). Scores on these items were averaged to create a single attitude index (Cronbach's alpha $=.85$ ).

\section{Ancillary measures}

To check whether the fear messages indeed were able to vary perceptions of severity under conditions of high susceptibility, we measured both constructs. Perceived severity of breast cancer was originally measured by three items, but weak inter-correlations between these items (Cronbach's alpha = .55) made us decide to use the single item that most directly measured perceived severity ("To what extent do you consider breast cancer a serious health problem: $1=$ not at all $-7=$ very serious"). Three items measured perceived susceptibility to breast cancer (Cronbach's alpha $=.78$; e.g., "To what extent do you think that breast cancer is a health problem that can happen to yourself; $\mathbf{i}=$ not at all $-7=$ very much").

The argument strength manipulation was checked after the post-experimental attitude measure by asking respondents "To what extent do you think that the message about BSE used strong arguments for advocating the performance of breast self-examination" ( $1=$ no strong arguments $-7=\mathrm{a}$ lot of strong arguments).

Finally, two items asked participants whether they knew somebody among their friends or family who (had) suffered from breast cancer (yesno) or another kind of cancer (yes - no).

\section{Debriefing}

Before leaving the cubicles, participants read a message on the computer screen that stated the actual objectives of the study. It further told them that the presented information was correct but differently worded between groups to induce different levels of perceived threat. On leaving the laboratory participants were individually and extensively debriefed. They were invited to talk about how they experienced the study. The experimenter was particularly alert on any signs of current fears as expressed by the participants. No such signs were perceived. On the contrary, many participants responded that they thought the study was interesting and that they learned something new, while others informed the experimenter that the topic was familiar to them because they knew somebody in their social environment who (had) suffered from breast cancer. No signs of fear were expressed, and none of the participants reported that they regretted their participation.

Furthermore, participants received a booklet about breast cancer and an instruction card on how to perform BSE. Both are used by the Dutch Cancer 
Society as standard materials in their educational program about breast cancer. Participants were urged to read the booklet and instruction card to correct any misinterpretations of the information provided in the experimental study. They further received a monetary reward of 10 Dutch Guilders (about 5 US dollars) for participating and were asked to be silent about the objectives of the study.

\section{RESULTS}

\section{Manipulation checks}

Fear of breast cancer was successfully evoked and manipulated. An independent samples $t$-test on actual fear showed that respondents in the mild fear condition reported more fear $(M=2.51, S D=0.58)$ than respondents in the low fear condition $(\mathrm{M}=1.98, \mathrm{SD}=0.55)$ after reading information about breast cancer, $\mathrm{t}(86)=4.43, \mathrm{p}<.001$. Furthermore, two 2 (Fear) $\times 2$ (Argument Strength) ANOVAs on perceived severity and perceived susceptibility, respectively, replicated the pretest findings that fear arousal can be successfully manipulated by varying severity information under conditions of high perceived susceptibility. The main effect of Fear was significant on perceived severity, $F$ $(1,84)=9.87, p<.001$, and not on perceived susceptibility, $F(1,84)=$ $2.19, p=.14$. Respondents in the mild fear conditions perceived breast cancer as more severe $(M=5.86, S D=0.93)$ than respondents in the low fear conditions $(M=5.11, S D=1.26)$. Both groups felt equally susceptible to breast. cancer $(M=4.55, S D=1.00$ vs. $M=4.21, S D=1.16$ respectively). No other statistically significant effects were found ( $p$ 's $>.28$ ).

The manipulation of argument strength was also successful. We only found a significant main effect of Argument Strength in a 2 (Fear) $\times 2$ (Argument Strength) ANOVA on perceived argument strength, $F(1,84)=$ $20.05, p<.001$. Respondents judged the strong message as having stronger arguments $(M=5.52, S D=1.02)$ than the weak message $(M=4.39, S D=$ 1.33). Neither the effect of Fear nor the interaction between Fear and Argument Strength was significant ( $p$ 's $>.21$ ).

\section{Pre-experimental attitude}

We carried out a randomisation check on pre-experimental attitude. This revealed that pre-experimental attitude was the same for all conditions of the design ( $p$ 's $>49$ ). Nevertheless, to increase the statistical power of our 
tests, we included pre-experimental attitude as covariate in the analyses reported below. The pre-experimental attitude was significantly related to post-experimental attitude in all analyses (p's < .001) and thus permitted a more powerful test of the effect under consideration.

\section{Manipulated fear and attitude toward BSE}

Manipulated fear (Fear) was used as a factor in the design to test the hypothesis that fear of breast cancer leads to more argument-based processing of BSE information. We expected the effect of argument strength on attitude toward BSE to be stronger in the mild fear conditions than in the low fear conditions. A 2 (Fear) $\times 2$ (Argument Strength) analysis of variance with pre-experimental attitude as covariate (ANCOVA) revealed a main effect of Argument Strength that approached significance, $F(1,83)=3.59, p=.06$. Respondents reported a more positive attitude toward BSE after reading the strong message $(M=6.15, S D=0.78)$ than after reading the weak message $(M=5.91, S D=0.70)$. The main effect of Fear was not statistically significant, $F(1,83)=1.73, p=.19$, and more importantly, neither was the predicted interaction between Fear and Argument Strength, $F<1.00$, ns. Therefore, this analysis provided no support for the hypothesis. The main effect of Argument Strength suggests argument-based message processing irrespective of the level of evoked fear.

\section{Reported fear and attitude toward BSE}

Next, we tested our hypothesis with measured fear, instead of manipulated fear. We first carried out a median-split procedure on the self-reported level of fear $(\mathrm{Med}=2.30)$. The resulting factor named Reported Fear was included in a 2 (Reported Fear: low versus mild) $\times 2$ (Argument Strength: weak versus strong) between-participants design. Four respondents who scored exactly on the median were excluded from the analyses $(N=84)$. The median-split procedure was successful as respondents were equally distributed over the four cells of the design, $\chi^{2}(1, N=84)=0.20, p=.66$. Including Reported Fear as a factor was justified and did not hamper causal interpretations of the findings. The measure of fear directly followed the fear manipulation and preceded the reading of the persuasive message. which constituted the argument strength manipulation.

A 2 (Reported Fear) x 2 (Argument Strength) ANCOVA with pre-experimental attitude as covariate revealed a significant effect of Argument Strength, $F(1,79)=3.92, p=.05$. The attitude toward BSE was more 
positive after reading the strong persuasive message $(M=6.16, S D=0.76)$ than after reading the weak persuasive message $(M=5.90, S D=0.70)$. More importantly, this effect of Argument Strength was qualified by an interaction with Reported Fear that approached significance, $F(1,79)=$ $3.18, p<.08$. To test our hypothesis that fear arousal increases motivation to elaborate on fear-relevant information, separate analyses were conducted for participants who reported low and mild fear arousal. As predicted, participants who reported mild fear based their attitude on the strength of the arguments presented, while participants who reported low fear did not (see Figure 3.1). More specifically, a significant effect of Argument Strength among participants who reported mild levels of fear of breast cancer indicated that they were more positive toward BSE after reading the strong persuasive message $(M=6.32, S D=0.71)$ than after reading the weak persuasive message $(M=5.76, S D=0.79), F(1,40)=8.18, p<.01$. In contrast. participants who reported low levels of fear did not seem to differ in their attitude toward BSE, whether they read the strong persuasive message ( $M=$ $6.02, S D=0.79)$ or the weak persuasive message $(M=5.99, S D=0.62), F$ $<1.00$, ns.

Figure 3.I Attitude toward BSE as a function of Fear Level and Argument Strength.

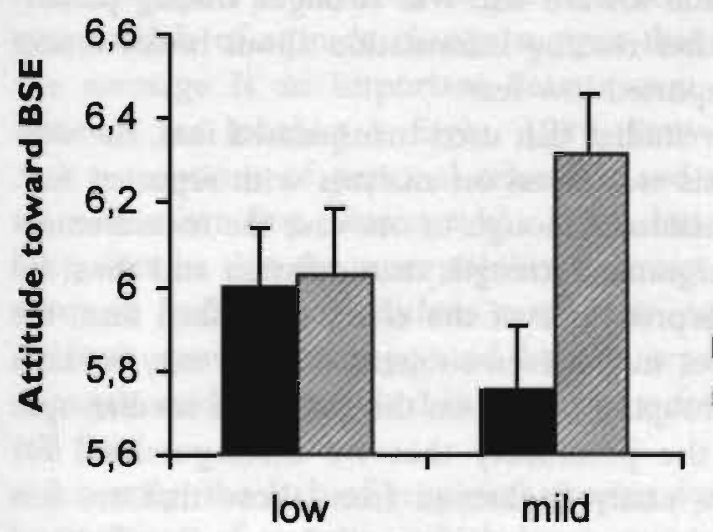

weak arguments

strong arguments

Fear Level

Legend. Bars show means with higher scores indicating more positive atcitude toward BSE performance. Error bars show mean +1.0 standard error of the mean. 


\section{DISCUSSION}

In the present study, we examined the effect of fear arousal on argumentbased processing of fear-relevant persuasive information. We built on earlier work that provided support for the positive effects of evoked fear on information processing in the domains of dental hygiene behaviour (Baron et al., 1994), campus safety (Gleicher \& Petty, 1992), environmental protection (Meijnders, 1998), and alcohol consumption (Pointer \& Rogers, 1993). We extended these earlier studies by focusing on the effect of fear of breast cancer on argument-based processing of information about BSE performance and by using self-reported fear as an independent variable in our analyses. The latter provides a more direct test of the effect of evoked fear on argument processing. We expected that the effect of argument strength on attitude toward BSE would be stronger in the mild fear conditions than in the low fear conditions. However, this was not supported by analyses with manipulated fear. Instead, the findings suggested that participants carefully read the persuasive information provide, irrespective of the threat information that they read.

The measurement of evoked fear between the manipulations of fear and argument strength allowed us to study the effect of reported (i.e., not manipulated) fear on argument-based processing of fear-relevant persuasive information. Consistent with our hypothesis, we found that the effect of argument strength on the attitude toward BSE was stronger among participants who reported mild fear after reading information about breast cancer than among participants who reported low fear.

Thus, in contrast to the earlier studies that used manipulated fear, the support we found for the hypothesis was based on analyses with reported fear. This requires some further discussion. Although in our case the measurement of reported fear preceded the argument strength manipulation and thus did not seem to hamper causal interpretations of the effect of evoked fear, the inclusion of self-report measures in between-subjects designs may weaken the sirength of these designs. Grouping people on the basis of a median-split. procedure does not exclude the possibility that we distinguished. for instance, people who are more easily frightened from those that are less easily frightened (e.g., neurotic), or people who are chronically afraid of breast cancer from those that are not (e.g., previous experience with breast cancer), or people who are reactive to experimental demands from those that are not trying to be helpful to the experimenters. In other words, a third variable or any other variable we are not aware of may have been responsible for the effect of evoked fear on argument-based message processing.

Nevertheless, we have reasons to assume that these kind of alternative interpretations of the effect of reported fear are less applicable to the present study. 
First, the self-report scale we used for measuring fear has been well validated in past fear appeal research (e.g., Mewborn \& Rogers, 1979) and is generally accepted as a measure of fear arousal in social psychology (Rogers, 1983; Witte, 1992a) and other domains such as clinical psychology (Rachman, 1998). Second, we found no relation between reported fear and previous experience with breast cancer patients, either in family or other social relationships ( $p$ 's $>.21$ ). Finally, none of the participants indicated during the debriefing procedure that he or she found out about the study objectives. Nevertheless, future studies would more easily reject these alternative explanations of our findings with reported fear if they would make use of psychophysiological indices to measure fear arousal, in addition to the cognitive responses to self-report measures of fear that we used. Psychophysiological indices, such as the startle reflex and galvanic skin response, have been successfully employed as valid measures of fear arousal (e.g., Lang, 1995). The additional advantage of these measures above self-report measures is that they do not interfere with the process that is being studied.

If we indeed measured evoked fear of breast cancer, then an important question to ask is why our hypothesis about the effect of evoked fear on argument-based processing was only supported for reported fear, and not for manipulated fear. Two answers can be proposed for this question, based on the way we manipulated fear. First, the effect of manipulated fear may have been hindered by deliberately creating low and mild fear messages that induced equal perceptions of personal relevance in both groups. Dual process models of attitude change suggest that perceived personal relevance of the message is an important determinant of processing motivation (for reviews, see Johnson \& Eagly, 1989; Petty \& Cacioppo, 1986). Assuming that perceptions of personal relevance and susceptibility are closely related to each other (e.g., Baron et al., 1994, but see also Ruiter et al., 2000), it may thus be that the susceptibility to breast cancer we imposed on respondents in both fear conditions resulted in equal high processing motivation in both groups, as suggested by the reported main effect of argument strength, and thus resulted in no support for the hypothesis with manipulated fear.

Secondly, the lack of empirical support for manipulated fear suggests that perceptions of severity, which were successfully varied, do not influence argument-based message processing; at least not when people already feel susceptible to the threat. This lack of support for variations of severity on argument-based processing may explain why of the four components that comprise a fear appeal (i.e., severity, susceptibility, response efficacy, selfefficacy; Rogers, 1983), perceptions of severity generally have been found to have the weakest relation with measures of precautionary motivation (Eagly \& Chaiken, 1993; Floyd et al., 2000; Milne et al., 2000; Ruiter et al., 
2000). Perceptions of severity may simply not raise sufficient attention for threat-related persuasive information, and thus do not reliably affect measures of precautionary motivation and self-protective action.

In conclusion, the present study supports the hypothesis that evoked fear motivates people into more argument-based processing. This conclusion supports earlier research that studied the effects of fear appeals from an information processing perspective. Future research should now focus on disentangling the effects of fear arousal, perceived severity, and perceived susceptibility on processing motivation. The effects of evoked fear may best be studied by using psychophysiological measures (e.gl. the startle reflex), whereas perceptions of susceptibility and severity need to be manipulated independently. To what extent the latter is possible, is an empirical question that awaits critical tests (cf. Eagly \& Chaiken, 1993).

The findings presented here are not without limitations. Dual process models in attitude theory suggest that argument-based attitudes are better predictors of behaviour than attitudes based on peripheral cues or heuristic reasoning (e.g., Petty, Haugtvedt, \& Smith, 1995). In the present study the effect of fear-instigated and argument-based attitude change on precautionary action could not be tested. It should be doubted, however, whether we would find this effect if we measured actual BSE performance. Attitudebehaviour research consistently shows that efficacy perceptions and goal intentions are more important predictors of precautionary action than threat perceptions and fear arousal (cf. Godin \& Kok, 1996). Furthermore, work by Gollwitzer and colleagues on implementation intentions has shown that statements by recipients of where and when they will perform the recommended action, which lack extensive reasoned processing, are simple but powerful tools in establishing behavioural change (Gollwitzer \& Moskowitz, 1996; Gollwitzer \& Schaal, 1998; e.g. Orbell, Hodgkins, \& Sheeran, 1997. for empirical evidence).

Furthermore, fear-arousing campaigns are typically used to motivate young people to safer behaviour. This partly justifies our choice for selecting first-year undergraduates as research participants. On the other hand, the high educational level of this group makes them not representative of the total population of young women in the Netherlands. Therefore, to generalize our findings, the current study needs to be replicated among other subpopulations of young women inciuding those with lower educational levels and other age groups.

Finally our findings may only generalize to the one health behaviour of performing BSE or, at best, a category of health behaviours that is defined by Rothman and Salovey (1997) as detection behaviours (e.g., getting regularly medical examinations), and is contrasted with (primary) prevention behaviours (e.g., using condoms to prevent HIV infection; exercising regu- 
larly). Recent studies by Rothman and Salovey and their colleagues into the effects of action framing on health protective actions, indeed suggest that negatively framed message that present the negative consequences of not performing the health action (e.g., fear appeals) are more effective when promoting detection behaviours, whereas positively framed messages that present the positive consequences of doing the health action are more effective when promoting prevention behaviours (Detweiler, Bedell, Salovey, Pronin, \& Rothman, 1999; Rothman, Martino, Bedell, Detweiler, \& Salovey, 1999; Rothman \& Salovey, 1997). To what extent different framing of the persuasive message within fear appeals influences the effects of evoked fear on precautionary motivation is an empirical question that has not been tested yet.

For the practice of health education and promotion, our findings suggest that evoked fear may only result in positive effects on precautionary motivation and action if campaign developers are able to sustain the recommended action with strong arguments. A main feature of strong arguments is that they are perceived as new, in addition to being relevant and in the right direction (Vinokur \& Burnstein, 1978; see also Petty \& Wegener, 1998). However, presenting strong arguments may not be easy, especially when most arguments are in the public domain and therefore are already known to the target audience, as is for example the case with breast cancer and performing BSE. Furthermore, practical use of fear appeals is mainly to be found in mass media campaigns. Typically, these campaigns emphasize the negative consequences of the unsafe behaviour (i.e., severity), followed by a brief formulation of the recommended action. These campaigns thus "forget" to stress essential psychological constructs in an effective fear appeal, which are the respondent's susceptibility to the threat and the effectiveness and feasibility of the recommended action. As we reviewed in the introduction, fear-arousing information may only result in health protective motivation if the threat is perceived as personally relevant and information is available that sustains the effectiveness and feasibility of the recommended action with strong arguments. 


\section{APPENDIX}

\section{Weak persuasive message}

\section{What can you do yourself: breast self-examination}

Many women examine their breasts for any changes every month. This booklet tells you why should also perform breast self-examination. But it first tells you how and when breast self-examination should be carried out.

\section{When and how?}

Performing breast self-examination means that a woman checks her breasts for changes once a month. The best time to do so is several days after menstruation. The breasts are then less swollen and therefore easier to examine. Many women have swollen breasts just before they have their periods, which often feel painful. As a result of a change in hormone production, lumps can sometimes be felt. After menstruation, these lumps will disappear or become smaller.

When your examine your breasts, be aware that they are never similar to each other. When you examine one breast and you think that you found something irregular but you are not sure, check the same part of your other breast. If you feel the same irregularity in both breasts, then this is probably due to the build of your breasts. If you have doubts about this, you should visit your GP. Do not keep yourself in a state of uncertainty.

\section{Why breast self-examination?}

Monthly breast self-examination is recommended by the European Cancer Code. This code was formulated by the Europe against Cancer organization and is part of a large program against cancer. The objective of this program is to reduce the risk of cancer and the expected death from cancer in the twelve EC countries.

More and more women perform monthly breast self-examinations, mainly because they are now more concerned with their lives. In addition, they have a sense of responsibility for their environment ("You do no want to burden others with a disease that you could have prevented"), which for many women is a reason to perform breast self-examination. To make breast self-examination a habit, it is wise to start early, for example during your years of study. After all, during your study period, organizing and planning daily activities becomes more and more important. That is why the period of study is an ideal time to incorporate breast self-examination in your daily schedule. Moreover, breast self-examination is a nice way to be intimate with yourself and to get to know your body. In that way, you 
combine pleasure with business. A last important reason is that by performing monthly breast self-examination you save the community a lot of money. The medical costs of the treatment of breast cancer are much higher when the disease is detected in an advanced stage, because more and more expensive specialist care is needed.

\section{Fear of detection}

Many women do not perform breast self-examination because they fear that they will detect breast cancer. Such fears are understandable but be aware that only by performing breast self-examination you will know whether you have breast cancer or not.

Some women decide to have their breasts examined by a physician. But if the physician instead of you yourself detects an abnormality, you immediately end up in the medical circuit. You will then have no opportunity to take your time and think about what is happening.

\section{Conclusion}

This booklet gives several reasons for performing monthly breast self-examination. The reasons are summarized below.

First, you take responsibility for your social environment and the society in general when you decide to perform monthly breast self-examination. After all, you cannot burden other people with a problem that you could have prevented yourself.

Second, your years of study are a perfect time to make the performance of monthly breast self-examination a habit in your life. During these years, you learn the best way to plan your daily activities.

Finally, by performing monthly breast self-examination you contribute to the objectives set by the "Europe against Cancer" organization. That is, to reduce the number of cancer deaths in the coming years.

\section{Strong persuasive message}

What you can do yourself: breast self-examination

Like you just read, you too could get breast cancer. If you develop breast cancer, it is of utmost importance that you detect it at an early stage. In this way you will considerably increase your chances of full recovery.

Worldwide scientific research has shown that the chance of full recovery is around $90 \%$ when breast cancer is detected at an early stage, that is before the formation of secondary tumors (metastasis). It is therefore very important for every woman to perform breast self-examination every month. 


\section{Breast self-examination: how often, when, and how?}

Performing breast self-examination means that you check your breasts for changes once a month. The best time to do so is a few days after menstruation. The breasts are then less swollen and thus, easier to examine.

Breast self-examination is easy to perform, quick to learn, and only takes 10 minutes every time. Furthermore, it costs no money and you do not need special equipment.

You will find a detailed description of how to carry out breast self-examination in the instructions that will be handed out to you at the end of the study. When your examine your breasts, be aware that they are never the same. When you examine one breast and you think that you found something irregular but you are not sure "then check the same part of your other. breast. When you feel the same irregularity in both breasts, this is probably due to the build of your breasts. Do not panic if you feel something that was not there last month. This certainly does not have to mean that you have cancer. Just do not keep yourself in a state of uncertainty and visit you GP.

\section{Why breast self-examination?}

Scientific research has shown that regular breast self-examination is the most effective and efficient way to detect breast cancer at an early stage. It is true that there has also been a national screening program for breast cancer using $x$-ray techniques (mammography) for a few years now, but this only targets women of 50 years of age and older. Performing breast self-examination does not replace mammography. The two methods complement each other.

Todlay, more women than ever before perform breast self-examination to check whether their breasts have changed. Especially the high survival rates when breast cancer is detected at an early stage and the fact that women can contribute to this thennselves, are important reasons for women to perform regular breast self-examination.

To make breast self-examination effective, it is important that you start at young age, preferably from 18 years onwards. If you spend some time every month to examine your breasts, it will become a habit and you will easily learn how your breasts normally feel. This increases your chances to detect any changes in your breasts. Moreover, you will be able to tell your GP what kind of changes you have felt. This is important to make a proper diagnosis.

\section{Overcome your fear}

Fear of detecting breast cancer is no cause of death from breast cancer. But fear may be more important than most people think. There are women, and maybe this is also true for you, who do not dare to perform breast self-exa- 
mination because they are afraid to detect something. Others who detect a change, do not dare to visit their GP because they might be diagnosed as having cancer.

Such fears are understandable but you have to realize that performing breast self-examination may save your life in case you develop breast cancer in the future. After all, by performing monthly breast self-examination you increase your chances of detecting breast cancer at an early and therefore better treatable stage. This increases your chances of full recovery. Furthermore, feelings of fear will decrease after you have performed breast self-examination for a few months and it has become a habit.

\section{Conclusion}

Every woman is susceptible to breast cancer. That is why it is important for every woman, and hence also for you, to perform monthly breast self-examination. Scientific research has repeatedly shown that you can detect breast cancer at an early and therefore better treatable stage if you perform monthly breast self-examination. This significantly increases your chances of full recovery if diagnosed with breast cancer. 


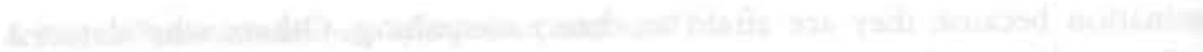

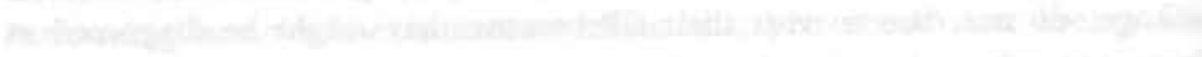

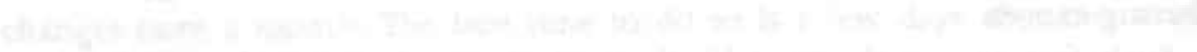

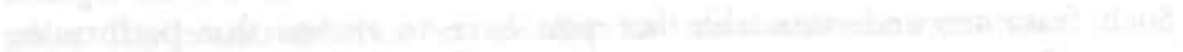
t5.

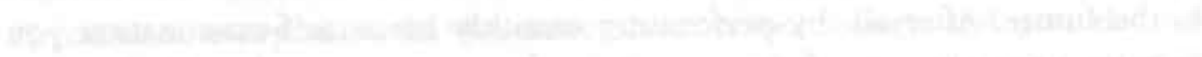

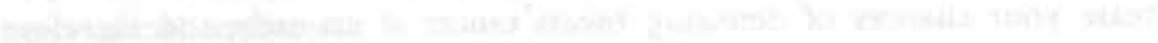

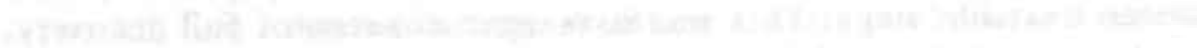

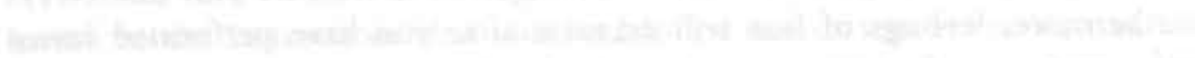

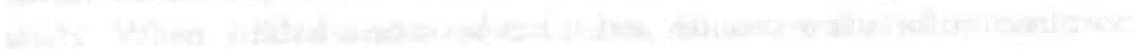

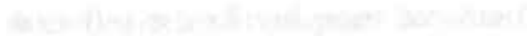

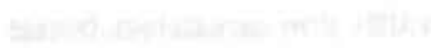




\section{CHAPTER 4}

THE EFFECTS OF SEVERITY AND SUSCEPTIBILITY INFORMATION ON THE SYSTEMATIC PROCESSING OF PERSUASIVE MESSAGES 


\section{INTRODUCTION}

Several theoretical frameworks explain the effects of fear appeals on precautionary motivation and self-protective action, such as the drive-reduction model (e.g., Hovland, Janis, \& Kelley, 1953), the parallel response model (Leventhal, 1970) and the protection motivation theory (Rogers, 1975; Rogers, 1983). Despite the many empirical tests of these models, there is not a full understanding of the processes explaining the effects of fear appeals on attitude and behaviour change yet (Eagly \& Chaiken, 1993, Ruiter, Abraham, \& Kok, 2000). In dealing with this problem, recent studies have. examined the effects of fear-arousing messages on the extent to which fearrelated persuasive messages are carefully (that is, systematically) processed (Baron, Logan, Illy, Inman, \& Brennan, 1994; Gleicher \& Petty, 1992; Meijnders, 1998; Pointer \& Rogers, 1993).

Drawing upon theoretical frameworks that describe the process of attitude change, such as the elaboration likelihood model (Petty \& Cacioppo, 1986) and the heuristic-systematic model (Chaiken, Liberman, \& Eagly, 1989), these studies claimed support for a positive relationship between fear arousal and systematic processing of fear-relevant persuasive information. For instance, Baron and colleagues (1994) reported that respondents in a dentist waiting room who received threatening information about the dental treatment they were about to undergo (high threat condition) reported more fear, and importantly, more carefully read persuasive information about dental hygiene behaviour than respondents who read reassuring information about the dental treatment they would undergo (low threat condition) and subsequently reported less fear. As a result, the first group based their attitude toward the recommended action on the arguments provided whereas the latter did not.

To investigate the effects of frightening information on systematic processing. past studies have manipulated fear by combining high severity and high susceptibility information in the high fear condition and low severity and low susceptibility information in the low fear condition (see e.g., Baron et al., 1994). However, this experimental procedure leaves it unclear to what. extent two main components of fear-arousing information - severity of the threat and recipient's susceptibility to it - influence systematic processing of fear-relevant persuasive messages. After all, the two threat components are necessarily confounded.

The present study examined the independent effects of severity and susceptibility information on the systematic processing of fear-relevant information. Its purpose was threefold. First, it could provide information about the extent to which both threat components influence processing motivation. Secondly, it could provide an answer to the weak support that generally has 
been found for the effects of perceived severity on precautionary motivation (see the meta-analytic reviews by Boster \& Mongeau, 1984; Floyd, PrenticeDunn, \& Rogers, 2000; Milne, Sheeran, \& Orbell, 2000). Thirdly, it could explain the lack of support we found in our first study for the effects of manipulated fear on processing motivation (Ruiter, Kok, Verplanken, \& Brug, in press; see also Chapter 3). The empirical and theoretical footing of the present study is further introduced below, after which the study's methodology and findings are described and discussed.

As stated before, earlier studies (Gleicher \& Petty, 1992; Meijnders, 1998; Pointer \& Rogers, 1993) were not able to examine the independent effects of severity and susceptibility information on systematic processing. Our first study could also not answer this empirical question (Ruiter et al., in press). In that study, to arouse different levels of fear, we manipulated threat by varying severity information under high susceptibility conditions. The only effect we found was a main effect of argument strength on attitude suggesting systematic information processing regardless of threat conditions. Thus, the threat manipulation did not seem to influence the extent of systematic processing, which may suggest that severity perceptions do not influence processing motivation, at least not under conditions of high susceptibility (see also below). However, our findings provided support for a relationship between the affective component within threat messages and systematic processing. That is, reported fear had a positive effect on systematic processing. To the extent that respondents reported more fear of breast cancer, they based their attitude toward breast self-examination (BSE) stronger on the strength of the presented arguments.

From the attitude change literature, it is known that one of the most important factors that motivate people into either central or peripheral processing is perceived personal relevance of the message's topic (Eagly \& Chaiken, 1993; Petty \& Cacioppo, 1986; Petty \& Wegener, 1998). If people evaluate the message as relevant to their own outcomes, values or self-presentation goals, they are motivated to carefully process the persuasive message (for a review, see Johnson \& Eagly, 1989; see also Petty \& Cacioppo, 1990; Johnson \& Eagly, 1990). If perceived personal relevance is low, attitude change may be considered as not important or be based on other characteristics of the message than its argumentation, such as credibility of the source. Attitude change based on such peripheral cues or "rule-of-thumb" reasoning is considered to be less stable over time, less resistant against counter-argumentation, and less predictive of behaviour than attitude change based on central route or systematic processing (for an overview, see Chaiken \& Trope, 1999).

The constructs of personal relevance and susceptibility have been used interchangeably in fear appeal research (e.g., Baron et al., 1994; Kuppens et 
al., 1996). We suggest here that this relationship is somewhat more complex, in the sense that people may think that the topic is relevant to them without feeling susceptible to it. This may, of course, be caused by processes of denial and unrealistic optimism (Weinstein, 1992). For example, a woman cannot deny that women in general run more risk of getting breast cancer in their lives than men. So, that same woman may agree that breast cancer is more relevant to her than to men. Nevertheless, she may have reasons to feel not more susceptible to it than men, because, for instance, nobody in her family suffered from breast cancer. This is not true the other way around. If people feel susceptible to a threat, then they will also think. that the threat is personally relevant to them. Thus, perceived susceptibility seems to be an important determinant of systematic processing through its influence on perceived personal relevance. Specifically, if perceptions of susceptibility increase, perceptions of personal relevance are expected to increase, and that, in turn, will increase systematic processing of relevant persuasive information.

The four main components of a fear appeal are information about the severity of and susceptibility to the threat, and the effectiveness and feasibility of the recommended action (Rogers, 1983). Empirical studies have shown that independent variations of these four information components are related to changes in precautionary motivation, as expressed in attitudes and intentions, and to a lesser extent self-protective action (Eagly \& Chaiken, 1993; Floyd et al., 2000; Milne et al., 2000). However, meta-analyses have also shown that the effect of perceived severity on precautionary motivation is weak compared to the effects of the other three components (Boster \& Mongeau, 1984; Floyd et al., 2000; Milne et al., 2000). So far, no appropriate answers have been found for the weak relationship between severity perceptions and measures of message acceptance. One explanation may be that perceptions of severity do not raise sufficient attention for threat-related persuasive messages, which then cannot exert their persuasive appeal.

As far as we know, the independent effect of severity perceptions on processing motivation has been examined by only one study before. Kuppens and colleagues (1996) manipulated the severity of stress-related diseases among participants who evaluated their risk of getting stress-related diseases (i.e., susceptibility) as either high or low. It was hypothesised that high severity information would increase more careful elaboration of persuasive information about stress-management training compared to low severity information. However, this was expected to be true only for participants who reported low susceptibility to stress-related diseases. They were expected to base their attitude toward participating in stress-management training on the quality of the arguments provided. Instead, for respondents who reported high susceptibility to stress-related diseases and subsequently read 
high severity information about the dangers of stress-related diseases, an over-stimulation hypothesis was developed (see also Jepson \& Chaiken, 1990). They were believed to react defensively to the persuasive message by not reading it carefully, and thus would not base their attitude on the arguments provided (just like the respondents that read low severity information). Findings revealed a (marginal) significant three-way interaction between susceptibility, severity and argument-strength on the attitude toward stress-management training that supported these hypotheses. In sum, Kuppens and colleagues (1996) provide a possible explanation for the lack of support we found in our first study (Ruiter et al., in press) for the threat manipulation. They suggest that perceived severity may enhance the elaboration likelihood of threat-related persuasive information, but only when people do not feel susceptible to the threat.

\section{The present study and hypotheses}

Based on the above discussion, the present study was aimed to investigate the independent effects of severity and susceptibility information on processing motivation. The study is situated in the area of early detection of breast cancer by performing monthly BSE. In contrast to Kuppens and colleagues (1996) who used a self-report measure of perceived susceptibility, we manipulated perceptions of susceptibility to exclude the influence of third, unknown variables that may influence processing motivation. The main dependent measure was the attitude toward performing monthly BSE. Because affective reactions are by definition inherent to emotional persuasive communications such as fear appeals, we choose to measure both a cognition-based and an affect-based attitude. This is consistent with recent research into the structure of attitudes that reveals a distinction between evaluations based on cognitive responses, such as rational arguments and beliefs, and evaluations based on affective responses, such as emotions and feelings (e.g., Eagly \& Chaiken, 1993; Verplanken, Hofstee, \& Janssen, 1998).

The present study further extended our first study (Ruiter et al., in press) by including measures of cognitive responses and actual performance of BSE. These measures may respectively indicate systematic processing and whether attitudes that are the result of systematic processing are indeed better predictors of behaviour (cf. Petty \& Cacioppo, 1986). Based on the extensive support that has been found for personal relevance as an important motivator of systematic processing (Eagly \& Chaiken, 1993; Johnson \& Eagly, 1989; Petty \& Cacioppo, 1986), it is first hypothesised that participants in the high susceptibility to breast cancer conditions read persuasive 
information about performing monthly BSE more systematically (due to heightened perceptions of personal relevance) than people in the low susceptibility conditions. Systematic processing implies a focus on arguments. Therefore, we expected that the effect of argument strength on attitude to perform monthly BSE is stronger under levels of high susceptibility than under levels of low susceptibility. In other words, we expect an interaction effect of susceptibility and argument strength on the measure of attitude (Hypothesis 1).

The weak support that has been found for the effect of perceived severity on precautionary motivation (e.g., Floyd et al., 2000; Milne et al., 2000) suggests that perceived severity is not influencing attention for threat-relevant persuasive information. However, the one study that examined the effects of severity information suggests that increases in perceived severity enhance the likelihood that respondents will process threat-relevant information, but only if their perceptions of susceptibility are low (Kuppens et al., 1996). If perceived susceptibility is high, perceived severity does not influence systematic motivation (see also Ruiter $t$ al., in press). Therefore, we expected that the effect of argument strength on attitude to perform. monthly BSE is stronger under levels of high severity than under levels of low severity, but only if perceived susceptibility is low. In other words, we expect a two-way interaction of severity and argument strength on the attitude toward BSE, which is qualified by a three-way interaction with susceptibility (Hypothesis 2).

To replicate earlier studies into the effect of threat information on information processing (Baron et al., 1994; Gleicher \& Petty, 1992; Meijnders, 1998; Pointer \& Rogers, 1993), we further hypothesised that in the high severity and high susceptibility condition (i.e., high threat condition) participants will be more motivated to systematically process information about performing monthly BSE than those in the low severity and low susceptibility condition (i.e., low threat condition). This implies that we expect that the effect of argument strength on attitudes toward BSE is stronger in the high threat condition than in the low threat condition. We thus expect a three-way interaction of severity, susceptibility and argument strength on the measure of attitude toward BSE performance (Hypothesis 3). 


\section{METHOD}

\section{Participants and design}

Study participants were 167 first-year female undergraduates of Maastricht University who were randomly assigned to the eight conditions of a 2 (Severity: low versus high) x 2 (Susceptibility: low vs. high) x 2 (Argument strength: weak versus strong) between-subjects design. Their mean age was 19 years.

\section{Procedure}

Participants came to the laboratory in groups of maximally four persons. The experimenter shortly explained the procedure of the study by telling them that they would be placed in separate cubicles, which were equipped with a computer, and then would evaluate some messages related to breast cancer developed by the department of health education and health promotion. The experiment was computer-controlled. Participants first read a message about the threat of breast cancer, which contained the manipulations of severity of breast cancer and participant's susceptibility to it. Next, participants received a message that urged them to do a monthly BSE. After reading the message, participants answered a questionnaire that administered respectively the dependent variables, fear arousal, manipulation checks, and earlier performance of BSE.

At the end of the experiment, a message on the computer screen explained the objectives of the study. On return to the experimenter, participants were given the opportunity to ask questions about the study, were paid for their participation (10 Dutch guilders, approximately 5 US dollars), and asked to be silent about the objectives and topic of the study. Furthermore, they received a booklet published by the Dutch Cancer Society about breast cancer and performing BSE and were urged to read this booklet carefully to correct any misinterpretations of the information provided.

\section{Manipulations}

\section{Severity}

The severity of breast cancer was manipulated by varying information about the consequences of breast cancer and its treatment. In the high severity conditions participants read, for instance, that most of the women with breast cancer die from their disease. Furthermore, a breast removal techni- 
que, called radical mastectomy, was described and presented as a cornmon treatment for breast cancer, but having serious physical and emotional consequences. In the low severity conditions participants read, for instance, that women with breast cancer have a good chance to fully recover from their disease. Success rates were given. Furthermore, the low severity message described a new treatment for breast cancer, called lumpectomy, which removes the tumour without affecting the outlook of the breast and thus has low physical and emotional consequences.

\section{Susceptibility}

The perceived personal relevance of breast cancer was manipulated by varying susceptibility information regarding the prevalence of breast cancer. In the high susceptibility conditions breast cancer was described as a high prevalent type of cancer among women younger than 30 years of age, and that recent studies show that breast cancer is more prevalent at increasingly younger age. The latter was explained by the higher number of highly educated women that live and work in more stressful environments. In the low susceptibility conditions it was stated that more than $95 \%$ of the patients with breast cancer are older than $\mathbf{4 5}$ years of age, and that cancer is relatively less prevalent among higher educated women probably due to healthier eating habits and more exercise.

\section{Argument strength}

The persuasive message tried to motivate people to perform monthly BSE by providing either eight weak or eight strong arguments. An example of a weak argument that was used was: "You take responsibility for your social environment and the society in general when you decide to perform monthly breast self-examination. After all, you cannot burden other people with a problern that you could have prevented yourself." An example of a strong argument was: "It is important that you start at young age, preferably from 18 years onwards. If you spend some time every month to examine your breasts, it will become a habit and you will easily learn how your breasts normally feel. This increases your chances to detect any changes in your breasts." (see Appendix in chapter 3. p. 54, for the complete messages)

\section{Measures}

The main dependent variables were the cognitive and affective attitudes toward monthly BSE. As additional indices of information processing we measured participant's thoughts while reading the information about monthly BSE (i.e. cognitive responses). Then, a measure of protection moti- 
vation was taken by asking respondents their intention to perform monthly BSE. This was followed by a measure of fear arousal and checks of the effectiveness of the manipulations, and earlier performance of BSE. After three months we carried out a follow-up measure in which we asked respondents whether they had performed BSE (behaviour).

\section{Attitude}

The attitude toward monthly BSE was measured through eight semantic-differentials on 9-point scales (unimportant - important; undesirable - desirable; bad - good; negative - positive; foolish - wise; worried - relaxed; unpleasant - pleasant; annoying - nice). On the eight items a factor analysis was carried out. In line with recent research (e.g., Verplanken et al., 1998), a principal axis factoring with a direct oblimin rotation revealed a twofactor solution showing that a distinction should be made between a cognition-based attitude (Eigenvalue $=3.04$; loadings higher than .40) and an affect-based attitude (Eigenvalue $=1.49$; loadings higher than .53). Based on reliability analyses, the first five semantic-differentials mentioned earlier were combined into a reliable scale to measure the cognitive attitude toward performing monthly BSE (Cronbach's alpha $=.70$ ). The latter three semanticdifferentials were combined to form a reliable index of affective attitude toward performing monthly BSE (Cronbach's alpha $=.76$ ).

\section{Cognitive responses}

To have more insight in the extent and valence of systematic processing additional measures, respondents were given 3 minutes to list "all the thoughts they had while reading the message about performing a monthly breast self-examination" (cognitive responses). The instructions were similar to the instructions Cacioppo and Petty used in their research (see Cacioppo \& Petty, 1981). Two independent judges were asked to rate a thought as positive when this thought was in support of the message's position (i.e. the performance of a monthly breast self-examination; e.g., "I should perform a breast self-examination myself"), to rate a thought as negative when this thought did not agree with the message's position (e.g., "the arguments are sometimes really ridiculous"), to rate a thought as irrelevant or neutral when this thought was unrelated to the message's position (e.g., "what a small room I am sitting in") or related but contained not a negative or positive evaluation of this position (e.g. "my aunt also had breast cancer and recovered from it"). They first rated twenty thought lists after which the ratings where discussed with the experimenter to further clarify the instructions. For the additional 146 ratings, interrater agreement was $88 \%$ and disagreements were solved through discussion. An index of cognitive responses was calculated by subtracting the number of negative responses 
from the number of positive responses, and dividing this difference by the total number of cognitive responses to correct for differences in the number of generated responses (see also Petty \& Cacioppo "1986).

\section{Intention}

Three items measured the intention to perform monthly BSE (e.g." "I plan tc do a breast self-examination the coming month"; 1 = totally disagree - 9 $=$ totally agree). The three items were combined into a reliable scale (Cronbach's alpho. $=.93$ ).

\section{Fear arousal}

The measure of fear arousal was based on procedures used in fear appeal research (e.g., Leventhal, Singer, \& Jones, 1965; Rippetoe \& Rogers, 1987; Rogers \& Mewborn, 1976), the UWIST mood adjective checklist (Matthews, Jones, Chamberlain, 1990) and Spielberger's (1980) trait- and state-anxiety index (STAI). Like the latter two scales, we used a 4-point scale with fixed answering categories $(1=$ not at all, $2=$ a little, $3=$ rather much, $4=$ very much). Respondents were asked to rate their feelings while reading the information about breast cancer on four mood adjectives (fearful, worried, frightened, uncomfortable). The four items were combined into a scale of fear arousal with bigh internal reliability (Cronbach's elpha $=.87$ ).

\section{Manipulation checks}

One item checked the manipulation of severity by asking respondents whether they thought that breast cancer is a serious disease ( 1 = not at all $7=$ very serious). The manipulation of susceptibility was checked by asking respondents whether they thought that their chances of developing breast cancer were small $(1=$ very much $-7=$ not at all $)$. We further measured the perceived personal relevance of breast cancer by asking respondents whether they agreed that they personally should consider breast cancer as important to them $(1=$ totally disagree $-7=$ totally agree). The argument strength manipulation was checked by asking respondents to what extent they evaluated the arguments in the message about BSE as weak or strong $(1=$ very weak arguments $-7=$ very strong arguments $)$ and to what extent they evaluated the message about BSE. as persuasive $(1=$ not at all persuasive $-7=$ very persuasive). These two items were combined into one index of perceived message strength $(r=.59, p<.001)$.

\section{Previous behaviour}

Previous performance of BSE was measured with one open question: "How often did you perform a breast self-exam in the previous twelve months?" 


\section{Behaviour}

At the three months follow-up measure, respondents were asked by telephone whether they had performed BSE (no-yes), and how many times they had performed it.

\section{RESULTS}

One respondent was removed from the analyses because of insufficient command of the Dutch language $(N=166)$. Unless otherwise reported, 2 (Severity) $\times 2$ (Susceptibility) $\times 2$ (Argument Strength) analyses of variance (ANOVA) were carried out to test the hypotheses. If previous behaviour was significantly related to the dependent variable $(p<.05)$, it was included as a covariate to permit a more powerful test of the effects under consideration.

\section{Manipulation checks}

\section{Severity}

The manipulation of perceived severity was successful as indicated by a significant main effect of Severity on perceived severity, $F(1,158)=12.00, p$ $<.001$. Respondents in the high severity conditions perceived breast cancer as more severe $(M=5.89 ; S D=1.07)$ than respondents in the low severity conditions $(M=5.27 ; S D=1.20)$. Furthermore, the main effect of Susceptibility approached significance, $F(1,158)=3.36, p=.07$. Respondents in the high susceptibility conditions seem to evaluated breast cancer as somewhat more severe $(M=5.76 ; S D=1.08)$ than respondents in the low susceptibility conditions $(M=5.43, S D=1.24)$. No other significant effects were found ( $p$ 's $>.23$ ).

\section{Susceptibility}

On the measure of perceived susceptibility we found the expected main effect of Susceptibility, $F(1,158)=24.23, p<.001$, thus supporting the effectiveness of the susceptibility manipulation. Respondents in the high susceptibility conditions thought that they were more susceptible to getting breast cancer $(M=6.00 ; S D=0.83)$ than respondents in the low susceptibility conditions $(M=5.21 ; S D=1.15)$. No other significant effects were found ( $p$ 's $>.13$ ). We further found that the main effect of Susceptibility was significant on the measure of perceived personal relevance, $F(1,158)=3.71$, $p<.03$ (one-tailed: hypothesised increase). Respondents in the high suscep- 
tibility conditions evaluated breast cancer as more personal relevant ( $M=$ 5.3.8; $\mathrm{SD}=1.19)$ than respondents in the low susceptibility conditions $(M=$ 5.00; $S D=1.34)$. However, when the measure of perceived susceptibility was included as covariate the main effect of Susceptibility on perceived personal relevance strongly reduced to non-significance $\mathrm{F}<1.00$, ns. This finding supports our notion put forward earlier that perceived susceptibility to a. threat mediates the effect of susceptibility information on perceptions of personal relevance.

\section{Argument strength}

The expected main effect of Argument Strength on perceived message strength was also significant, $F(1,158)=8.77, p<.01$, thus indicating the effectiveness of this manipulation. Respondents in the strong arguments conditions evaluated the message about $B S E$ as stronger $(M=5.07 ; S D=$ 0.79 ) than respondent in the weak arguments conditions $(M=4.64 ; S D=$ 1.08). However, a significant three-way interaction, $F(1,158)=4.68, p<$ .05 , revealed that this difference was only significant when severity was presented as high and susceptibility as low. Participants in the high severity - low susceptibility condition evaluated the persuasive message as stronger after reading the strong arguments $(M=5.25 ; S D=0.90)$ than after reading the weak arguments $(M=4.10 ; S D=1.14), t(4.0)=3.65, p<.001$ (see Table 4.1). In the discussion we will elaborate further on the meaning of this finding, as it seems to support hypothesis 2 . No other significant effecis were found ( $p$ 's $>.12$ ).

Table 4.1 Percelved message strength as a function of Severity, Susceptibility and Argument Strength.

\begin{tabular}{llll}
\hline & Argument strength & Low & Husceptibility \\
\cline { 2 - 4 } & Weak & $4.81(1.01)$ & $4.71(1.02)$ \\
& Strong & $4.98(0.91)$ & $5.05(0.69)$ \\
\cline { 2 - 4 } & Weak & $4.10^{\mathrm{a}}(1.14)$ & $4.93(1.05)$ \\
& Strong & $5.25^{\mathrm{b}}(0.90)$ & $5.00(0.69)$ \\
\hline
\end{tabular}

Note. Means with different superscript differ significantly $(p<.001)$. Higher numbers indicate higher perceived message strength (range 1 - 7). Values enclosed in parentheses represent standard deviations. 


\section{Fear arousal}

On the measure of fear arousal a main effect of both Severity, $F(1,158)=$ 27.15, $p<.001$, and Susceptibility was found, $F(1,158)=23.03, p<$ .001 . In the higher levels of each factor more fear was reported $(M=2.09$; $S D=0.63$ and $M=2.09 ; S D=0.71$, respectively) than in the lower levels $(M=1.62 ; S D=0.57$ and $M=1.65 ; S D=0.49$, respectively). No other significant effects were found ( $p$ 's > .50).

In line with the notion that fear arousal is the result of a perception of both high severity and high susceptibility (Frijda, 1986). Tukey post-hoc comparisons revealed that the reported fear was higher in the high severity - high susceptibility condition $(M=2.33, S D=0.66)$ than in the three other combinations of severity and susceptibility information ( $p$ 's $<.001$ ), and lower in the low severity - low susceptibility condition $(M=1.45$, SD $=0.39$ ) than in the three other combinations of severity and susceptibility information ( $p$ 's < .02). This confirms our idea that the highest threat of breast cancer was presented when the severity of breast cancer and respondent's susceptibility to it were emphasised, and the lowest threat when both components were described as low (see Figure 4.1).

Figure 4.I Reported fear as a function of Severity and Susceptibllity.

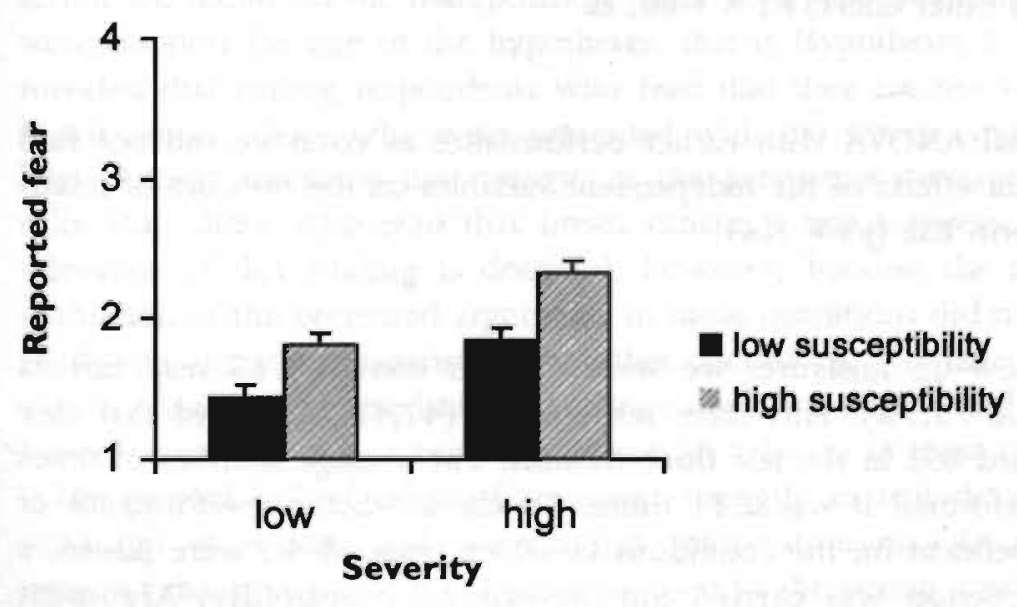

Legend. Bars show means with higher scores indicating higher levels of fear. Error bars show mean +1.0 scandard error of the mean. 


\section{Dependent variables}

\section{Attitude}

Analyses on the cognitive component of attitude with earlier performance as a covariate revealed a main effect of Severity, $F(1,157)=4.13, p<.05$. Respondents in the high severity conditions evaluated BSE performance somewhat more positively $(M=7.74 ; S D=1.05)$ than respondents in the low severity conditions $(M=7.53 ; S D=0.88)$. However, no support was found for the hypotheses. Respectively, the expected two-way interaction of Susceptibility and Argument Strength (Hypothesis 1), and the three-way interaction of Severity, Susceptibility and Argument Strength (Hypotheses 2 and 3) failed to reach reliable significance levels, $F^{\prime} s<1.00$, ns. No other significant effects were found either ( $p$ 's $>.25$ ).

Also on the affective component of attitude we found no support for the hypotheses on the relevant interaction tests, F's $<1.00$, ns. However, the main effect of Susceptibility was significant, $F(1,158)=5.76, p<.05$. Respondents in the high susceptibility conditions felt less positive about performing BSE ( $M=4.99 ; S D=1.28$ ) than respondents in the low susceptibility conditions $(M=5.48 ; S D=1.31)$. The analyses revealed no other significant findings ( $p$ 's $>.22$ ).

\section{Cognitive responses}

On the measure of cognitive responses, no support was found for the hypotheses or any other effect, F's $<1.00$, ns.

\section{Intention}

A full-factorial ANOVA with earlier performance as covariate did not find any significant effects of the independent variables on the measure of intention to perform BSE (p's > .14).

\section{Behaviour}

On the follow-up measure, we were able to contact 125 respondents (response rate $75,3 \%$ ). Fifty-three respondents $(42,4 \%)$ indicated that they had performed BSE in the last three months. The average number of times they had performed it was 2.21 times. To check whether performance of BSE was dependent on the conditions in which respondents were placed, a logistic regression was carried out. Severity, Susceptibility, Argument Strength, all two-way interactions and the three-way interaction were regressed on BSE performance. This analysis revealed no significant findings (p's > .11). A full-factorial ANOVA revealed that also the number of times respondents performed BSE was not dependent on the information respondents received ( $p$ 's > .19). 


\section{DISCUSSION}

The current study investigated the effects of severity and susceptibility information on the cognitive processing of a threat-relevant persuasive message. It was first hypothesised that people who learned that they are susceptible to getting breast cancer would process subsequent information about performing monthly BSE more systematically, due to heightened perceived personal relevance of breast cancer, than people who learned that their susceptibility to breast cancer is low. The second hypothesis predicted that respondents who read that breast cancer has severe negative consequences would elaborate more on persuasive information about BSE than respondents who read that breast cancer is now better treatable and thus has less severe consequences, but only when the respondents' susceptibility to breast cancer was described to them as low. Finally, it was expected that respondents who read high threatening information about breast cancer would process persuasive information about BSE more carefully than respondents who read low threatening information.

The findings of the present study can be briefly summarised as disappointing. Despite seemingly successful manipulations, no support was found for any of the hypotheses. The expected interactions between the susceptibility and severity manipulations and argument strength manipulation on the cognitive and affective component of attitude, which would indicate systematic message processing, did not reach reliable levels. Only the three-way interaction we found on the manipulation check of argument strength indicated some support for one of the hypotheses, that is Hypothesis 2. This finding revealed that among respondents who read that they are not susceptible to breast cancer, those who were presented with the severe consequences of breast cancer evaluated the strength of the persuasive message more critically than those who read that breast cancer is not a severe disease. The relevance of this finding is doubtful, however, because the more critical evaluation of the presented arguments in these conditions did not result in a change in attitude compared to the other conditions. The latter is probably due to a lack of perceived need to change one's attitude toward BSE because breast cancer was not perceived as personally relevant in these conditions.

The general lack of effect of argument strength on attitude as a result of variations in severity and susceptibility information may be explained in terms of the strength of the arguments used in the strong argument condition compared to those used in the weak argument condition. One important characteristic of convincing arguments is the extent to which they are believed to be new (Vinokur \& Bernstein, 1978). In the process of changing attitudes, only arguments that are perceived as new (on top of being convincing and not counterarguable; Petty \& Cacioppo, 1986) may motivate 
people to evaluate their current behaviour and think about other behavioural options. The main argument used in the strong message was that "performing monthly BSE may increase your chances of detecting breast cancer in an earlier, and therefore more treatable, stage". This argument has been evaluated in pretest studies as the most convincing one, but at the same time as the most familiar one. Especially, if the issue of interest is in the public domain, as is the case with breast cancer prevention, it may be better to accompany familiar arguments with new information by using formulations such as: "As you probably know ...., but did you know that ....".

Furthermore, strong arguments should lead to favourable thoughts about the message's position, whereas the weak message should provide counterarguable arguments that lead to unfavourable thoughts about the message's position (cf. Pelty \& Cacioppo, 1986; Cacioppo \& Petty, 1981). These thoughts then mediate attitude change with positive thoughts leading to more positive attitudes, and negative thoughts leading to more negative attitudes (Petty \& Cacioppo, 1986). Although a pretest of the argument strength manipulation did obtain the expected valence in thoughts, the current study seemed to have failed in reaching this objective because no significant effects were found on this measure.

We say here "seemed to have failed", because doubts have been raised about the validity of thought listing techniques in identifying systematic processing by several authors (Meijnders, 1998; Nisbett \& Wilson, 1977). The best observable indicator for this lack of validity is the inconsistency in which cognitive response indices have been scored to serve as indicators of message processing across different empirical studies. As Meijnders (1998) stated: "Some studies calculated the index of cognitive responses by the total number of relevant responses, other studies used the number or proportion of positive responses or the number or proportion of negative responses, and again other studies used the difference between the number or proportion of positive and negative responses" (p. 112). In addition, past studies have clearly demonstrated the lack of introspective ability people have to identify relevant thoughts that influence their opinions and decisions (e.g. Fesinger \& Carlsmith, 1959: Nisbett \& Wilson, 1977). Also, in the experiment reported here, participants asked the experimenter: "Why did you not tell us in advance that we should write down our thoughts? That would have made it much easier." (personal observations) Moreover, recent applications of subliminal priming paradigms in, for instance, social stereotyping literature have clearly illustrated that stimuli and subsequent cognitive processes may operate outside a person's awareness (for an overview, see Wegner \& Bargh, 1998).

Next to the potential to generate valid and interesting findings, procedures to estimate the extent of systematic information processing, such as manipulating argument strength and listing cognitive responses, seem to have 
important shortcomings. More implicit measures might be needed to assess the extent of systematic information processing. The time participants spend on reading the persuasive message might be such an implicit measure. However, a good control measure for individual differences in reading speed is often missing. Moreover, it is often unclear to what extent an increase in reading time reflects an increase of motivation to elaborate on the presented information or a decrease of capacity to read it (e.g., Mackie \& Worth, 1989; Schwarz, Bless, \& Bohner, 1991). Other, more promising techniques could be reaction time procedures in which participants decide as fast as possible whether they agree or disagree with attitudinal statements (e.g., Petty, Haugtvedt, \& Smith, 1995). In this respect, a critical review of the reliability and validity of experimental procedures to assess the extent of systematic information processing is missing.

In the present study, the manipulations of severity, susceptibility, and argument strength neither influenced the attitude and intention toward performing BSE nor the performance of BSE. One reason why it may be hard to change BSE motivation and performance is that women consider BSE as a risky behaviour. Risky, in the sense, that they fear the risk of detecting a potentially deadly disease when performing it. The present study found support for this notion as respondents who read that they were susceptible to breast cancer had more negative feelings toward performing BSE than respondents who learned that their susceptibility to breast cancer is low. Obviously, the performance of BSE seems to be evaluated more on its shortterm, negative effects (e.g., detection of breast cancer) than on its longterm, positive effects (e.g., better treatment possibilities due to early detection).

A practical and also empirical question, therefore, is how to make the positive effects of performing BSE more salient than its negative effects? One straightforward way to reach this objective is to stress the positive consequences of BSE performance and avoid speaking about the negative consequences of BSE. Positive beliefs will then be most accessible in memory from which, in turn, a positive attitude toward BSE can be automatically derived (see also Ajzen \& Fishbein, in press; Ajzen \& Sexton, 1999). This procedure of stressing the positive consequences and avoiding the negative consequences strongly resembles procedures employed in testing the effects of action framing (for a review, see Rothman \& Salovey, 1997). This research compares the persuasive effects of frames that emphasise the positive consequences of performing the recommended action (gain frame; e.g. by performing BSE you will detect breast cancer in an early stage) with frames that present objectively the same information but emphasise the negative conseguences of not performing the recommended action (loss frame; e.g., by not performing BSE you will not detect breast cancer in an early stage). 
However, so far this research has concluded that attitude toward detection behaviours, such as skin self-examination to detect skin cancer or getting regularly medical checkups, can be best promoted by negatively framed messages; whereas attitudes toward prevention behaviours, such as using; sun screen and exercising, regularly, can best be promoted by positively framed messages (for empirical evidence, see Detweiler, Bedell, Salovey, Pronin, \& Rothman, 1999; Rothman, Martino, Bedell, Detweiler, \& Salovey, 1999). Explanations for these findings are based on assumptions of prospect theory that when being confronted with losses people will choose the risky option, while being confronted with possible gains people will choose the certain option (Kahneman \& Tversky, 1984; Rothman \& Salovey, 1997). In chapter 6 a study is reported that tested the effects of action framing under conditions of fear arousal.

Finally, the role of fear arousal in influencing processing motivation and precautionary action. Although in the present study, as expected, the combination of high susceptibility and high severity information (high threat condition) produced the most fear arousal and the combination of low severity and low susceptibility information (low threat condition) the lowest fear arousal, no support was found for an effect of the threat manipulation on the extent of systematic processing. Thus, this study did not replicate earlier studies that used the same empirical paradigm (e.g., Baron tt al., 1994; Gleicher \& Petty, 1992: Pointer \& Rogers, 1993). In contrast to our first study (see chapter 3 ), we did not measure fear arousal before presenting the persuasive message because we did not want to not disturb the process under study. On-line measurement of fear arousal by means of physiological. measures such as the startle reflex and the galvanic skin response could have been helpful here to study the causal effects of fear arousal on systematic processing.

In conclusion. Eagly and Chaiken (1993) proposed to study the effects of fear appeals from an information processing perspective. Their argument was that more should be learned about the cognitive processes that mediate the effects of frightening information on precautionary motivation and action. Probably many studies have been carried out since that used dual process paradigms (i.e., manipulation of argument strength) to study the ("obvious") hypothesis that fear arousall motivates respondents into more systematic processing of fear-relevant information. However, only a few studies have been successful in finding support for this hypothesis. These were also the only ones published in relevant scientific journals. Baron and colleagues (1994) found support for the hypothesis in the domain of dental hygiene behaviour, whereas Gleicher and Petty (1992) found conditional evidence indicating that the hypothesis is only true when respondents are not reassured in advance about the effectiveness of the recommended 
action. Remarkably, no replications have been published so far of these two studies, although replication attempts have been made. For instance, three doctorate studies by different persons in the Netherlands have had major problems in finding support for the hypothesis (Das, 2000; Meijnders, 1998, Ruiter et al., in press). A new approach to study the persuasive impact of fear arousal seems to be necessary. One promising approach has been given by Witte (1992a) who suggested a renewed attention for fear arousal and how it may prompt fear-driven processes such as message avoidance, denial and defensive avoidance that could easily interfere with processes of attitude and intention formation. 


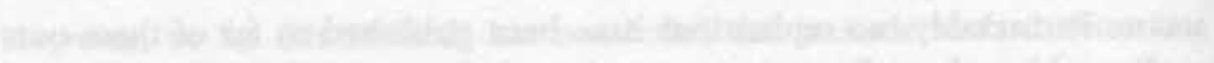

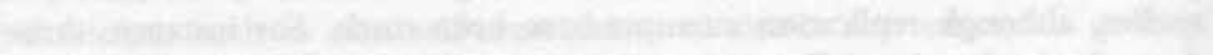

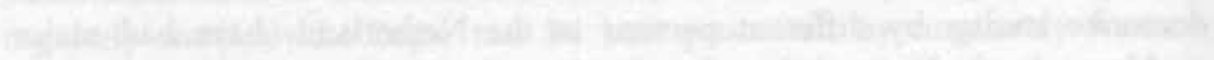

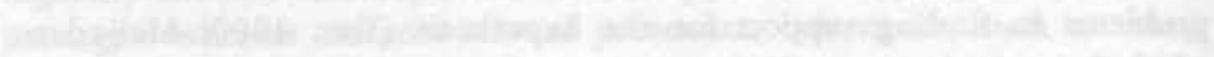

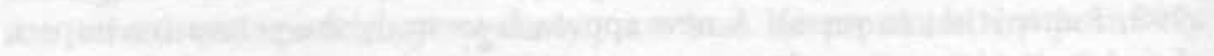

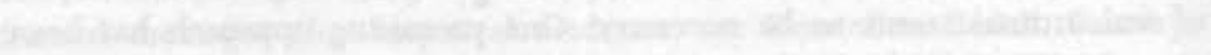

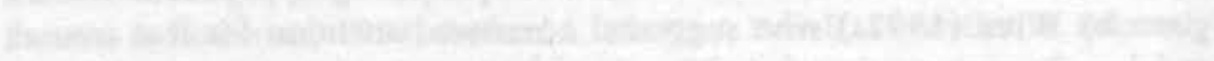

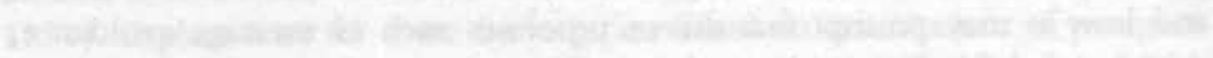

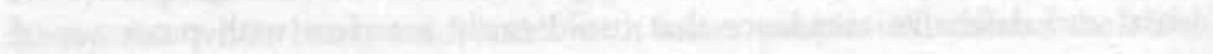

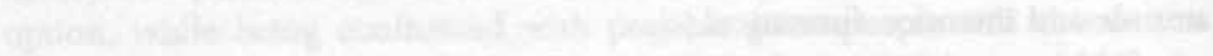

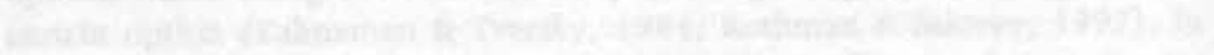

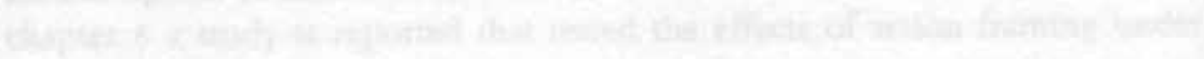

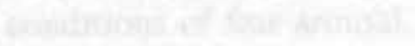

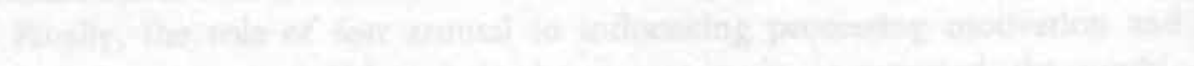
14.

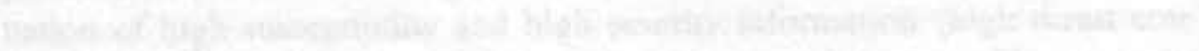

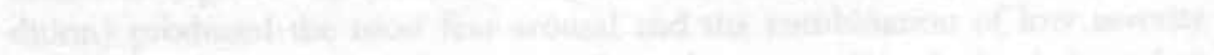

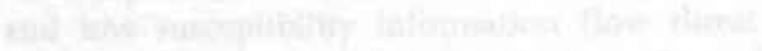

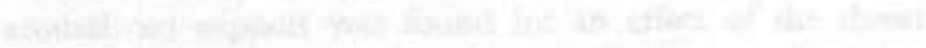

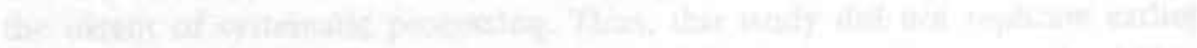

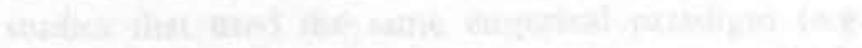

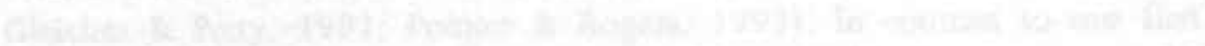

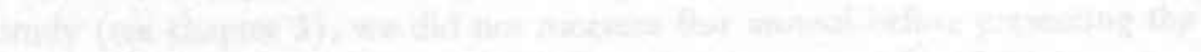

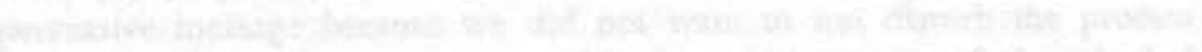

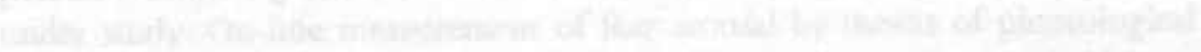

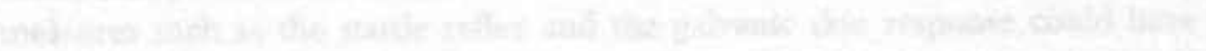

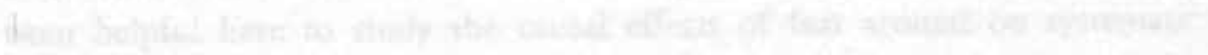




\section{CHAPTER 5}

THE EFFECTS OF FEAR-AROUSING HEALTH INFORMATION ON PROCESSES OF FEAR CONTROL AND DANGER CONTROL: THE (PRESUMED) MODERATING ROLE OF INDIVIDUAL DIFFERENCES IN EFFICACY EXPECTANCIES

Submitted for publication as:

Ruiter, R. A. C., Kok, G., Verplanken, B, \& Werrij, M.

(2000). The effects of fear-arousing health information on processes of fear control and danger control:

The (presumed) moderating role of individual differences in efficacy expectancies. 


\section{INTRODUCTION}

In the last 45 years several theoretical models have been formulated to explain the effects of fear appeals on precautionary motivation and self-protective action, among those are the Drive Reduction Model (Hovland, Janis, \& Kelley, 1953; Janis, 1967; McGuire, 1968; McGuire, 1969), the Parallel Response Model (Leventhal, 1970), and the Protection Motivation Theory (Rogers, 1975; Rogers, 1983). In general, these models (see Eagly \& Chaiken, 1993, for a description of these models) assume that fear-arousing information is only effective in inducing attitude and behaviour change if people belief that they have the necessary coping abilities to avert the threat, that is if people believe whether the recommended action can avert the threat (i.e., response efficacy; Rogers, 1975) and they feel confident to perform the recommended action (i.e., self-efficacy; Bandura, 1986; Rogers, 1983). However, empirical support for this interaction effect of threat and efficacy variables on measures of message acceptance has been weak or, at best, inconsistent (Eagly \& Chaiken, 1993; Rogers \& Prentice-Dunn, 1997; Ruiter, Abraham, \& Kok, 2000; Witte \& Allen, in press). For example, in a review of protection motivation theory Rogers and Prentice-Dunn (1997) concluded that support for the predicted interaction between threat and efficacy variables has been found in (only) $50 \%$ of the empirical tests.

In an attempt to clarify this empirical problem, Witte (1992a) proposed the Extended Parallel Process Model (EPPM), which combines the abovementioned theoretical frameworks. This model was designed to explain, next to success, also failures of fear appeals by emphasising the central role of fear and its influence on defensive responses such as avoidance and denial. Specifically, EPPM specifies two processes in response to a confrontation with fear-arousing information: danger control and fear control (see also Leventhal, 1970, and Lazarus' distinction between problem-focussed and emotion-focussed coping responses to stressful events; Lazarus, 1966; Lazarus \& Folkman, 1984). Danger control processes are defined as cognitive processes that describe the way threat perceivers react to the presented threat (including assessment of threat seriousness and personal susceptibility) and suggested coping responses (including assessments of response efficacy and self-efficacy). High threat and efficacy beliefs may prompt acceptance of the recommended precaution indicated by positive attitude, intention and behaviour change (see also Rogers, 1983). Fear control processes, on the other hand, operate when threat perceptions are high but efficacy expectancies are low. They are defined as affective processes that are directed toward finding reassurance for the experienced fear - not the presented threat - through avoidance, denial or derogation of the message (Witte, 1992a), while maintaining or even intensifying the risk behaviour 
generating the threat (see also Rogers, 1983). These responses are maladaptive because they do not avert the presented threat.

\section{The presumed moderating role of efficacy beliefs}

Thus following EPPM, both fear control responses and danger control responses are determined by efficacy beliefs (and, of course, by perceived threat and fear arousal which are the motivational forces for either action). This is also supported by a study by Rippetoe and Rogers (1987). Their findings indicated that, under conditions of high threat, people with high response efficacy and self-efficacy expectancies preferred adaptive responses (e.g., intention to perform breast self-examination) over maladaptive ones (e.g., avoid thinking about breast cancer), while people with low response efficacy and self-efficacy preferred maladaptive responses over adaptive ones. More recent empirical work by Witte, however, does not provide as much support for the moderating role of efficacy beliefs in fear control processes as it supports their moderating role in danger control processes (Witte, 1994; Witte, Berkowitz, Cameron, \& McKeon, 1998).

This work consistently identified efficacy expectancies as main predictors of danger control responses (Witte, 1992b; Witte, 1994; Witte et al., 1998). In fear control processes, however, efficacy expectancies seem to have a less consistent role. Hypotheses and empirical support concerning the moderating role of efficacy expectancies in fear control processes differ between studies. Witte and colleagues (1998, p. 574) found partial support for their hypothesis that "Individuals exposed to the fear appeal campaign message with lowefficacy expectancies should have a greater degree of defensive avoidance, perceived manipulation, and issue derogation than those with high-efficacy expectancies." However, Witte (1994, pp. 117 - 118) reported support for the hypotheses that "There is a direct relationship between fear and message rejection outcomes, such as defensive avoidance and reactance." and "Perceived efficacy .... is unrelated to message rejection outcomes such as defensive avoidance or reactance." Witte (1992b) even did not hypothesise on the relation between efficacy beliefs and fear control responses although both constructs were measured. Moreover, protection motivation theory and more general explanatory models of behaviour, such as the theory of planned behaviour (Ajzen, 1988) and social cognitive theory (Bandura, 1986), relate efficacy beliefs specifically to the recommended precaution and thus range them among danger control processes (see also Rogers, 1983).

In sum, we argue here that efficacy expectancies have a more important role in the deliberative, conscious processes of action planning that characterise danger control than in the affective, unconscious processes that repre- 
sent fear control. This argument is further based on recent research into automatic processes within social cognition and action (for useful reviews, see Eagly \& Chaiken, 1993; Petty \& Wegener, 1998; Wegner \& Bargh, 1998) that suggests, that affective processes can operate largely automatically and at a pre-conscious level (see also, Murphy \& Zajonc, 1993; Zajonc, 1980; Zajonc, 1984). For example, Wegner and Bargh (1998) suggest that negative emotions may automatically activate defence mechanisms to control the emotion. Such fear control processes may result in conscious responses such as avoiding situations that would evoke the emotion, but they may also prompt automatic, unconscious responses such as suppression of the emotional response. Thus fear may be a primary response that leads to automatic fear control processes. Assuming that assessing the effectiveness (response efficacy) and feasibility (self-efficacy) of the recommended action is a conscious rather than automatic process, efficacy beliefs may have a less important role in fear control processes than in danger control processes.

\section{Overview of the study}

In the present study we were specifically interested to what extent efficacy expectancies moderate the effects of fear arousal on fear control responses. Apart from the abovementioned studies by Witte and colleagues and Rippetoe and Rogers (1987), this question has hardly received any research attention. A vast majority of fear appeal studies, especially those that tested Rogers' Protection Motivation Theory (for meta-analyses, see Floyd, Prentice-Dunn, \& Rogers, 2000; Milne, Sheeran, \& Orbell, 2000), only focused on the role of efficacy expectancies in danger control processes (i.e., processes of attitude and behaviour change). Moreover, in studying these effects efficacy expectancies were typically manipulated (e.g., Maddux \& Rogers, 1983; Rippetoe \& Rogers, 1987; Witte, 1992b). It may be more useful, however, to study the effects of existing individual differences in efficacy beliefs (see also Witte et al., 1998). After all, the most popular channel for fear-arousing health messages are mass media. campaigns. Typically, these campaigns result in limited exposure and are therefore not likely to influence efficacy expectancies. EPPM would predict that only those in the target population that already have high efficacy expectancies may profit from these campaigns (Witte, 1992a).

To exclude priming effects on dependent variables, existing efficacy beliefs may be measured either directly after the dependent variables or well in advance of the actual study. We present here two experiments that measured efficacy beliefs at these two moments, respectively. This gave us the opportunity to distinguish between the effects of efficacy expectancies 
accessible at the presentation of fear-arousing information (Experiment 1) and those measured well in advance of the actual study (Experiment 2). Furthermore, in Experiment 2 we measured efficacy expectancies also a second time, directly after the dependent variables (like in Experiment 1). This gave us the opportunity to see whether the effects we find with postexperimental efficacy beliefs are consistent over two studies. As argued above but also elsewhere (Ruiter et al., 2000; reported in chapter 2), fear appeal research is characterised by its inconsistency between empirical findings. Typically, successful replications of earlier studies are rare (compare, for example, Janis \& Feshbach, 1953, and Leventhal \& Singer, 1966; see also Eagly \& Chaiken, 1993; Rogers \& Prentice-Dunn, 1997).

The present paper thus presents two experiments that are exact copies of each other, except for the measurement of pre-experimental efficacy expectancies in Experiment 2. In both experiments a high versus a low fear-arousing message about breast cancer was presented by varying information about the severity of breast cancer and recipients' personal susceptibility to it. Danger control and fear control served as dependent measures. Danger control responses were operationalised through measures of attitude and intention toward performing monthly breast self-examination (BSE) (cf. Witte et a., 1998). Because we were studying the effects of emotional information we chose to measure both a cognition-based component and an affect-based component of attitude. This is consistent with recent research into the structure of attitudes that reveals a distinction between evaluations based on cognitive responses, such as rational arguments and beliefs, and evaluations based on affective responses, such as emotions and feelings (e.g., Eagly \& Chaiken, 1993; Verplanken, Hofstee, \& Janssen, 1998). Fear control responses were operationalised through measures of defensive avoidance, message derogation, and perceived manipulation (cf. Witte et al., 1998).

\section{Hypotheses}

In general, we expect that under conditions of fear efficacy expectancies have a stronger effect on danger control responses than on fear control responses. More specifically, we first predict that more fear results in more danger control responses but only if respondents have high efficacy expectancies (see also Rogers, 1983; Witte, 1992a). We thus expect an interaction effect between fear arousal and efficacy expectancies that shows that participants in the mild fear conditions with high efficacy expectancies have more positive attitudes and intention toward BSE performance than participants with low efficacy expectancies and than participants in the low fear conditions regardless of their efficacy expectancies (Hypothesis 1). 
Furthermore, we predict that respondents will show more fear control responses (i.e., defensive avoidance, issue derogation, perceived manipulation) after reading mild fear information than after reading low fear information. Because of the supposedly automatic and pre-conscious nature of fear control responses (e.g., Wegner \& Bargh, 1998; see also Witte, 1992a), we do not expect that this main effect of fear is qualified by efficacy expectancies (Hypothesis 2).

Finally, in at recent meta-analysis, Witte and Allen (in press) found evidence for a negative relationship between fear control and danger control processes, which suggests that fear control responses may interfere with. danger control processes in motivating people to safer behaviour. By using correlational analyses we checked whether we could replicate this finding in the present study.

\section{METHOD}

To test the hypotheses, two almost identical experiments were carried out. The only aspect on which both experiments differed was the measurement of pre-experimental efficacy expectancies, which was only done in Experiment 2. The methods of both experiments will be described next, except for the measurement of pre-experimental efficacy expectancies in. Experiment 2, which will be described directly in advance of presenting the results of Experiment 2.

\section{Participants and design}

Fifty-nine (Exp. 1) and 71 (Exp. 2) female first-year undergraduates of Maastricht University were randomly assigned to one of two conditions. The experiment used a one-factorial design in which participants either received low fear-arousing or mild fear-arousing information about breast cancer. These two samples were drawn from two different classes (1998 and 1999) by means of registration forms that asked for participants in a series of behavioural science studies. Participants left their names and telephone numbers on these forms and were later invited to the laboratory by a female experimenter. They received no other information than that they would read some texts and should answer some questions, and in return would receive 10 Dutch guilders (about 5 US dollars) for their participation. 
Respondents came to the laboratory in groups of maximally four people, but were placed in separate cubicles that were equipped with a computer. The experiment was computer-controlled. After some explanation about the length of the experiment and the use of the computer, the experiment began with a message about breast cancer that contained the manipulation of fear arousal. After reading the message, fear arousal was measured, followed by measures of fear control responses. Then a message appeared on the screen, which stated that: "Performing a breast self-examination means that you check your breasts for changes every month. Now, some questions will be asked about performing a monthly breast self-exam." This was followed by a questionnaire measuring danger control processes, efficacy expectancies, and previous BSE performance. All measures used 9-point scales (1 9), unless otherwise mentioned.

Fear manipulation

Fear arousal was varied by manipulating the severity of breast cancer and personal susceptibility to it. The low fear-arousing message described the participant's susceptibility to breast cancer as low. This was done by stating, for example, that "Breast cancer is a form of cancer that is most common among women older than 50 years of age.", and by describing the Dutch medical examination programme for breast cancer which invites biannually all women between 50 and 70 years to undergo a mammography. The severity of breast cancer was ignored by providing boring, biological information about the causes of breast cancer along with pictures of cell divisions.

In contrast, the mild fear-arousing message told the respondent that she was susceptible to getting breast cancer already in her younger years. Thisi was mainly done by introducing the topic of breast cancer by means of a photograph of a peer group member on the computer screen who ostensibly stated that she discovered breast cancer herself after participating in the same study last year (in the low fear message the same picture was used, but the girl stated that the present study was part of a research project she was carrying out). Furthermore, the severity of breast cancer was emphasised by describing breast cancer as a very serious disease with significant physical and emotional consequences that often ends in death. This written information was illustrated with photographic material showing pictures of women that had undergone amputation of one of the breasts. Both messages were equal in length, contained the same number of photographs, and were judged as equal in difficulty and believability among a sample $(\mathrm{N}=20)$ of second-year female undergraduates. 


\section{Measures}

\section{Fear arousal}

The amount of fear participants experienced after reading the message about breast cancer was measured to check for a successful manipulation of fear arousal. Four mood adjectives measured fear arousal (cf. Mewborn \& Rogers, 1979; Witte et al., 1998): "To what extent did you feel (i) afraid, (ii) frightened, (iii) worried, (iv) uncomfortable while reading the text about breast cancer (not at all - very much). These items were combined in a scale of fear arousal, which had very high internal reliability in both experiments (Exp. 1: Cronbach's alpha $=.98$; Exp. 2: Cronbach's alpha $=.94)$.

\section{Fear control processes}

One item measured defensive avoidance of the message about breast cancer: "When I read the message about breast cancer my first. reaction was that I did not want to think about breast cancer (totally disagree - totally agree)". Two items measured message derogation (Exp. 1: $\mathrm{r}=.68 ; \mathrm{p}<.001$; Exp. 2: $\mathrm{r}=$ $.76 ; p<.001)$. The items used were: "The information about breast cancer was (i) not at all overblown - very overblown, (ii) not at all extreme - very extreme". Two items concerning perceived manipulation measured the extent to which participants thought the message about breast cancer deliberately tried to manipulate their feelings (Exp. 1: $r=.44 ; \mathrm{p}<.001$; Exp. 2: $\mathrm{r}=$ $.53, \mathrm{p}<.001)$. The items used were: "Information about breast cancer tried to (i) manipulate my feelings, (ii) distort the truth (totally disagree - totally agree)".

\section{Danger control responses}

The attitude toward monthly BSE was measured through eight items on which a factor analysis was carried out. In line with recent research into the structure of attitudes (e.g., Verplanken et al., 1998), principal axis factoring with oblimin rotation revealed a two-factor solution showing that a distinction could be made between a cognition-based component of attitude (Exp. 1: Eigenvalue $=3.64$, factor loadings higher than $.63 ;$ Exp, 2: Eigenvalue $=$ 4.15, factor loadings higher than .37) and a more affect-based component of attitude (Exp. 1: Eigenvalue = 1.37, factor loadings higher than .34; Exp. 2: Eigenvalue $=1.14$, factor loadings higher than .49 ).

Based on internal reliability analyses, the cognitive attitude toward performing monthly BSE was measured through five semantic-differentials: unimportant - important; bad - good; insensible - sensible; negative - positive; foolish wise. These were combined into one reliable scale measuring cognitive attitude (Exp. 1: Cronbach's alpha $=.86 ;$ Exp. 2: Cronbach's alpha $=.85$ ) . 
The affective attitude was measured through three semantic-differentials that were combined in one scale: unpleasant - pleasant; annoying - nice; frightening - comforting. The internal reliability was weak in Experiment 1 (Cronbach's alpha $=.56)$ and good in Experiment 2 (Cronbach's alpha $=.74)$.

The intention to perform monthly BSE was measured with two items: "Do you plan to perform a breast self-examination this month (surely not surely yes)" and "How often do you plan to do a breast self-examination? (not at all - every month)". These items were combined in one moderate reliable scale that measured intention (Exp.1: $r=.70 ; p<.001 ;$ Exp. $2: r=$ $.77, p<.001)$.

\section{Efficacy expectancies}

Participants' beliefs about the efficacy of BSE to detect breast cancer in an early stage (i.e., response efficacy) were measured directly after the danger control responses through five items. For example, "The performance of a monthly breast self-exam is very effective to detect breast cancer in an early stage (totally disagree - totally agree)". Participants" beliefs in their ability to perform BSE (i.e., self-efficacy) were measured through three items. One of the items used was: "Suppose you are planning to do a monthly breast selfexamination, how easy or difficult do you think the performance of a monthly breast self-exam will be? (very easy - very difficult)". In line with the procedure followed by Witte et al. (1998) the eight items were combined into one scale measuring perceived efficacy of BSE (low - high). The internal reliability of this scale was good in both experiments (Exp. 1: Cronbach's alpha $=.77 ;$ Exp. 2: Cronbach's alpha $=.77$ ).

\section{Previous behaviour}

Previous performance of BSE was measured with one open question on a continuous scale: "How often did you perform a breast self-exam in the previous twelve months?". If previous behaviour was significantly related to a dependent variable $(p<.05)$, it was included as a covariate to permit a more powerful test of the effect under consideration.

\section{Debriefing}

After finishing the experiment participants were individually and extensively debriefed by the female experimenter. They were invited to talk about how they experienced the study. The experimenter was particilarly alert on any signs of current fears as expressed by the participants. No such signs were perceived and none of the participants regretted participating. On the contrary, many participants responded that they thought the study was interes- 
ting and that they learned something new, while others informed the experimenter that the topic was familiar to them because they knew somebody in their family or social relationships who has or had breast cancer.

If questions were asked the experimenter was able to answer them adequately. Participants also received a booklet about breast cancer and an instruction card on how to perform BSE. Both are used by the Dutch Cancer Society as standard materials in their educational program about breast cancer. Participants were urged to read the booklet and instruction card to correct any misinterpretations of the information provided in the experimental study, paid for their participation, and were asked to be silent about the topic and objectives of the study.

\section{EXPERIMENT I}

To create the factor Efficacy a median split procedure on the index measuring efficacy expectancies was carried out (Median = 5.43). Eight respondents scored on the median but were included in the high efficacy group to keep a reasonably balanced design and sufficient power. Importantly, an effect of the factor Fear on the measure of efficacy expectancies was not found, $t<1.00$, ns, and a chi-square analysis on the cross tabulation of the factors Fear (low vs. mild) and Efficacy (low vs. high) was also not significant, $\chi^{2}(1,59)=1.36, p=.30$. This indicates that Fear and Efficacy are independent factors, and that the participants are equally distributed across the conditions.

\section{Results}

\section{Fear arousal}

A 2 (Fear) × 2 (Efficacy) analyses of variance (ANOVA) revealed a significant main effect of Fear on the measure of fear arousal, $F(1,55)=28.97$, $\mathrm{p}<.001$. Respondents in the mild fear condition reported more fear $(M=$ $5.68 ; S D=1.79)$ than respondents in the low fear condition $(M=3.37 ; S D$ $=1.31)$. The main effect of Efficacy and the interaction between Fear and Efficacy were not significant ( $p$ 's $>16$ ). The manipulation of fear arousal was thus successful. 


\section{Danger control responses}

To test hypothesis 1, a multivariate 2 (Fear) $\times 2$ (Efficacy) analysis of variance with previous BSE performance as covariate (MANCOVA) was carried out on the three indices of danger control. This analyses revealed a multivariate main effect for Fear, $F(3,52)=3.32, p<.05$. No univariate effects of Fear were significant ( $p$ 's $>.08$ ). Instead the multivariate main effect seemed to be fully qualified by a significant multivariate interaction effect with Efficacy, F $(3,52)=4.26, p<.01$. Univariate analyses for the interaction of Fear and Efficacy on the separate indices of danger control are described below.

\section{Cognitive attitude}

On the cognitive attitude toward BSE the univariate interaction effect was significant, $F(1,54)=5.13, p<.05$. In support of hypothesis 1 , simple contrast analyses on the data pattern shown in Figure 5.1 showed that under conditions of mild fear respondents with high efficacy expectancies had more positive thoughts about monthly BSE than respondents in the other three conditions ( $p$ 's $<.03$; one-sided: hypothesised increases). The main effect of Fear, $F(1,54)=2.95, p=.09$, and Efficacy, $F(1,54)=$ 2.06, $p<.16$, were not significant.

Figure 5. I Cognitive attitude toward BSE as a function of Fear and Efincacy.

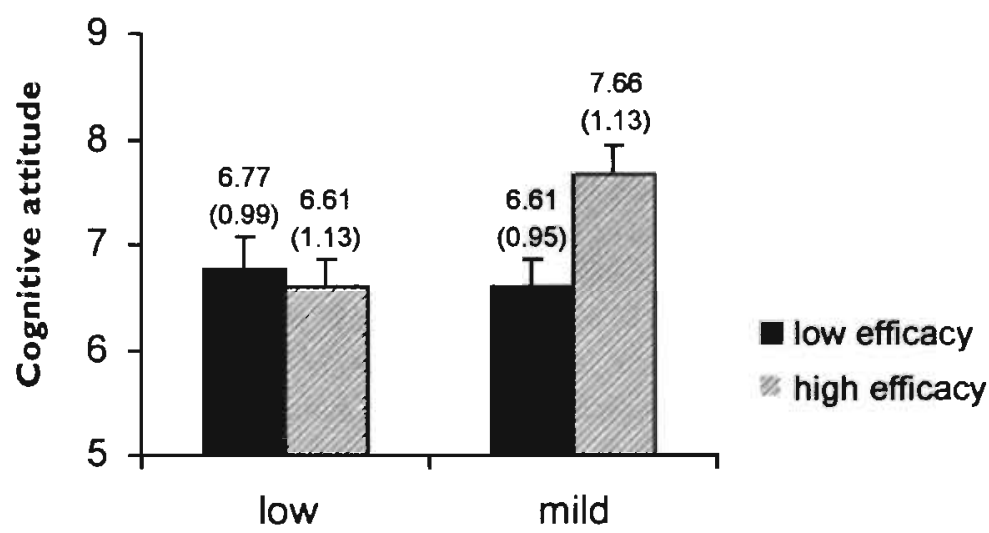

Fear

Legend. Bars show means with higher scores indicating a more positive cognitive attitude toward BSE. performance and, between brackets, standard deviations. Error bars show mean +1.0 stanctard error of the mean. 


\section{Affective attitude}

The univariate interaction effect of Fear and Efficacy was also significant on the affective attitude toward monthly BSE, F $(1,54)=10.87, p<.01$, although the data pattern was different than expected on the basis of Hypothesis 1. Simple contrast analyses on the means presented in Figure 5.2 showed that respondents in the mild fear respondents who had low efficacy expectancies had less positive feelings about monthly BSE than respondents in the other three conditions $(p$ 's $<.02)$. The main effects of Fear, $F(1,54)=$ $2.89, \mathrm{p}=.10$, and Efficacy, $\mathrm{F}(1,54)=2.35, \mathrm{p}<.13$, were not significant.

Figure 5.2 Affective attitude toward BSE as a function of Fear and Eficacy.

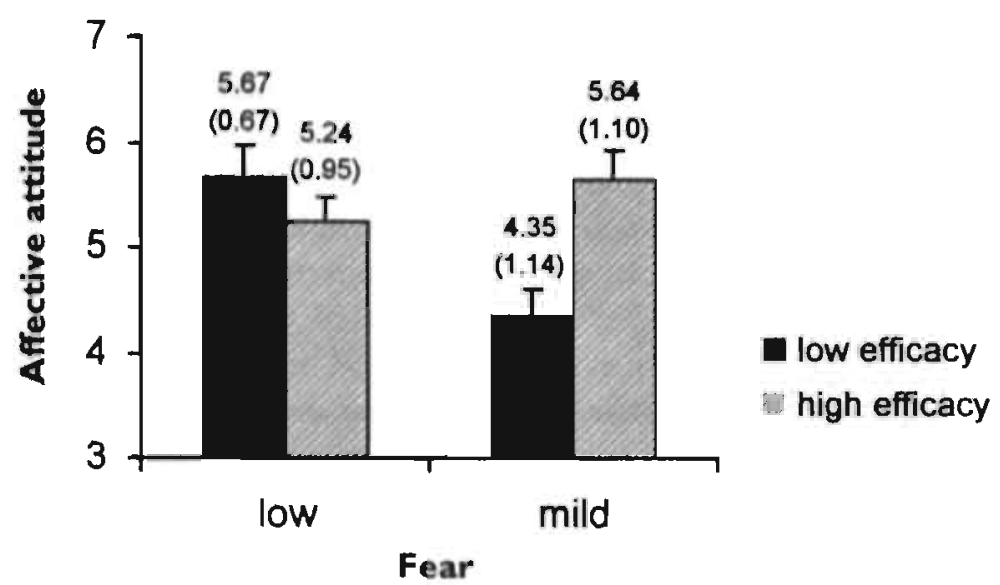

Legend. Bars show means with higher scores indicating a more positive affective attitude toward BSE performance and, between brackets, standard deviations. Error bars show mean +1.0 standard error of the mean.

\section{Intention}

An analysis of variance with previous behaviour as a covariate (ANCOVA) on the intention to perform BSE again indicated support for Hypothesis 1. The expected interaction effect of Fear and Efficacy was significant, F (1, $54)=5.03, p<.05$. Participants in the mild fear condition seemed to be more motivated to perform monthly BSE, but only if they had high efficacy expectancies concerning the performance of monthly BSE (see Figure 5.3). Simple contrast analyses showed that their intentions differed significantly from participants' intentions in the mild fear conditions who had low effi- 
cacy expectancies ( $p=.05$; one-sided: hypothesised increase), and from participants' intentions in the low fear condition who had high efficacy expectancies ( $p<.03$; one-sided: hypothesised increase). However, no significant difference was found with participants' intentions in the low fear conditions who had low efficacy expectancies although the means were in the predicted direction $(p=.11$; one-sided: hypothesised increase). The main effects of Fear, $F(1,54)=1.84, p=.18$, and Efficacy, $F<1.00$, ns, were not significant.

Figure 5.3 intention toward BSE as a function of Fear and Efficacy.

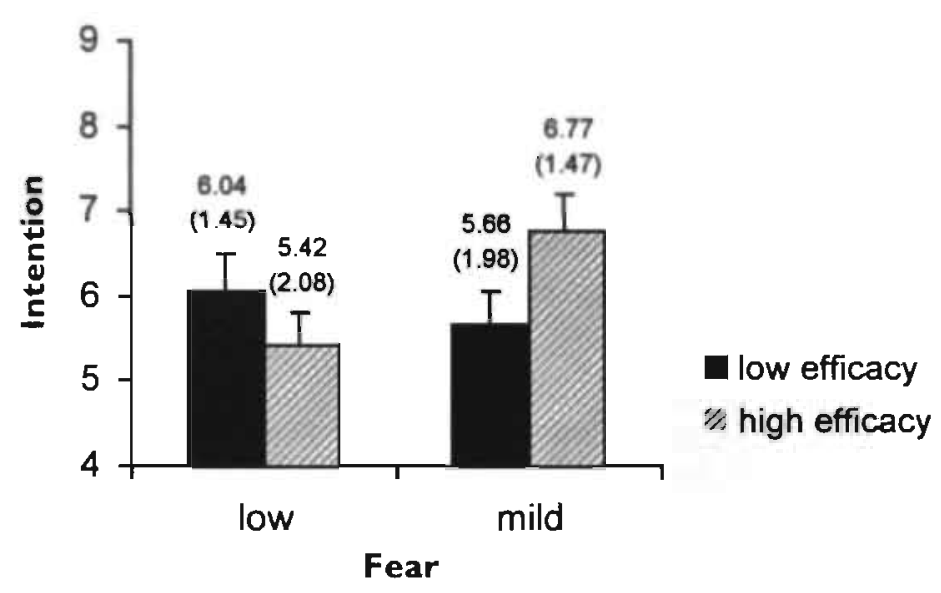

Legend. Bars show means with higher scores indicating a more positive intention to perform BSE and, between brackets, standard deviations. Error bars show mean +1.0 standard error of the mean.

Fear control responses

To test hypothesis 2, a multivariate 2 (Fear) $\times 2$ (Efficacy) analysis of variance (MANOVA) was carried out on the three indices of fear control. This analyses revealed multivariate main effects of Fear, $F(3,52)=10.15$, $p<.001$, and Efficacy, $F(3,52)=4.03, p<.05$. No support was found for the multivariate interaction between Fear and Efficacy, $F(3,5.2)=1.58$, $p=.22$. Univariate analyses for the main effects of Fear and Efficacy on the separate indices of fear control are described below.

\section{Defensive avoidance}

On the item measuring defensive avoidance, the univariate effect for Fear was significant, $\mathrm{F}(1,55)=4.44, \mathrm{p}<.05$. Participants in the mild fear con- 
ditions were less willing to think about breast cancer $(M=4.14 ; S D=$ 2.40) than people in the low fear conditions $(M=2.93 ; S D=1.60)$. This finding supports Hypothesis 2. The univariate main effect of Efficacy was also significant, $\mathrm{F}(1,55)=10.64, \mathrm{p}<.01$. Participants with high efficacy expectancies were more willing to think about breast cancer $(M=2.71$; SD $=1.35$ ) than people with low efficacy expectancies $(M=4.43 ; S D=2.43)$. However, this effect seemed to be qualified by an univariate interaction effect of Fear and Efficacy, $F(1,55)=4.70, p<.05$. The data pattern (see Figure 5.4) shows that participants in the mild fear conditions with low efficacy expectancies were less willing to think about breast cancer than those in the other three conditions ( $p$ 's $<.03$ ).

Figure 5.4 Defenslve avoldance as a function of Fear and Eficacy.

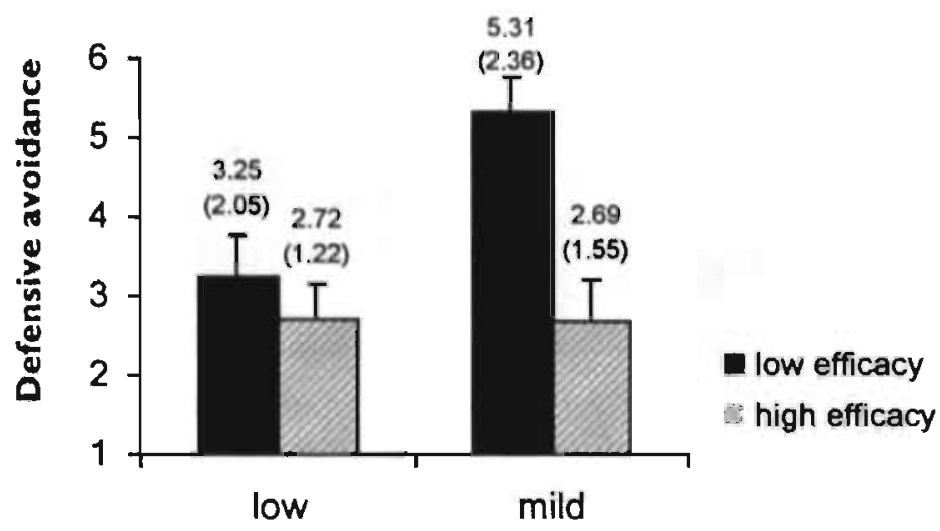

Fear

Legenid. Bars show means with higher scores indicating more defensive avoidance and, between brackets, standard deviations. Error bars show mean + 1.0 standard error of the mean.

\section{Message derogation}

In support of Hypothesis 2, the univariate effect of Fear was also significant on message derogation, $F(1,55)=30.80, p<.001$. Respondents in the mild fear condition fled more into message derogation $(M=4.16 ; S D=$ 1.86) than respondents in the low fear conditions $(M=2.03 ; S D=0.80)$. The univariate main effect of Efficacy and the interaction between Fear and Efficacy were not significant on this measure, F's $<1.00$, ns. 


\section{Perceived manipulation}

Furthermore, on the measure of perceived manipulation respondents in the mild fear conditions felt stronger that their feelings were deliberately manipulated $(M=4.19 ; S D=1.80)$ than respondents in the low fear conditions $(M=3.00 ; S D=1.53), F(1,55)=6.11, p<.05$. This finding further supports Hypothesis 2. The univariate main effect of Efficacy was also significant, $F(1,55)=4.78, p<.05$. Respondents with low efficacy expectations felt more that their feelings were manipulated $(M=4.17 ; S D=1.70)$ than respondents with high efficacy expectations $(M=3.06 ; S D=1.67)$. The interaction between Fear and Efficacy was not significant, $\mathrm{F}<1.00$, ns.

\section{Relationship between fear control and danger control responses}

Correlational analyses were carried out to explore the relationships between fear control and danger control responses. The resulting correlation matrix (see Table 5.1) shows that both kinds of responses are predominantly negatively related to each other ", but not strongly. Fear control responses do not relate to intention, only perceived manipulation is negatively related to the cognitive component of attitude while the affective component of attitude is negatively related to defensive avoidance and perceived manipulation.

\section{Table 5.I Pearson correlations of danger control and fear control responses over all} conditions.

$\begin{array}{llllll}1 & 2 & 3 & 4 & 5 & 6\end{array}$

I Cognitive attitude

1.00

2 Affective attitude

$0.39 * * \quad 1.00$

3 Intention

$0.51^{* *} \quad 0.35^{* *} \quad 1.00$

4 Defensive avoidance

$-0.16-0.34 * 0.04$

1.00

5 Message derogation

$-0.01$

$-0.22$

0.21

$0.40^{\text {k* }}$

1.00

6 Perceived manipulation

$-0.3 I^{*}$

$-0.30^{*}$

0.07

$0.44^{\text {*** }} \quad 0.59^{* *}$

* Correlation is significant at the 0.05 level.

* Correlation is significant at the 0.01 level.

\section{Discussion}

In this first experiment multivariate: analyses provided strong support for the hypotheses. In support of Hypothesis 1, the predicted interaction of fear arousal and efficacy expectancies was found on all three indices of danger 
control. Efficacy expectancies thus seem to have an important role in determining the extent to which frightened respondents are motivated to avert the threat (i.e., danger control). However, on the affective component of attitude toward BSE the data pattern of the interaction effect was different than expected. Feelings toward BSE performance were not more positive in the "mild fear-high efficacy" condition than in the three other conditions. Instead, the data pattern showed that feelings toward BSE performance were more negative in the "mild fear-low efficacy" condition than in the three other conditions. In other words, feelings toward BSE performance are less positive when one is made afraid for breast cancer while having low efficacy expectancies. This may be explained by increased feelings of hopelessness under these circumstances. Participants in this condition were also the least willing to think about breast cancer as shown on the measure of defensive avoidance. Furthermore, the difference in findings on the cognitive and affective components of attitude supports the relevance of distinguishing between a cognition-based component and an affect-based component of attitude. Behaviours such as BSE performance or, for example, going to the dentist may be evaluated as useful but at the same time as scary. These evaluations may then have opposing effects on intention formation.

In support of Hypothesis 2, the predicted main effect of fear arousal was found on all three indices of fear control. Greater fear arousal led to more fear control through avoidance of the threat and criticising the information. Importantly, the multivariate main effect of fear arousal was not qualified by a multivariate interaction with efficacy expectancies. This suggests that the effect of fear arousal on fear control responses is not consistently moderated by efficacy expectancies as predicted by Hypothesis 2. Furthermore, the multivariate main effect of efficacy expectancies was significant. On two out of three indices, respondents with low efficacy expectancies reported more fear control than respondents with high efficacy expectancies. It may be that respondents with low efficacy expectancies about how to avert the threat may have experienced feelings of hopelessness when confronted with the threat of breast cancer and thus responded with more fear and subsequently fear control than respondents with high efficacy expectancies (see also the general discussion).

In a more explorative framework, we looked at the relationships between fear control and danger control processes. Correlations between both kinds of responses suggest that they are negatively, but weakly related to each other. Intention formation processes do not seem to be influenced by fear control responses while, not surprisingly, fear control responses seem to be stronger related to the affective component of attitude than to its cognitive component. The weak relations may suggest that both kind of control processes run largely independent of each other, and that fear control processes 
do not influence intention formation processes otherwise than through the attitude component.

Overall, the findings of the present study thus supported our notion that individual differences in efficacy expectancies have a more important role in danger control processes than in fear control processes. However, in this first experiment post-experimental efficacy beliefs were used to test the hypotheses. This excludes the possibility to make causal inferences about the role of individual differences in efficacy expectancies in influencing fear control and danger control processes. To make causal explanations more valid efficacy expectancies should be measured in advance of the actual study or be manipulated. The latter, however, would not resemble everyday practice that shows that fear appeals are especially used in mass media communications and thus have to deal with existing efficacy beliefs (see introduction). Therefore, we decided in Experiment 2 to measure efficacy beliefs concerning the BSE performance in advance of the actual study and used these beliefs as factor in our design. We further copied the design of Experiment 1.

\section{EXPERIMENT 2}

In Experiment 2, efficacy expectancies were measured four to six weeks in advance of the actual study as part of a larger survey among 115 female first-year undergraduates of the faculties of Health Sciences and Psychology at Maastricht University. Two items that used VAS scales $(10 \mathrm{~cm})$ measured response efficacy beliefs toward BSE performance and early detection of breast cancer by asking whether (i) "A correct performance of breast selfexamination will enable detection of breast cancer in an early stage of development (totally disagree - totally agree)" and (ii) "The chance that you will detect breast cancer in an early stage by means of a correct performance of breast self-examination is very small - very large." These items were significantly related $(r=.40 ; p<.001)$. Participants' beliefs in their ability to perform and regularly repeat BSE (i.e., self-efficacy) were also measured through two items using VAS scales: (i) "Suppose you are planning to do a monthly breast self-examination, how easy or difficult will it be? (very easy - very difficult)" and (ii) "Suppose you are planning to do a monthly breast self-examination, will you do it correctly? (surely not = surely yes)". These items were also significantly interrelated $(r=-.51 ; p<.001)$. After recoding the first self-efficacy item, the four items were combined into an overall index measuring perceived efficacy of BSE. This scale had a weak 
internal consistency (Cronbach's alpha $=.57$ ) compared to Experiment 1 , which was probably due to the smaller number of items that comprised the scale, four instead of eight items'. Based on a median split procedure (Median $=6.43$ ) respondents were divided in a high and low efficacy group (see also Witte et al., 1998).

\section{Results}

Out of the 115 respondents, a random sample of 71 respondents was invited to the laboratory for the actual study (62\%). All these respondents were included in the analyses $(N=71)$. The respondents were almost equally distributed across the four conditions of a 2 (Fear: low vs. high) $\times 2$ (Efficacy: low vs. high) factorial design, $x^{2}<1.00$, ns.

\section{Fear orousal}

A 2 (Fear) x 2 (Efficacy) ANOVA revealed a significant main effect of Fear on the measure of fear arousal, $\mathrm{F}(1,67)=26.38, \mathrm{p}<.001$. Respondents in the mild fear condition reported more fear $(M=5.29 ; S D=1.38)$ than respondents in the low fear condition $(M=3.40 ; S D=1.81)$. This finding supports the effectiveness of the fear arousal manipulation. The main effect of Efficacy also reached significance, $F(1,67)=5.15, p<.05$. Respondents who felt low efficacious regarding BSE performance reported more fear $(M=4.73 ; S D=1.97)$ than respondents who felt high efficacious $(M=3.96 ; S D=1.69)$. The interaction between Fear and Efficacy was not significant, $\mathrm{F}<1.00$, ns.

\section{Danger control responses}

To rest hypotheses 1, a 2 (Fear) x 2 (Efficacy) MANCOVA. with earlier BSE performance as covariate was carried out on the three indices of danger control. This analysis only revealed a multivariate main effect of Fear, F (3, $64)=2.83, p<.05$. No support was found for a multivariate qualification by the interaction with Efficacy, $\mathrm{F}<1.00$, ns. The multivariate main effect of Efficacy was also not significant, $\mathrm{F}<1.00$, ns.

\footnotetext{
1 Compared to the findings presented below with the combined scale of efficacy, separate analyses for response efficacy and self-efficacy revealed a similar pattern of findings. The main difference in findings was that the multivariate main effect of respectively response efficacy and self-efficacy on indices of fear control were not significant $(p>.06$ and $p>, 15$, respectively). Furthermore, the multivariate interaction of fear arousal and self-efficacy approached significance $(p=.05)$ on the indices of fear control, but none of the univariate effects were significant ( $p$ 's > $>10)$.
} 
For the separate indices of danger control, the univariate effect of Fear was not significant on the cognitive and affative componants of attitude toward BSE, neither were any other effects, F's $<1.00$, ns. The univariate main effect of Fear was only significant on intention, $F(1,66)=6.32, p<.05$. Respondents in the mild fear conditions were more motivated to perform BSE $(M=4.87 ; S D=1.71)$ than respondents in the low fear conditions $(M$ $=4.22 ; \mathrm{SD}=1.91)$. No other significant effects were found on this measure, $\mathrm{F}<1.00$, ns.

\section{Fear control responses}

To test hypothesis 2, a 2 (Fear) $\times 2$ (Efficacy) MANOVA was carried out on the three indices of fear control. This analyses revealed multivariate main effects of Fear, $F(3,65)=12.44, p<.001$, and Efficacy, $F(3,65)=3.36$, $p<.05$. No support was found for the multivariate interaction between Fear and Efficacy, $F(3,65)=1.89, p=.14$. Univariate analyses for the main effects of Fear and Efficacy on the separate indices of fear control are described below.

\section{Defensive avoidance}

On defensive avoidance the main effect of Fear approached significance, $\mathrm{F}$ (1, $67)=2.05, p=.08$ (one-sided: hypothesised increase). Respondents in the mild fear conditions seemed to be less willing to think about breast cancer ( $M$ $=4.43 ; S D=2.27)$ than respondents in the low fear conditions $(M=3.58$; $S D=2.25)$. No significant support was found for the main effect of Efficacy, or the interaction between Fear and Efficacy, F's $<1.00$, ns.

\section{Message derogation}

The univariate effect of Fear was highly significant on the measure of message derogation, $F(1,67)=36.57, p<.001$. Respondents in the mild fear conditions evaluated the information about breast cancer more as overblown and extreme $(M=4.34 ; S D=1.81)$ than respondents in the low fear conditions $(M=2.33 ; S D=0.83)$. This finding supports Hypothesis 2 . The univariate main effect of Efficacy was not significant here, $F(1,67)=2.03$, $p=.16$. The interaction between Fear and Efficacy unexpectedly approached significance, $F(1,67)=3.76, p=.06$. Simple contrast analysis showed that in the mild fear conditions respondents with low efficacy expectancies seemed to use some more message derogation than respondents with high efficacy expectancies, but this effect was not significant, $t(33)=1.84, \mathrm{p}=$ .08 (see Figure 5.5). The effect of Efficacy was also not significant under conditions of low fear, $t<1.00$, ns. 


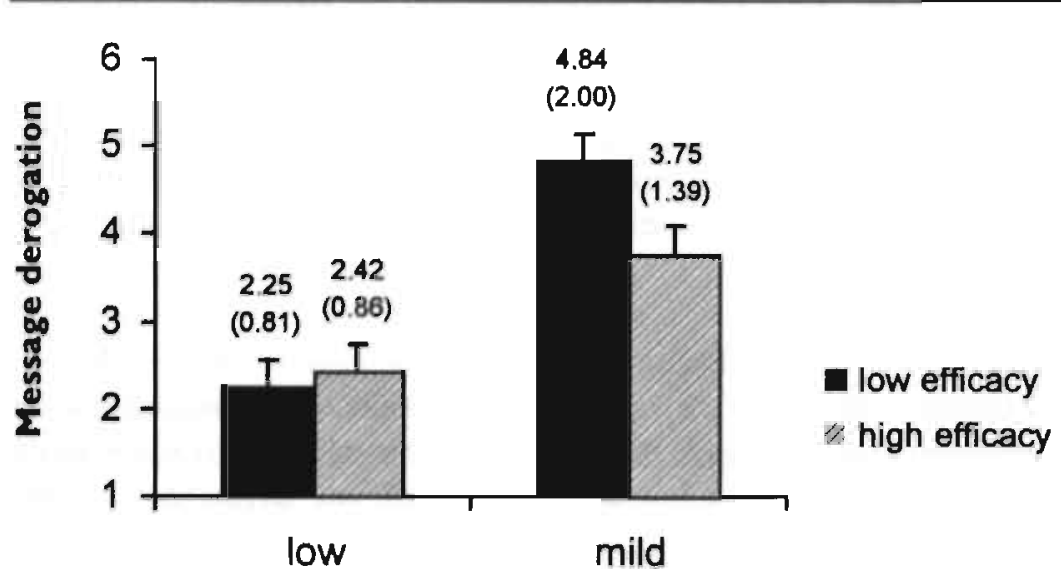

Fear

Legend. Burs show means with higher scores indicating more message derogation and, between brackets, standard deviations. Error bars show mean + 1.01 standard error of the mean.

Perceived manipulation

A.lso on perceived manipulation we found support for the univariate main effeci of Fear, $F(1,67)=17.91, p<.001$. In accordance with Hypothesis, 2 , respondents in the mild fear conditions felt stronger that their feelings were manipulated $(M=4.17 ; \mathrm{SD}=1.79)$ than respondents in the low fear conditions $(M=2.57 ; S D=1.42)$. Also the univariate main effect of Efficacy was significant on this measure, $F(1,67)=8.38, p<.05$. Respondents with low pre-existing efficacy expectancies felt stronger that their feelings were manipulated $(M=3.89 ; S D=1.73)$ than respondents with high efficacy expectancies $(M=2.77 ; S D=1.69)$. The interaction between Fear and Efficacy was not significant, $F(1,67)=1.30, p=.30$.

\section{A replication of Experiment I}

To include post-experimental efficacy beliefs in the analysis a median-split procedure was carried out on its measure (Median $=5.38$ ). The resulting variable was labelled Efficacy-b. Four respondents that scored on the median were excluded from the design to keep a well-balanced design $(\mathrm{N}=67)$. Importantly, an effect of the factor Fear on the index of efficacy expectancies was not found, $\mathrm{t}<1.00, \mathrm{~ns}$, and a chi-square analysis on the cross tabulation of the factors Fear and Efficacy-b was also not significant, $\chi^{2}(1,59)=1.36$, $p=.30$. This indicates that Fear and Efficacy-b are independent factors, and 
that the participants are equally distributed across the conditions.

A 2 (Fear: low versus mild) x (Efficacy-b: low versus high) MANCOVA on the indices of danger control yielded significant multivariate main effects for Fear, $F(3,60)=3.00, p<.05$, and Efficacy-b, $F(3,60)=3.51, p<$ .05 . The interaction between Fear and Efficacy-b was not significant, $F<$ 1.00 , ns. Univariate analyses revealed that the main effect of Fear was significant only on the measure of intention, $F(1,62)=5.32, p<.05$. Respondents in the mild fear conditions were more motivated to perform BSE $(M=4.90 ; S D=1.79)$ than respondents in the low fear conditions ( $M$ $=4.22 ; \mathrm{SD}=1.91)$. The main effect of Efficacy- $\mathrm{b}$ was significant on the cognitive component, $F(1,62)=6.11, p<.05$, and on the affective component, $F(1,62)=4.97, p<.05$, of attitude. Respondents who reported high efficacy expectancies had indicated more positive thoughts $(M=6.78$; $S D=1.31)$ and feelings $(M=5.19 ; S D=1.33)$ toward BSE performance than respondents who reported low efficacy expectancies $(M=6.04 ; S D=$ 0.91 and $M=4.51 ; S D=0.81$, respectively). No other significant effects were found on the indices of danger control, F's $<1.00$, ns.

On the indices of fear control, a 2 (Fear) $\times 2$ (Efficacy-b) MANOVA revealed significant main effects of Fear, $F(3,61)=14.13, p<.001$, and Efficacy-b, $F(3,61)=4.17, p<.01$. The interaction effect was not significant, $F(3,61)=1.43, p=.24$. Univariate analyses revealed that the univariate effect of Fear was significant on the measures of message derogation, $F$ $(1,63)=41.13, p<.001$, and perceived manipulation, $F(1,63)=19.94$, $p<.001$. Respondents in the mild fear conditions thought more that the message was overblown and extreme $(M=4.45 ; S D=1.89)$ and that their feelings were deliberately manipulated $(M=4.16 ; S D=1.81)$ than respondents in the low fear conditions $(M=2.33 ; S D=0.83$ and $M=2.57 ; S D=$ 1.42 , respectively). The main effect of Fear was not significant on the measure of defensive avoidance, $F(1,63)=1.19, p=.28$. Furthermore, respondents who reported low efficacy expectancies had indicated more that the message was overblown and extreme $(M=3.66 ; S D=1.71), F(1,63)$ $=6.10, \mathrm{p}<.05$, and that their feelings were deliberately manipulated $(\mathrm{M}=$ 3.88; $\mathrm{SD}=1.82), \mathrm{F}(1,63)=11.70, \mathrm{p}<.001$, than respondents who reported high efficacy expectancies $(M=2.95 ; \mathrm{SD}=1.77$ and $M=2.71 ; \mathrm{SD}$ $=1.57$, respectively). No significant main effect of Efficacy was found on the measure of defensive avoidance, $F<1.00$, ns. The interaction of Fear and Efficacy-b did not reach significance levels on all three indices of fear control (p's > .17).

\section{Relationships between fear control and danger control responses}

Compared to Experiment 1, the correlation matrix between fear control and danger control responses revealed a similar pattern of findings. Fear control 
responses and danger control responses do seem to be predominantly negatively related to each other, but these relationships are not strong (see Table 5.2). The only significant relations between danger control and fear control responses were those between defensive avoidance and perceived manipulation, on the one hand, and the affective component of attitude, on the other hand.

Table 5.2 Pearson correlations of danger control and fear control responses over all conditions.

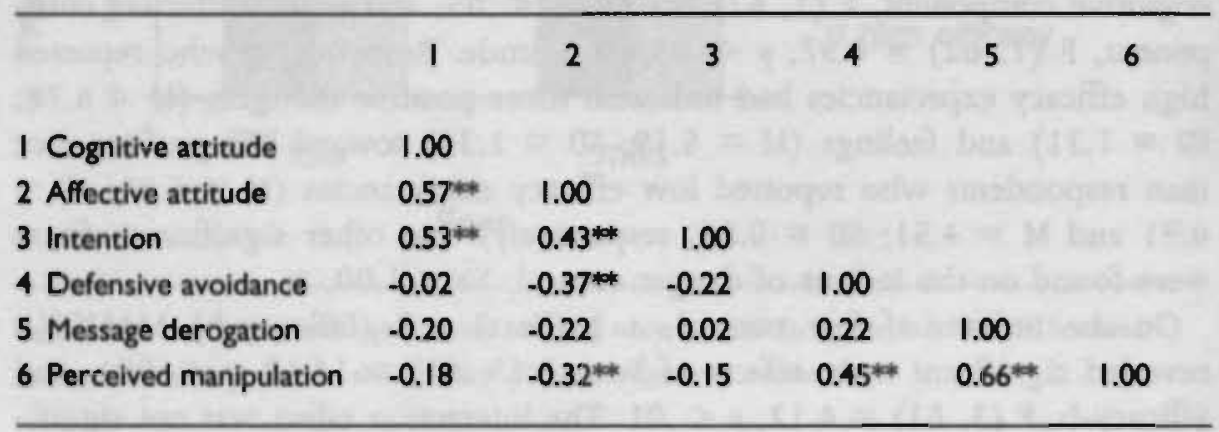

** Correlation is significant at the 0.01 level.

\section{Discussion}

The findings with pre-measured efficacy expectancies did not support Hypothesis 1 and thus also did not replicate the findings of Experiment 1. Respondents in the mild fear condition were more motivated to protect themselves against the threat of breast cancer by performing BSE than. respondents in the low fear conditions but regardless whether they had high or low pre-experimental efficacy expectancies. The attitude toward performing BSE was not influenced at all by frightening information and pre-experimental efficacy expectancies. Of course, this lack of support for hypothesis I could be due to the rather low interna! reliability of the index that measured pre-existing efficacy beliefs. However, the analyses with posthoc efficacy expectancies, which exactly replicated those of Experiment 1. did also not find the predicted interaction effect of Fear and Efficacy on indices of danger control. Higher post-experimental efficacy beliefs resulted in more danger control responses but this effect was not stronger in the mild fear conditions than in the low fear conditions.

In contrast, Experiment 2 replicated the findings of Experiment I regarding Hypothesis 2 to a large extent. Multivariate analyses revealed that greater 
fear led to more fear control without moderation of pre-experimental effcacy expectancies. This finding thus provided further support for our prediction that more fear leads to more fear control regardless the beliefs people have about the effectiveness of BSE performance and their ability to carry it out. This relationship between fear arousal and fear control was especially apparent for responses that represent reactions to the presented message (i.e., perceived manipulation and message derogation) rather than to the presented threat (i.e., defensive avoidance). Furthermore, efficacy expectancies seemed to influence fear control responses. The univariate effect of pre-measured efficacy beliefs was significant on one out of three indices of fear control (i.e., perceived manipulation), whereas the effect of post-hoc measured efficacy beliefs was also significant on the index of message derogation. In addition, correlational analyses suggested that fear control and danger control responses are inversely related to each other, but that these relations are rather weak. Both control processes may thus run independently from each other in response to fear-arousing information.

\section{GENERAL DISCUSSION}

The present paper describes two experiments that tested the postulate that, under conditions of fear arousal, efficacy expectancies more strongly influence danger control than fear control responses. More specific hypotheses predicted that, for the effect of fear-arousing information on danger control responses, greater fear arousal results into more positive attitude and intention toward BSE performance but only if people have high efficacy expectancies concerning the recommended precaution (Hypothesis 1). For the effect of frightening information on fear control responses, it was predicted that greater fear arousal results into more defensive avoidance and criticising of the presented threatening information regardless of existing efficacy expectancies (Hypothesis 2). In addition, the relationships between fear control processes and danger control processes were explored.

Overall, the findings provided strong support for Hypothesis 2. Presenting fear-arousing information made respondents less willing to read additional information about breast cancer (only in the first experiment) and more critical to the presented threat information by derogating its contents and indicating feelings of being deliberately manipulated (in both experiments). Importantly, existing efficacy expectancies did not consistently influence these processes under conditions of fear arousal, that is no support was found for a multivariate interaction of fear and efficacy beliefs on fear con- 
trol responses. Our findings therefore suggest that, in response to fear-arousing information, fear control responses are not under the control of beliefs about the effectiveness and feasibility of suggested coping strategies.

To what extent future action in terms of acceptance of the recommended precaution (attitude and intention) is influenced by efficacy beliefs could not be clearly answered by the present study. Empirical support for Hypothesis 1 was only found in the first experiment. The findings of this experiment suggest that among respondents with high efficacy expectancies greater fear leads to increased motivation to perform the recommended precaution. These findings could not be supported in the second experiment neither with pre-experimental efficacy beliefs nor with post-experimental efficacy beliefs. This inconsistency between the two experiments regarding the relationship between threat and efficacy expectancies on precautionary motivation thus reflects conclusions presented elsewhere that the relation between both classes of variables is not fully understood yet (Eagly \& Chaiken, 1993; Rogers \& Prentice-Dunn, 1997; Witte \& Allen, in press). Obviously, there are variables influencing the effects of fear arousal on precautionary motivation that we have not successfully identified, and that mediating processes may run differently than expected. For example, chronic fear of cancer may be important in processes of fear control (see Jepson \& Chaiken, 1990), while recent meta-analytic findings that efficacy expectancies are stronger related to intention formation than threat perceptions (Floyd et al., 2000; Milne et al., 2000) may suggest that the former mediate, instead of moderate the effects of fear-arousing information on precautionary motivation (see also Ruiter et al., 2000).

Summarising the findings concerning hypotheses 1 and 2, threatening messages that successfully arouse fear may easily result in responses that question the believability of these messages. At the same time, however, greater fear arousal seems to generate willingness to avert the threat as indicated by the significant multivariate effects of fear arousal on. indices of danger control in both experiments. To what extent efficacy beliefs on top of fear arousal determine precautionary motivation is still unclear. More clear is that efficacy beliefs have no role in influencing negative evaluations of threatening information when recipients feel afraid. However, existing efficacy beliefs may make recipients less frightened when being confronted with threatening messages, as suggested by the main effects of efficacy beliefs on fear control responses that were found in the present research and is also reported by Witte and Allen (in press) in a recent meta-analysis on the effects of fear appeals. But, paradoxically, lower levels of fear may, in turn, reduce precautionary motivation.

The complex pattern of findings in the present study confirms our ideas we presented elsewhere (Ruiter et al., 2000). A process model is suggested 
that re-conceptualises the complex and potentially contradictory relationships between fear arousal, threat perception, fear control and precautionary motivation and includes recommendations for future research. It suggests that fear arousal may prompt precautionary motivation through enhanced systematic processing of related persuasive messages (for empirical evidence, see Baron, Logan, Lilly, Inman, \& Brennan, 1994) and heightened efficacy expectancies (Experiment 1 of the present study; Witte et al., 1998). At the same time, however, the present research suggests that fear arousal may lead to denial and other forms of avoidant coping that undermine the establishment of precautionary motivation. Thus, fear arousal may both facilitate and inhibit the acceptance of recommended precautions, which may explain to some extent the inconsistent empirical support that has been found in the fear appeal literature for the interaction of threat and efficacy variables on measures of attitude and intention. It may be that threatening information instigates both danger control and fear control responses, which, in turn, have opposing effects on precautionary motivation (see also Ruiter et al., 2000; Witte \& Allen, in press). Findings in the first experiment on the cognitive and affective component of attitude indeed suggest such a possibility. BSE performance was evaluated positively but at the same time seemed to induce negative feelings when respondents thought about performing it.

A maybe remarkable overall finding of the present research is that two almost similar experiments did not yield consistent results on the dependent variables. One may argue, however, that the two experimental studies were not exact copies of each other, which caused the differences in findings between the two studies. More specifically, only the second study included a pre-experimental measurement of efficacy beliefs. This measure may have influenced participants' expectations about the experiment in which they were going to participate, and thus may have influenced their responses to the presented information, dependent measures, and the post-experimental measure of efficacy beliefs. An argument in favour of this explanation is that, despite the measurement of efficacy beliefs took place four to six weeks in advance of the actual study and was concealed by other questions, pre-experimental efficacy beliefs seemed to have influenced feelings of fear on the manipulation check of fear arousal. Low efficacious participants reported more fear than high efficacious participants did. It may thus be that during the second experimental study efficacy beliefs about BSE performance were salient and consequently resulted in different findings. compared to the first experimental study, which 'activated' efficacy beliefs only after the dependent measures. As a result, the second experiment should not be considered an exact replication of the first experimental study. However, none of the participants indicated a relationship between the experiment 
and the questionnaire they answered four to six weeks before. Furthermore, the second study may have been more informative regarding the (presumed) role of efficacy beliefs in processes of fear control and danger control, despite its low reliable measure of pre-experimental efficacy beliefs.

Nevertheless, the two empirical studies were largely similar to each other because they used similar procedures, materials and measures. The differences in findings between the two studies should, therefore, not be ignored. A lack of consistency between two comparable studies is not foreign and even seems to be characteristic for the area of fear appeals (compare, for example, Rogers \& Deckner, 1975; Rogers \& Mewborn, 1976; Rogers \& Thistlethwaite, 1970; cf. Eagly \& Chaiken, 1993). This inconsistency between empirical findings strongly suggests that we still have insufficient knowledge of the true effects of fear appeals, it also endangers future thinking about the study of fear appeals. That is, studies that support hypotheses generated by existing theoretical frameworks are more easily published (or less easily rejected) than studies that do not support these hypotheses. The result is a publication bias toward studies with significant findings and, more importantly, "type 2 errors" concerning the validity of existing theoretical frameworks. In other words, theoretical frameworks that should be re(de)fined on the basis of (non significant) empirical findings are not changed or removed from the literature and thus keep informing the public wrongfully about the "state-of-arts".

The present study leaves some important empirical questions unanswered. First, we found some evidence that fear control and danger control processes are negatively related to each other, which confirms meta-analytic findings by Witte and Allen (in press). Future research should, however, address the relationships between fear control and danger control more extensively. For example, assuming that affective processes such as fear control are more automatic than danger control processes, it could be that fear control processes are more immediate than danger control processes. The former could thus interfere with the latter because attention may be distracted from subsequent reassuring messages. This could be tested by using online eye-movement registration (in case of exposure to text or video fragments on a computer screen) that measures attention independently of self-report cognitive measures.

Secondly, correlations between indices of self-efficacy and response efficacy were low in both experiments. This is consistent with theoretical notions that distinguish response efficacy beliefs (or outcome expectancies) from self-efficacy beliefs because they have been found to have independent effects on behavioural intentions (Abraham, Sheeran, \& Johnston, 1998; Bandura, 1997; Maddux, Norton, \& Stoltenberg, 1986; Maddux, Sherer, \& Rogers, 1982). To what extent these independent effects also occur under 
conditions of fear arousal could not be tested in the present experiments due to low sample sizes but needs future tests.

Thirdly, our findings may not generalise beyond the specific behavioural domain of breast cancer detection and the subpopulation of highly educated young women. Future research should test to what extent the presented findings also hold within other domains of self-protective action and among other subpopulations including those with different gender, lower educational levels, and other age groups.

Finally, the present research did not include BSE performance as a dependent variable. Including BSE performance in the analyses requires a followup measure outside the laboratory. However, when including such a variable, sufficient measures should be taken to control for possible negative effects of the fear manipulation when participants have left the controlled setting of the laboratory without, of course, neutralising the fear manipulation. Alternatively, behaviours may be considered that can be observed in the laboratory such as registering for a course on how to perform BSE.

In conclusion, the present study suggests that fear-arousing information is easily followed by emotional reactions that try to deny or avoid the presented information, which may interfere with adoption of the recommended action. This finding raises doubt about the renewed interest in fear arousal that we witness in health education practice in the Netherlands. Examples are commercials that portray how a young girl changes into an old woman the moments she lights a cigarette, or show traffic accidents with bloody and deadly consequences. Obviously, programme developers presume that fear arousal motivates people to safer behaviour. Our findings with regard to defensive responses and the general inconsistency in the empirical literature regarding the effects of fear appeal components on precautionary motivation and action, however, suggest that fear arousal should be used with greater caution in health education practice, preceded by extensive pilot testing. 
Whin

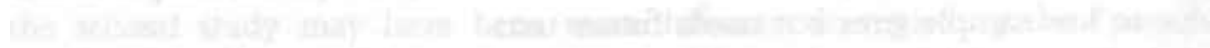

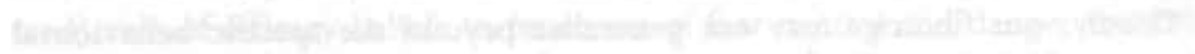

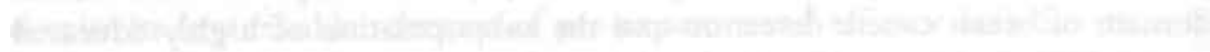

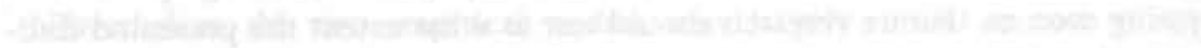

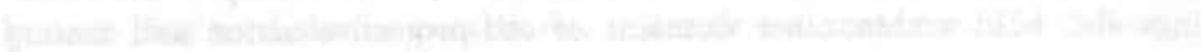

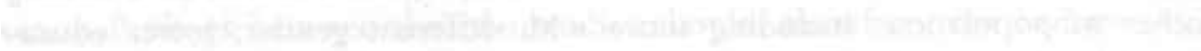

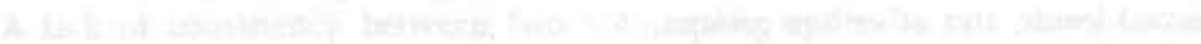

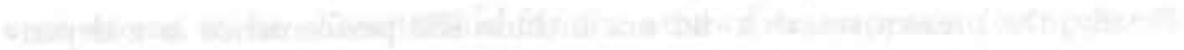

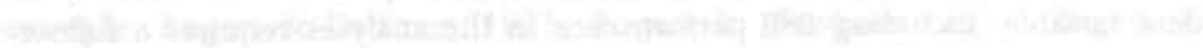

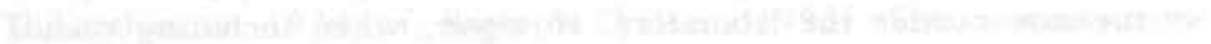

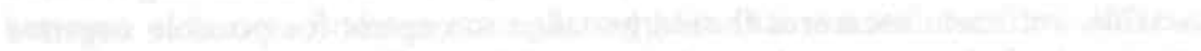

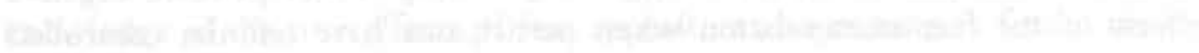

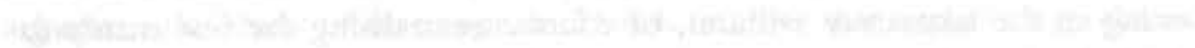

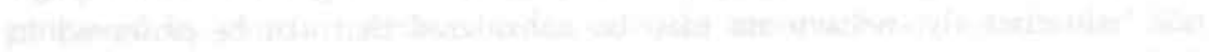
-

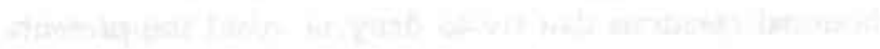

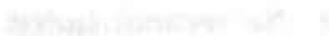




\section{CHAPTER 6}

STRENGTHENING THE PERSUASIVE IMPACT OF FEAR APPEALS: THE ROLE OF ACTION FRAMING 


\section{INTRODUCTION}

Whether persuasive information should be presented in positive wordings or negative wordings is a longstanding issue in persuasion research (e.g., Hovland, Janis, \& Kelley, 1953). More recent research has taken up this issue under the heading of action framing which refers to presenting objectively the same persuasive information in terms of either gains of losses (Levin, Schneider, \& Gaeth, 1998; Rothman \& Salovey, 1997). Drawing upon the original work of Kahneman and Tversky $(1979,1984)$, several studies have shown that action framing systematically influences decision making in the context of health behaviour (Detweiler, Bedell, Salovey, Pronin, \& Rothman, 1999; Meyerowitz \& Chaiken, 1987; Rothman, Martino, Bedell, Detweiler, \& Salovey, 1999; Rothman, Salovey, Antone, Keough, \& Martin, 1993). The persuasive effects of presenting the negative consequences of not performing the healthy behaviour (loss frame; e.g., "By not performing breast self-examination [BSF] you will not detect breast cancer in an early stage and thus may die from it") have been compared to the effects of presenting the positive consequences of performing the healthy behaviour (gain frame; e.g., "By performing BSE you will detect breast cancer in an early stage and thus may fully recover from it") on measures of attitudes and behaviour (e.g., Meyerowitz \& Chaiken, 1987). The present study links this research to the area of fear appeals. It is hypothesised that that the persuasive impact of fear appeals may be increased by tailoring the valence of the persuasive information to the characteristics of the targeted behaviour. To provide support for this hypothesis we will first briefly review the literature on action framing, after which we will describe and discuss the methods and results of the present study.

Based on the work of Meyerowitz and Chaiken (1987) it was believed that under conditions of systematic information processing, the loss frame will have more impact on measures of message acceptance than the gain frame (see also Maheswaran \& Meyers-Levy, i990). This was explained by referring to the negativity bias: negatively framed information would receive more attention than positively framed information (Levin et al.s 1998). However, this explanation is not in line with more recent findings that showed a greater impact of the gain frame, for example, in promoting sunscreen use to prevent skin cancer (Rothman et al., 1993).

In a review of the action framing literature, Rothman and Salovey (1997) suggested that the type of behaviour that is promoted determines which action frame will have the most impact, provided that the persuasive message is considered as personally relevant and thus systematically processed, and the valences of the presented frames are recognised and accepted. Under these latter conditions, findings suggest that behaviours that focus on early 
detection of health problems are best promoted by loss frames (e.g., "Failing to use a disclosing rinse before brushing limits your ability to detect areas of plaque accumulation"; Rothman et el., 1999, p. 1361), whereas primary prevention behaviours are best promoted by gain frames (e.g., "People who use a mouth rinse daily are taking advantage of a safe and effective way to reduce plaque accumulation"; Rothman et al., 1999, p. 1361). Rothman and Salovey (1997) explain these findings in terms of the greater perceived risk associated with detection behaviours. Although the long-term importance of, for example, performing BSE is generally acknowledged the short-term negative consequences may be especially important to intention formation and implementation (Weinstein, 1988). Prevention behaviours, in contrast, typically result in relatively certain, desirable outcomes so that not performing the behaviour becomes the more risky option. Kahneman and Tversky $(1979,1984)$ have shown that people prefer risky options when confronted with losses but prefer certainty when considering gains.

Fear appeal theory (Rogers, 1983, Witte, 1992a) suggests that fear-arousing information will result in more positive evaluation of recommended action, but only if the recommendation is evaluated as effective in averting the threat (i.e., response efficacy) and easy to perform (i.e., self-efficacy). So far, no experimental study has been reported that investigated whether framing precautionary information that emphasises the effectiveness and feasibility of the recommended action in terms of either gains or losses moderates the effects of fear-arousing information on precautionary motivation. The present study addressed exactly this question in the area of early detection of breast cancer. Fear arousal was manipulated by varying information about the threat of breast cancer. After measuring fear arousal, respondents read precautionary information that advocated the feasibility of performing breast self-examination (BSE) and its effectiveness in averting the threat of breast cancer either in a loss frame or in a gain frame. The main dependent variables were an absolute and relative evaluation of BSE performance, operationalised as respectively attitude toward BSE and relative importance of BSE.

Based on the assumptions that (i) fear arousal results in a more positive evaluation of recommended action (Rogers, 1983) and (ii) detection behaviours are better promoted by loss frames than by gain frames (Rothman \& Salovey, 1997), it was hypothesised that mild fear arousal would result in a more positive evaluation of BSE performance than low fear arousal, but that this effect would be stronger for the condition that presented response efficacy and self-efficacy information in a loss frame than for the condition that presented this information in a gain frame. We thus expected an interaction effect between fear arousal and action frame on attitude toward BSE and perceived importance of BSE. Because the fear arousal measure preceded the 
persuasive information about BSE performance, it was possible to also include reported fear level into the analyses without seriously hampering causal interpretations.

\section{METHOD}

\section{Participants, design and procedure}

Forty-one first-year undergraduates of Maastricht University were randomly distributed across the four conditions of a 2 (Fear Arousal: low vs. mild) $\times 2$ (Action Frame: loss vs. gain) factorial design. They were seated in separate cubicles. The experiment was completely computer-controlled. Participants first read a message about breast cancer that contained the manipulation of fear arousal. The fear-arousing messages were identical to the threat messages used in the studies reported in chapter 5. Recipients in the mild fear arousal condition read information that stressed the severity of breast cancer and recipients' susceptibility to it, while severity and susceptibility were described as low in the low fear arousal condition (for a more extensive description, see chapter 5). Next, fear arousal was measured followed by a message about performing BSE in which the action frame was manipulated. The gain frame reported about the positive consequences of performing BSE and its easiness to perform if started early in life, while the loss frame reported about the negative consequences of not performing BSE and its difficulty to perform if staried late in life. The information in both messages was objectively the same and centred around three arguments (e.g., "By [not] performing BSE you may detect breast cancer in a [late] early stage and thus increase your chances of [dying of the breast cancer] full recovery from the consequences of breast cancer."). Finally, attitude toward BSE and perceived imporiance of BSE were measured, followed by some ancillary measures.

After leaving the cubicles participants were extensively debriefed by the female experimenter who was especially alert to any signs of current fears as expressed by the participants. All participants were told that their chance of getting breast cancer was actually low because it is most common among women older than $\mathbf{4 5}$ years of age. They then received information about breast cancer and BSE performance issued by the Dutch Cancer Society and were urged to read it carefully. Participants received 10 Dutch guilders for their participation and were asked to be silent about the objectives and topic of the study to fellow students. 


\section{Measures}

\section{Fear arousal}

Four items measured fear arousal on a 9-point scale (worried, afraid, uncomfortable, frightened). The four items were summarised into an index of fear arousal (Cronbach's alpha $=.96)$.

\section{Evaluation of BSE performance}

The attitude toward monthly performance of BSE was measured by seven semantic-differentials that used 9-point scales. Factor analysis and reliability analysis (see chapter 5, for the same procedure) selected five items that measured the cognitive component of attitude (unimportant - important, foolish - wise, insensible - sensible; bad - good, negative - positive; Cronbach's alpha $=.84)$, while two items measured the affective component of attitude (unpleasant - pleasant, annoying - nice; $r=.79$ ).

In the previous studies we had problems in detecting significant changes on the measures of attitude. We therefore decided to include a measure of relative importance of performing BSE. Participants were asked to rank order the following six health behaviours in the order to which the performance of these behaviours was important for themselves: using condoms, using sun protection, eating healthy, not smoking, exercising, and performing breast self-examination ( $1=$ least important $-6=$ most important).

\section{Ancillory measures}

One item checked the manipulation of action frame by asking respondents whether the information about BSE was negatively or positively formulated ( 1 = negative $-9=$ positive). They were further asked how many times they had performed breast self-examination in the last 12 months. As previous BSE performance was significantly related to attitude toward BSE and perceived importance of BSE, it was included as covariate to permit more powerful tests of the hypothesised effects.

\section{RESULTS}

\section{Manipulation checks}

Fear arousal was successfully evoked and manipulated. An independent samples t-test on reported fear showed that respondents in the mild fear 
arousal condition reported more fear $(M=4.86, S D=2.23)$ than respondents in the low fear arousal condition $(M=3.28, S D=1.80)$ after reading information about breast cancer, t $(39)=2.48, \mathrm{p}<.01$ (one-tailed: hypothesised increase). Furthermore, a two 2 (Fear Arousal) $\times 2$ (Action Frame) ANOVA on the perceived valence of wording found a main effect of Action Frame, $F(1,37)=22.64, p<.001$. Participants in the loss frame conditions evaluated the formulation of the information about BSE performance as more negative $(M=3.65 ; S D=2.35)$ than participants in the gain frame conditions $(M=6.48 ; S D=1.40)$. The action frame manipulation. was thus successful. The main effect of Fear Arousal, $\mathrm{F}<1.00$, ns, and the interaction effect were not significant, $F(1,37)=1.71, p=.20$.

\section{Evaluation of BSE performance}

No support was found for the hypothesis with manipulated fear arousal in the design. Three 2 (Fear Arousal) $\times 2$ (Action Frame) univariate analyses of variance with previous BSE performance as covariate (ANCOVA) did not find significant support for the interaction of Fear Arousal and Action Frame on respectively the cognitive component and affective component of attitude toward BSE performance, nor on the ranking score of BSE importance, F's $<1.00$, ns. Neither were any other significant effects found (p's > .15). The hypothesis was thus not supported with the experimental manipulation of fear arousal as a factor in the design.

To test the hypothesis with reported fear level in the design, a median-split procedure was carried out on the self-reported level of fear (Med. $=4.00$ ). The resulting factor named Fear Level was included in a 2 (Fear Level: low versus mild) x 2 (Action Frame: loss versus gain) between-participants design. Three respondents who scored exactly on the median were excluded from the analyses to keep a well-balanced design $(N=38)$. The mediansplit procedure was successfull as respondents were equally distributed over the four cells of the design, $x^{2}(1, N=38)=1.69, p=.19$.

A full-factorial ANCOVA did not yield significant support for the postulated interaction effect of Fear Level and Action Framing on the cognitive and affective components of attitude, F's $<1.00$, ns, neither were any other significant effects found ( $p$ 's $>.34$ ). However, analyses on the ranking score of BSE importance found a significant main effect of Fear Level, F $(1,33)$ = 5.66, p <.05. Respondents who reported mild fear for breast cancer evaluated BSE performance as relatively more important compared to other health behaviours $(M=2.94 ; S D=1.35)$ than respondents who reported low fear for breast cancer $(M=2.15 ; S D=1.23)$. Importantly, the predicted interaction effect between Fear Level and Action. Frame was in the expected direc- 
tion, although not significant, F $(1,33)=1.63, \mathrm{p}=.11$ (one-tailed: hypothesised direction). Among respondents who reported mild fear of breast cancer, those who read the loss frame seemed to give more importance to BSE performance $(M=3.43 ; S D=1.62)$ than those who read the gain frame $(M=2.64 ; S D=1.12), F(1,15)=2.95, p=.05$ (one-tailed: hypothesised increase). Among respondents who reported low fear of breast cancer, those who read the loss frame seemed to give equal importance to BSE performance $(M=2.08 ; S D=1.38)$ as those who read the gain frame $(M=2.25 ; S D=1.04), F(1,15)<1.00$, ns (see Figure 6.1).

Figure 6.1 Percelved relative importance of BSE performance $(i=$ least important -6 - most important) as a function of Fear Leve! and Action Franne.

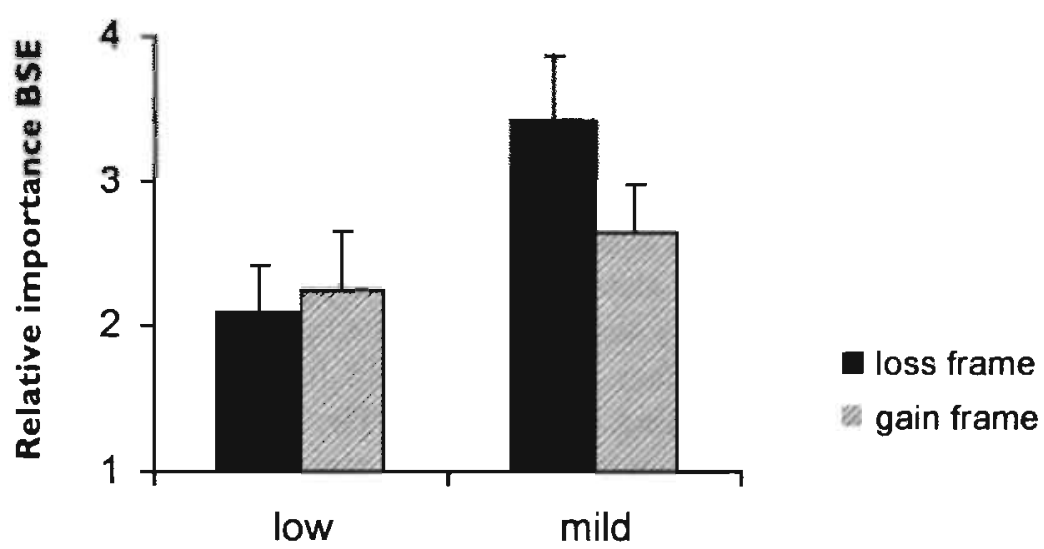

Fear Level

Legend. Bars show means with higher scores indicating more perceived importance of BSE performance. Error bars show mean +1.0 standard error of the mean.

\section{DISCUSSION}

In the present study we hypothesised that the persuasive impact of frightening information would be increased by framing precautionary information negatively rather than positively. More specifically, it was predicted that in the mild fear conditions the evaluation of BSE performance would be more positive after reading a loss frame than after reading a gain frame. This 
hypothesis was not supported on either of the evaluation indices of BSE performance. Analyses with reported fear level, however, found partial support for this hypothesis. Participants who reported mild fear arousal gave BSE performance more importance compared to other health behaviours than participants who reported low fear arousal. This was especially true if they read information about BSE performance that was presented in a loss frame rather than in a gain frame. This finding was not confirmed on measures of the cognitive component and affective components of attitude.

The findings of the present study suggest that action framing may strengthen the persuasive impact of fear appeals to a certain extent. The findings are limited, however, to the evaluation of BSE performance in terms of importance and may further be limited to a specific sample of young women with a high educational background. Future research should explore the role of action framing in fear appeals in different health settings and among different populations. Furthermore, the support for the hypothesis was statistically weak and only found on analyses that used reported (instead of manipulated) fear level as predictor variable. The difference between findings with manipulated and reported fear level suggests that the mediansplit procedure on reported fear level did not completely rule out the influence of a third variable or any other variable we were not aware of and thus could not control for (see also chapter 3). Importantly, however, including reported fear level in the analysis did not hamper causal interpretations because the measure of fear arousal directly followed the threat manipulation and preceded the frame manipulation. The fact that we found support for the hypothesis on the relative evaluation measure of BSE performance may indicate that this measure is more sensitive than an absolute evaluation measure such as the semantic-differential measure. The former may therefore be better applicable in studies that deal with a topic such as BSE performance that is known and in general favourably evaluated in the public domain (overail mean score on attitude was 6.21).

Rothman and Salovey (1997) have suggested that action framing may only exert its influence on precautionary motivation if the information is systematically processed. The findings of the studies reported in chapter 3 and the present chapter carefully support the moderating role of systematic processing: the study reported in chapter 3 suggests that mild fear arousal may prompt argument-based processing, while the present study only found support for a framing effect among respondents who reported mild fear arousal. Whether fear arousal should be used to enhance systematic processing is, however, doubtful. Fear arousal may easily result in message denial and avoidance (see chapter 5). Other options are open to increase perceptions of personal relevance, for example, by personalising precautionary information (for an overview, see Brug \& De Vries, 1999). 
In conclusion, the present study was a first study into the effects of action framing on precautionary motivation under conditions of fear arousal. The findings were by far not conclusive. Future research should therefore further examine these effects. Special attention may be directed to identifying relevant mediating processes and variables. For example, from the present study it is not clear whether increased systematic processing may mediate the effects of action framing or increased feelings of fear after reading the loss frame. 



\section{CHAPTER 7}

THE EFFECTS OF THREATENING INFORMATION AND FEAR AROUSAL ON ACTION PLANNING 


\section{INTRODUCTION}

Health education researchers and practitioners are familiar with failures among their recipients to translate stated goal intentions into performance of recommended action. Explanatory models of behaviour such as the theory of planned behaviour (Ajzen, 1988) have identified this gap between precautionary motivation and self-protective action and attributed it to factors such as perceptions of one's abilities to perform the recommended action, actual abilities (skills), and physical and social barriers that are present in their environments. More recently, Gollwitzer, working within experimental social psychology, has highlighted the role of implementation intentions (Gollwitzer, 1993) or action planning (Abraham, Sheeran, \& Johnston, 1998) in bringing people from precautionary motivation to self-protective action. Simple plans of specifying where and when a recommended action will be performed have been found to distinguish between intenders who do act and those who do not act (for an overview, see Gollwitzer \& Schaal, 1998). For example, Orbell, Hodgkins, and Sheeran (1997) showed that, among women who intended to perform a breast self-examination (BSE), all women $(100 \%)$ who formed implementation intentions reported to have performed this self-exam at a 1-month follow-up measure, whereas in the control group that did not form implementation intentions $53 \%$ performed BSE. Gollwitzer (1993; Gollwitzer \& Schaal, 1998) explains the effects of implementation intentions by drawing similarities to the operation of habitual behaviour (e.g., Verplanken \& Aarts, 1999). He argues that such detailed plans create cues to action in relevant environments, which prompt intenders to act automatically when these cues are encountered.

A number of theorists have distinguished between two stages of action control: (i) a decisional or motivational stage which culminates in intention formation and (ii) a postdecisional or volitional stage which involves selfregulatory activities directed toward the enactment of intentions (Gollwitzer. 1993: Gollwitzer \& Moskowiz, 1996; Kuhl, 1992: Schwarzer, 1992). The present study combines fear appeals with postdecisional processes and, in particular, investigated the effects of frightening information on postdecisional action planning.

The study of postdecisional processes is not new in fear appeal research. Leventhal and colleagues studied the relationship between frightening information and the provision of specific instructions on how to take precautionary action (Leventhal, Jones, \& Trembly, 1966; Leventhal, Singer, \& Jones, 1965: Leventhal, Watts, \& Pagano, 1967). Findings were consistent and are illustrated by the first of these studies (Leventhal at al., 1965). Respondents read a potentially fear-arousing message about the negative consequences of tetanus and were advised to have a vaccination injection at the local hospital. 
Half the respondents received a map highlighting the location of the hospital and were instructed to think about their daily schedule in order to arrange classes so that they would have time to visit the hospital. Results showed that those in the high fear condition had more positive attitudes and intentions toward tetanus injections than those in the low fear conditions, whereas the action instructions had no influence on attitudes and intentions. Action instructions did, however, influence action: $30 \%$ of the students receiving action instructions had an injection while only $3 \%$ did so in the absence of action instructions. Thus fear had a positive effect on the antecedents of precautionary motivation (i.e., attitudes) and on precautionary intention formation. This effect did not, however, translate into a greater likelihood of action. Motivation (fear) was nonetheless crucial to action. Nobody in the control condition (with no fear message) went for an injection, irrespective of whether or not they received specific instructions. Thus fear appeared to create the motivational potential to act while specific instructions facilitated the translation of good intentions into action.

These findings correspond thus to those of more recent work suggesting that postdecisional or volitional processes explain why some intenders act while others do not. It also raises interesting questions about the relation between fear arousal and postdecisional processes such as action planning. In a recent study, Abraham, Sheeran, Norman, Conner, De Vries, and Otten (1999) assessed the extent to which participants had thought about how they would use condoms. These self-report measures of action planning are not direct expressions of implementation intentions of the kind employed by Gollwitzer (1993) and Orbell and colleagues (1997) but like implementation intentions they predicted subsequent behaviour over and above goal intentions.

The present study investigated the question whether fear arousal enhances action planning. The study was situated in the area of early breast cancer detection. Fear of breast cancer was aroused among female students by presenting threatening information about breast cancer. The main dependent variable was the extent to which participants planned future BSE performance to detect breast cancer in an early and therefore more treatable stage. Based on the definition of fear arousal as being an emotional state that urges people to cognitive and behavioural action to create a situation that is perceived as safe (cf. Frijda, 1986), it was first hypothesised that fear arousal will motivate people to plan specific actions that can avert the presented threat such as BSE performance (Hypothesis 1). Work by Gollwitzer and others (e.g., Orbell et al., 1997), however, suggest that implementation intentions are especially effective among people who have formed positive goal intentions. Our second hypothesis was therefore that the effect of fear arousal on action planning would be stronger among participants who stated high rather than low goal intentions to perform BSE (Hypothesis 2). 


\section{METHOD}

\section{Participants, design and procedure}

One hundred and twelve first-year undergraduates of Maastricht University were randomly distributed across the two conditions of a one factorial experimental design that manipulated fear arousal (low vs. mild). The experiment was computer-controlled. Participants were seated in separate cubicles and either read mild fear-arousing information or low fear-arousing information about breast cancer (for a more extensive description, see chapters 5 and 6). Next a statement appeared on the screen that read: "Performing breast selfexamination means that you check your breasts for changes every month. Following, next are some questions about performing breast self-examination. Please, answer these question as accurately and truthfully as you can." Participants then answered questions about their intention to perform BSE and how many times they had performed BSE performance in the last 12 months. A final item then measured action planning.

After leaving the cubicles participants were extensively debriefed by the fernale experimenter who was especially alert to any signs of current fears as expressed by the participants. All participants were told that their chance of getting breast cancer was actually low, that it is most common among women older than 45 years of age and that they thus should not worry about getting breast cancer. They then received information about breast cancer and BSE performances issued by the Dutch Cancer Society and were urged to read it carefully. Participants received 10 Dutch guilders (around 5 US dollars) for their participation and were asked not to discuss the topic and objectives, of the study to fellow students.

\section{Measures}

Fear arousal

Four items measured fear arousal on a 9-point scale (worried " afraid, uncomfortable, frightened). The four items were summarised into a highly reliable index of fear arousal (Cronbach's alpha $=.95$ ).

\section{Goal intention}

Three items that were combined into a single index (Cronbach's alpha $=.85$ ) measured goal intention to perform BSE on a 9-point scale (e.g., "I intend to perform a breast self-examination in the coming month; surely not surely yes"). 


\section{Previous BSE performance}

One open question asked participants how many times they had performed breast cancer in the previous 12 months. Previous BSE performance was significantly related to the measure of action planning $(p<.05)$ and therefore included as covariate to permit more powerful tests of the effects under consideration.

\section{Action planning}

Participants were asked to what extent they planned future BSE performance on a five point scale: 1 = it has not occurred to me, 2 = I have not thought about it much, 3 = it has occurred to me that I might do this, $4=I$ have some idea about how I might do this, $5=$ I have a clear plan about how I would do this.

\section{RESULTS}

\section{Fear arousal}

Fear arousal was successfully manipulated. An independent samples t-test on reported fear showed that respondents reported more fear after reading the mild fear-arousing information $(M=5.12, S D=1.75)$ about breast cancer than after reading low fear-arousing information $(M=3.35, S D=1.79), t$ $(110)=5.29, p<.001$.

\section{Action planning}

A one factorial (Fear Arousal: low vs. mild) analysis of variance (ANOVA) with previous BSE performance as covariate yielded support for Hypothesis 1. The manipulation of fear arousal significantly influenced action planning, $F(1,109)=3.17, p<.04$ (one-sided: hypothesised increase). Respondents in the mild fear arousal condition planned future BSE performance more ( $M$ $=3.05 ; \mathrm{SD}=0.83$ ) than respondents in the low fear arousal condition ( $M$ $=2.80 ; \mathrm{SD}=0.89$ ).

To test Hypothesis 2, a median-split was performed on the index measuring intention to perform BSE (Med. = 5.33), which resulted in a group of low intenders to perform BSE $(\mathrm{N}=54)$ and a group of high intenders $(\mathrm{N}=$ 47). Eleven respondents scored exactly on the median and were excluded 
from subsequent analyses $(N=101)$. To test the prediction that the effect of fear arousal on action planning would be stronger among respondents who stated high rather than low goal intentions, a 2 (Fear Arousal: low vs. mild) $\times 2$ (Intention: low versus high) ANOVA was carried out on the measure of action planning. No support was found for this prediction, because the interaction of Fear Arousal and Intention was not significant, $F$ $<1.00$, ns. Instead, a significant main effect of Intention was found, F (1, $96)=10.60, p<.01$. Not surprisingly, respondents with high intentions to perform BSE had planned BSE performance more $(M=3.31 ; S D=0.84)$ than respondents with low intentions $(M=2.59$; $S D=0.81)$. Surprisingly, the main effect of Fear Arousal did not approach significance on this analysis, $\mathrm{F}(1,96)=1.23, \mathrm{p}=.14$ (one-sided).

\section{Additional analyses}

Because in earlier studies the manipulation of fear arousal yielded different findings on dependent measures than reported fear level (see chapters 3 and 6), we tested the hypotheses also with reported fear level in a quasi-experimental design. The sample was divided into low $(\mathrm{N}=55)$ and mild $(\mathrm{N}=$ 53) fear groups using a median split (Med $=4.25$ ). The resulting variable was labelled Fear Level. Four respondents who scored exactly on the median were excluded from the analyses $(\mathrm{N}=108)$. Analyses with Fear Level as a factor was justified and should not hamper causal interpretations of the findings because the measurement of fear preceded the dependent measure.

Support was again found for Hypothesis 1. The effect of Fear Level on action planning was significant, $F(1,105)=6.87, \mathrm{p}<.01$. Respondents who reported mild fear planned future BSE performance more $(M=3.11$ : SD $=0.78)$ than respondents who reported low fear $(M=2.73 ; S D=0.93)$.

To test Hypothesis 2, a median-split was performed on the index measuring intention to perform BSE (Med. = 5.33), which resulted in a group of low intenders to perform BSE $(\mathrm{N}=5.2)$ and a group of high intenders $(\mathrm{N}=$ 46). Ten respondents scored exactly on the median and were excluded from subsequent analyses $(\mathrm{N}=98)$. Hypothesis 2 was again not supported. A 2 (Fear Level: low vs, mild) $\times 2$ (Intention: low vs. high) ANOVA revealed no significant support for the interaction of both factors, $F<1.00$, ns. Instead, the main effect of Fear Level was significant, $F(1,93)=4.32, p<.05$. Respondents who reported mild fear planned BSE performance more $(M=$ 3.13: $S D=0.82)$ than respondents who reported low fear $(M=2.74 ; S D=$ $0.96)$. Also the main effect of Intention was significant, $F(1,93)=12.37$, $p<.001$. High intenders planned BSE performance more $(M=3.33 ; S D=$ $0.84)$ than low intenders $(M=2.58 ; S D=0.82)$. 


\section{DISCUSSION}

The present study studied the effect of fear arousal on action planning. The findings supported the first hypothesis that more fear arousal results in more action planning. Participants who read mild fear-arousing information about breast cancer and subsequently reported mild levels of fear thought more about performing BSE than participants who read low fear-arousing information and reported low levels of fear. However, the second hypothesis was not supported, neither on analyses with manipulated fear nor on analysis with reported fear. The effect of fear on action planning was not stronger among high intenders than among low intenders.

The present study did not measure BSE performance. Future research could explore whether action planning and also implementation intentions would indeed be more effective in prompting behaviour when fear arousal is mild rather than low and people have positive intentions to perform the recommended precaution. To test the relationship between fear arousal and action planning on actual behaviour a longitudinal design is needed that controls for relevant variables such as existing plans and self-efficacy and intention toward performing the recommended action by including premeasures of these variables.

Inclusion of actual behaviour in the fear arousal paradigm should be accompanied further by measures that prevent any long-term negative effects of the fear manipulation. The present study did not seem to have aroused extreme levels of fear. None of the respondents showed signs of fear at the debriefing. However, we could not be completely sure about this and thus extensively informed the participants about their low susceptibility to breast cancer. By doing this we probably neutralised the fear manipulation and thus could not test the effect of action planning (or implementation intentions) on BSE performance under conditions of fear. This problem suggests that these theoretical ideas may be better tested using behaviours that can be observed immediate after presenting fear-arousing information in the laboratory. For example, participants could be given the opportunity to register for a course on how to perform BSE or may order a free information leaflet on the Internet.

In conclusion, the present study supports the importance of linking fear appeal research to research that investigates the effects of postdecisional processes such as action planning and implementation intentions on self-protective action. Our findings are inconclusive but highlight the possibility that fear may be positively related to action planning. Future research should try to extend these findings by using samples from other populations than young females with a high educational background, covering different health topics and behaviours, and including measures of actual performance 
without ignoring ethical guidelines regarding long-term effects of fear-arousing information outside the laboratory. 


\section{REFERENCES}

Abraham, C. S., Sheeran, P., Abrams, D., \& Spears, R. (1994). Exploring teenagers' adaptive and maladaptive thinking in relation to the threat of HIV infection. Psychology and Health, 9, 253272.

Abraham, C., Sheeran, P. \& Johnston, M. (1998). From health beliefs to self-regulation: Theoretical advances in the psychology of action control. Psychology and Heolth, 13, 569-591.

Abraham, C., Sheeran, P., Norman, P., Conner, M., De Vries, N., \& Otten, W. (1999). When good intentions are not enough: Modeling post-intention cognitive correlates of condom use. Journal of Applied Social Psychology, 29, 2591-2612.

Ajzen, L. (1988). Attitudes, personolity, and behovior. Chicago: Dorsey.

Ajzen, I. (1991). The theory of planned behavior. Organizational Behavior and Human Decision Processes, 50, 179-211.

Ajzen, L., \& Fishbein, M. (in press). Attitudes and the attitude-behavior relation: Reasoned and automatic processes. In W. Stroebe \& M. Hewstone (Eds.), European Review of Social Psychology (Vol. II). Chichester, UK: John Wiley \& Sons.

Ajzen, L., \& Sexton, J. (1999). Depth of processing, belief congruence, and attitude-behavior correspondence. In S. Chaiken \& Y. Trope (Eds.), Duol-process theories in social psychology (pp. 117. 138). New York: The Guilford Press.

Bandura, A. (1986). Sociol foundations of thought and action: A social cognitive theory. Englewood Cliffs, NJ: Prentice-Hall.

Bandura, A. (1997). Seffefficacy: The exercise of control (Ist ed.). New York: Freeman.

Bargh, J. A., \& Chartrand, T. L. (1999). The unbearable automaticity of being. American Psychologist, $54,462-479$.

Baron, R. M., \& Kenny, D. A. (1986). The moderator-mediator variable distinction in social psychological research: Conceptual, strategic, and statistical considerations. Journal of Personality and Social Psychology, 51, 1173-1182.

Baron, R., Logan, H., Lilly, J., Inman, M., \& Brennan, M. (1994). Negative emotion and message processing. Journal of Experimental Social Psychology, 30, 181-20I.

Beck, K. H., \& Frankel, A. (1981). A conceptualization of threat communications and protective health behaviour. Social Psychology Quarterly, 44, 204-217.

Beck, K. H., \& Lund, A. K. (198I). The effects of health threat seriousness and personal efficacy upon intentions and behavior. Journal of Applied Social Psychology, II, 40I-4I5.

Becker, M. H. (1974). The health belief model and personal health behavior. Heath Education Monogrophs, 2, 324-508.

Berkowitz, L., \& Cottingham, D. R. (1960). The interest value and relevance of fear-arousing communications. Journol of Abnormol and Social Psychology, 60, 37-43.

Berntson, G. G., \& Cacioppo, J. T. (2000). Psychobiology and social psychology: Past, present, and future. Personality and Social Psychology Review, 4, 3-15.

Boster, F. J., \& Mongeau, P. (1984). Fear-arousing persuasive messages. In R. N. Bostrom (Ed.). Communication Yearbook: An annual review published for the Imternotional Communication Association (pp. 330-375). Beverly Hills, CA: Sage. 
Brug, J., \& De Vries, H. (1999). Computer-tailored education [Special issue]. Potient Educotion \& Counseling, 36(2).

Cacioppo, J. T., \& Petty, R. E. (1981). Social psychological procedures for cognitive response assessment: The thought-listing technique. In T. V. Merluzzi, C. R. Glass, \& M. Genest (Eds.), Cognitive Assessment (pp. 309-342). New York: The Guilford Press.

Cacioppo, 1. T., Tassinary, L. G., Bernts, G. G. (Eds.). (1990). Handbook of psychophysiology. Cambridge, UK: Cambridge University Press.

Chaiken, S. (1980). Heuristic versus systematic information processing and the use of source versus message cues in persuasion. Journal of Personality and Sociol Psychology, 39. 752-766.

Chaiken, S., Giner-Sorolla, R., \& Chen. S. (1996). Beyond accuracy: Defense and impression motives in heuristic and systematic information processing. In P. M. Gollwizer \& J. A. Bargh (Eds.), The psychology of action: Linking cognition and motivotion to behavior (pp. 553-578). New York: The Guilford Press.

Chaiken, S., Liberman, A., \& Eagly, A. H. (1989). Heuristic and systematic processing within and beyond the persuasion context. In J. S. Uleman \& J. A. Bargh (Eds.), Unintended thought (pp. 212-252). New York: The Guilford Press.

Chaiken, S., \& Trope, Y. (Eds.). (1999). Dualprocess theories in social psychology. New York: The Guilford Press.

Conner, M., \& Norman, P. (1996). Predicting heath behoviour: Research and practice, with social cognition models. Buckingham, UK: Open University Press.

Cooper, J., \& Fazio, R. H. (1984). A new look at dissonance theory. In L. Berkowitz (Ed.), Advances in experimental social psychology (Vol. 17, pp. 229-266). San Diego: Academic Press.

Das, E. (2000. August 19th 2000). Fear appeats in health promotion: (How) does it work? Paper presented at the Models of health and illness behaviour: The 14th conference of the European Health Psychology Society, Leiden University.

Detweiler, J. B., Bedell, B. T., Salovey, P., Pronin, E., \& Rothman, A. J. (1999). Message framing and sunscreen use: Gain-framed messages motivate beach-goers. Health Psychology, 18, 189-196.

Dijker. A. J., Koomen, W., \& Kok, G. (1997). Interpersonal determinants of fear of people with AiDS: The moderating role of predictable behavior. Basic and Applied Social Psychology, 19, 61. 79.

Dillard. J. P. (1994). Rethinking the study of fear appeals: An emotional perspective. Communication Theory, 4, 295-323.

Ditto, P. H., Jemmott, J. B., \& Darley, J. M. (1988). Appraising the threat of illness: A mental representational approach. Health Psychology. 7, 183-2,00.

Eagly, A. H., \& Chaiken, S. (1993). The psychology of attitudes. Fort Worth, TX: Harcourt Brace Jovanovich.

Edwards, W. (1954). The theory of decision-making. Psychological Bulletin, I/I, 380-417.

Festinger, L., Carlsmith, J. M. (1959). Cognitive consequences of forced compliance. Journol of Abnormal and Social Psychology, 58, 203-210.

Fishbein, M., \& Ajzen, I. (1975). Beliefs, attitudes, intention, and behavior: An introduction to theory and research. Reading, MA: Addison-Wesley.

Fisher, J. D., \& Fisher, W. A. (1992). Changing AIDS-risk behavior. Psychological Bulletin, 111, 455-474. 
Floyd, D. L, Prentice-Dunn, S., \& Rogers, R. W. (2000). A meta-analysis of research on protection motivation theory. Journal of Applied Social Psychology, 30, 407-429.

Forgas, J. P. (1992). Affect in social judgments and decisions: A multi-process model. In M. Zanna (Ed.), Advances in experimental social psychology (Vol. 25, pp. 227-275). San Diego, CA: Academic Press.

Frijda, N. (1986). The Emotions. Cambridge, England: Cambridge University Press.

Gleicher, F. \& Petty, R. E. (1992). Expectations of reassurance influence the nature of fear-stimulated attitude change. Journal of Experimental Social Psychology, 28, 86-100.

Godin, G., \& Kok, G. (1996). The theory of planned behavior: A review of its applications to health-related behaviors. Americon Journal of Health Promotion, 11,87-98.

Gollwitzer, P. M. (1993). Goal achievement: The role of intentions. European Review of Social Psychology, 4, 141-185.

Gollwitzer, P. M., \& Moskowitz, G. B. (1996). Goal effects on action and cognition. In E. T. Higgins \& A. Kruglanski (Eds.), Social psychology: Handbook of basic principles (pp. 361-399). New Yorkc The Guilford Press.

Gollwitzer, P. M., \& Schaal, B. (1998). Metacognition in action: The importance of implementation intentions. Personality and Social Psychology Review, 2, 124-136.

Greenberg J., Solomon, S., \& Pyszczynski, T. (1997). Terror management theory of self-esteem and cultural worldviews: Empirical assessments and conceptual refinements. In M. P. Zanna (Ed.), Advances in Experimental Social Psychology (Vol. 29, pp. 61-139). New York: Academic Press.

Greenwald, A. G. (1968). Cognitive learining, cognitive response to persuasion, and attitude change. In A. G. Greenwald, T. C. Brock, \& T. M. Ostrom (Eds.), Psychological foundations of attitudes. San Diego, CA: Academic Press.

Griffeth, R. W., \& Rogers, R. W. (1976). Effects of fear-arousing components of driver education on students' safety attitudes and simulator performance. Journol of Educational Psychology, 68, 501-506.

Groner, R., McConkie, G., \& Menz, G. (Eds.). (1985). Eye movements and human information processing. Amsterdam: Elsevier.

Harmon-Jones, E., Brehm, J. W., Greenberg, J., Simon, L, \& Nelson, D. E. (1996). Evidence that the production of averse consequences is not necessary to create cognitive dissonance. Journal of Personality and Social Psychology, 70, 5-16.

Hendrick, C., Giesen, M., \& Borden, R. (1975). False physiological feedback and persuasion: Effect of fear arousal vs. fear reduction on attitude change. Journal of Personality, 43, 196-214.

Higbee, K. L. (1969). Fifteen years of fear arousal: Research on threat appeals: 1953-1968. Psychological Bulletin, 72, 426-444.

Hovland, C. I., Janis, I. L. \& Kelley, H. H. (1953). Communication and persuasion: Psychological studies of opinion change. New Haven, CT: Yale University Press.

Jacoby, J., Jaccard, J., Kuss, A. Troutman, T., \& Mazursky, D. (1987). New directions in behavioral process research: Implications for social psychology. Journal of Experimental Social Psychology, 23, 146-175. 
Janis, I. L. (1967). Eflects of fear arousal on attitude change: Recent developments in theory and experimental research. In L Berkowiz (Ed.), Advances in experimental social psychology (Vol. 3, pp. 166-224). San Diego, CA: Academic Press.

Janis, I. L., \& Feshbach, S. (1953). Effects of fear-arousing communications. The journal of Abnormal and Sociol Psychology, 48, 78-92.

Janis, I. L., \& Leventhal, H. (1968). Human reactions to stress. In E. F. Borgata \& W. W. Lambert (Eds.), Handbook of personality theory and reseorch (pp. 1041-1085). Chicago: Rand McNally.

Janz, N. K. \& Becker, M. H. (1984). The health belief model: A decade later. Health Education Quoinerly, II, 1-47.

Jepson, C., \& Chaiken, S. (1990). Chronic issue-specific fear inhibits systematic processing of persuasive communications. Journal of Social Behovior and Personality, 5, 61-84.

Johnson, B. T., \& Eagly. A. H. (1989). Effects of involvement on persuasion: A meta-analysis. Psychological Bulletin, 106, 290-314.

Johnson, B. T. \& Eagly, A. H. (1990). Involvement and persuasion: Types, traditions, and the evidence. Psychological Bulletin, 107, 375-384.

Kahnernan, D., \& Tversky, A. (1979). Prospect theory: An analysis of decision under risk. Econometrica, 47, 2631-291.

Kahneman, D., \& Tversky, A. (1984). Choices, values, and frames. Americon Psychologist, 39, 341350.

Kirby, D., Short, L., Collins, J., Rigg, D., Kolbe, L., Howard, M., Miller, B., Sonnenstein, F., \& Zabin, L. S. (1994). School-based programs, to reduce sexual behaviours: A review of effectiveness. Public Health Reports, 10, 339-360.

Kleinot, M. C., \& Rogers, R. W. (1982), Identifying, effective components of alcohol misuse prevention programs. Journal of Studies on Alcohol, 43, 802-8! I.

Kuhl. J. (1992). A theory of self-regulation: action versus state oriencation, self-discrimination and some applications. Applied Psychology. An International Review, 41, 97-129.

Kuppensi, M., De Wit; J., \& Stroebe, W. (1996). Angstaanjagende voorlichting. Een dual process analyse [Fear-arousing communications: A dual process analysis. Gedrag \& Gezondheid, 24, 241 248.

Lang. P. J. (1995). The emotion probe: Studies of motivation and attention. American Psychologist, 50, 372-385.

Lazarus, R. S. (1966). Psychological stress and the coping process. Newr York McGraw-Hill.

Lazarus, R. S. (1984). On the primacy of cognition. American Psychologist, 39, 124-129.

Lazarus, R. S. (199/a). Cognition and motivation in emotion. American Psychologist, 46, 352-367.

Lazarus, R. S. (1991/b). Progress on a cognitive-motivational-relational theory of emotion. Americon Psychologist, 46, 819-834.

Lazarus, R. S., \& Folkman, S. (1984). Stress, oppraisal and coping. New York Springer.

Leventhal, H. (1970). Findings and theory in the study of fear communications. In L Berkowitz (Ed.), Advances; in experimental social psychology (Vol. 5, pp. 119-187). New York: Academic Press.

Leventhal, H. (1971). Fear appeals and persuasion: The differentiation of a motivational construct. American Journal of Public Health, 61, 1208-1224. 
Leventhal, H. Jones, S., \& Trembly, G. (1966). Sex differences in attitude and behavior change under conditions of fear and specific instructions. Journal of Experimental Social Psychology, 2. 387-399.

Leventhal, H., \& Niles, P. (1965). Persistence of influence for varying durations of exposure to threat stimuli. Psychological Reports, 16, 223-233.

Leventhal, H., Singer, R., \& Jones, S. (1965). Effects of fear and specificity of recommendation upon attitudes and behavior. Journol of Personolity and Social Psychology, 2, 20-29.

Leventhal, H., \& Singer, R. P. (1966). Affect arousal and positioning of recommendations in persuasive communications. Journal of Personality and Social Psychology, 4, 137-146.

Leventhal, H., Watts, J. C., \& Pagano, F. (1967). Effects of fear and instructions on how to cope with danger. Journal of Personality and Social Psychology, 6, 313-321.

Levin, I. P. Schneider, S. L. \& Gaech, G. J. (1998). All frames are not created equal: A typology and critical analysis of framing effects. Organizational Behavior and Human Decision Processes, 76, 149. 188.

Lion, R., \& Meertens, R. (in press). Seeking information about a risky therapeutic medicine: Effects of risk taking tendency and accountability. Journal of Applied Social Psychology.

Mackie, D. M., \& Worth, L. T. (1989), Cognitive deficits and the mediation of positive affect in persuasion. Journal of Personality and Social Psychology, 57, 27-40.

Maddux, J. E., Norton, L W. \& Stoltenberg, C. D. (1986). Self-efficacy expectancy, outcome expectancy, and outcome value: Relative effects on behavioral intentions. Journal of Personality and Social Psychology, 51, 783-789.

Maddux. J. E., \& Rogers, R. W. (1983). Protection motivation and self-efficacy: A revised theory of fear appeals and attitude change. Journol of Experimental Social Psychology, 19, 469-479.

Maddux, J. E., Sherer, M., \& Rogers, R. W. (1982). Self-efficacy expectancy and outcome expectancy: Their relationship and their effects on behavioral intentions. Cognitive Therapy and Research, 6, 207-211.

Maheswaran, D., \& Meyers-Levy, J. (1990). The influence of message framing and issue involvement journal of Marketing Research, 27, 361-367.

Maibach, E., \& Parrott, R. L (Eds.). (1995). Designing heath messages: Approaches from communication theory and public health proctice. Thousand Oaks, CA: Sage Publications.

Matthews, G., Jones, D. M., \& Chamberlain, A. G. (1990). Refining the measurement of mood: The UWIST Mood Adjective Checklist. British Journal of Psychology, 81, 17-42.

McGuire, W. ) (1968). Personality and susceptibility to social influence. In E. F. Borgatta \& W. W. Lambert (Eds.), Handbook of personality theory and research (PP. II30-1187). Chicago: Rand McNally.

McGuire, W. J. (1969). The nature of attitudes and attitude change. In G. Lindzey \& E. Aronson (Eds.), Handbook of social psychology (2nd ed., Vol. 3, pp. 136-314). Reading, MA: Addison-Wesley.

Meijnders, A. L (1998). Climate change and changing attitudes: Effect of negative emotion on information processing. Eindhoven University of Technology. Eindhoven.

Mewborn, C. R., \& Rogers, R W. (1979). Effects of threatening and reassuring components of fear appeals on physiological and verbal measures of emotion and attitudes. Journol of Experimentol Social Psychology. 15, 242-253. 
Meyerowitz, B. E., \& Chaiken, S. (1987). The effect of message framing on breast self-examination attitudes, intentions, and behavior. Journal of Personality and Social Psychology, 52, 500-510.

Milne, S., Sheeran, P., \& Orbell, S. (2000). Prediction and intervention in health-related behavior: A meta-analytic review of protection motivation theory. Journal of Applied Social Psychology, 30, 106-143.

Mulilis, J. P., \& Lippa, R. (1990). Negative threat appeals: A test of protection motivation theory. Journal of Applied Social Psychology, 20, 619-638.

Murphy, S. T., \& Zajonc, R. B. (1993). Affect, cognition, and awareness: Affective priming with optimal and suboptimal stimulus exposures. Journal of Personality and Social Psychology, 64, 723-739.

Nisbett, R. E., \& Wilson, T. D. (1977). Telling more than we can know: Verbal report on mental processes. Psychological Review, 84, 231-259.

Orbell, S., Hodgkins, S., \& Sheeran, P. (1997). Implementation intentions and the theory of planned behavior. Personality and Social Psychology Bulletin, 23, 945-954.

Petty, R. E., \& Cacioppo, J. T. (1986). Communication and persuasion: Central and peripheral routes to ottitude change. New York: Springer-Verlag.

Petty, R. E., \& Cacioppo, J. T. (1990). Involvement and persuasion: Tradition versus integration. Psychological Bulletin, 107, 367-374.

Petty, R. E., Haugtvedt, C., \& Smith, S. M. (1995). Elaboration as a determinant of argument strengch: Creating attitudes that are persistent, resistant, and predictive of behavior. In R. E. Petty \& J. A. Krosnick (Eds.), Attitude strength: Antecedents and consequences (pp. 93-130). Mahwah, NJ: Erlbaum.

Petty, R. E., \& Wegener, D. T. (1998). Attitude change: Multiple roles for persuasion variables. In D. T. Gilbert, S. T. Fiske, \& G. Lindzey (Eds.), The handbook of social psychology (4th ed., Vol.I, Pp. 323-390). Boston: McGraw-Hill.

Plotnikoff, R. C., \& Higginbotham, N. (1995). Predicting low-fat diet intentions and behaviors for the prevention of coronary heart disease: An application of protection motivation theory among an Australian population. Psychology and Health, 10, 397-408.

Plotnikof, R. C., \& Higginbotharn, N. (1998). Protection motivation theory and the prediction of exercise and low-fat diet behaviours among Australian cardiac patients. Psychology and Heatth, 13. $411-429$.

Pointer, J. L., \& Rogers, R. W. (1993). Cognitive processing and persuasive effects of threat, argument: quality, ond source expertise. Paper presented at the Meeting of the American Psychological Society. Chicago.

Prentice-Dunn, S., Jones, J. L., \& Floyd, D. L. (1997). Persuasive appeals and the reduction of skin cancer risk: The roles of appearance concern, perceived benefits of a tan, and efficacy information. Joumal of Applied Sociol Psychology, 27, 1041 - 1047.

Rachman, S. J. (1998). Anxiety, Hove, UK: Psychology Press.

Research and Evaluation Committee of the Nationai Expert Advisony Committee on Tobacco (1999). Australia's notional tobocco compaign: Evaluation report volume one: Every cigarette is doing you domoge. Commonwealth Department of Health and Aged Care, Australia.

Rigby, K., Brown, M., Anagnostou, P., Ross, M. W. \& Rosser, B. R. S. (1989). Shock nactics, to counter AIDS: The Australian experience. Psychology and Health, 3, 145-159. 
Rippetoe, P. A. \& Rogers, R. W. (1987). Effects of components of protection motivation theory on adaptive and maladaptive coping with a health threat. Journal of Personality and Social Psychology, 52, 596-604.

Rogers, R. W. (1975). A protection motivation theory of fear appeals and attitude change. The Journal of Psychology, 91, 93-114.

Rogers, R. W. (1983). Cognitive and physiological processes in fear appeals and attitude change: A revised theory of protection motivation. In J. T. Cacioppo \& R. E. Petty (Eds.), Social psychophy siology: A sourcebook (pp. 153-176). New York: Guilford Press.

Rogers, R. W., \&eckner, C. W. (1975). Effects of fear appeals and physiological arousal upon emotion, attitudes, and cigarette smoking. Journol of Personality and Social Psychology, 32, 222. 230.

Rogers, R. W. \& Mewborn, C. R. (1976). Fear appeals and attitude change: Effects of a threat's noxiousness, probability of occurrence, and the efficacy of coping responses. Journal of Personality and Social Psychology, 34, 54-61.

Rogers, R. W. \& Prentice-Dunn, S. (1997). Protection motivation theory, In D, S. Gochman (Ed). Handbook of health behavior research $k$ Personal and social determinants (Vol. I, pp. I13-132). New York Plenum Press.

Rogers, R. W., \&: Thistlectwwaite, D. L. (1970). Effects of fear arousal and reassurance on attitude change. Journal of Personality and Social Psychology, 15, 227-233.

Ross, M. W., Rigby, K., Rosser, B. R. S., Anagnostou, P., \& Brown, M. (1990). The effect of a national campaign on attitudes toward AIDS. Aids Care, 2, 339-346.

Rothman, A. J., Martino, S. C., Bedell, B. T., Detweiler, J. B., \& Salovey, P. (1999). The systematic influence of gain- and loss-framed messages on interest in and use of different types of health behavior. Personality and Social Psychology Bulletin, 25, 1355-1369.

Rothman, A. J., \& Salovey, P. (1997). Shaping perceptions to motivate healthy behavior: The role of message framing. Psychological Bulletin, 121, 3-19.

Rothman, A. J., Salovey, P., Antone, C., Keough, K., \& Martin, C. D. (1993). The influence of message framing on intentions to perform health behaviors. Journal of Experimental Social Psychology. $29,408-433$.

Ruiter, R. A. C., Abraham, C., \& Kok, G. (2000). Scary warnings and rotional precautions: A review of the psychology of fear appeals. Manuscript under revision.

Ruiter, R. A. C., Kok, G., Verplanken, B., \& Brug. J. (in press). Evoked fear and effects of appeals on attitudes to performing breast self-examination: An information processing perspective. Health Education Research.

Schwarz, N., Bless, H., \& Bohner, G. (1991). Mood and persuasion: Affective states influence the processing of persuasive communications. In M. P. Zanna (Ed.), Advances in experimental sociol psychology (Vol. 24, pp. 161-199). San Diego, CA: Academic Press.

Schwarzer, R. (1992). Self-efficacy in the adoption and maintenance of health behaviors: Theoretical approaches and a new model. In R. Schwarzer (Ed.), Selfefficacy: Thought control of action (pp. 217-243). Washington: Hemisphere Publishing Corporation.

Self, C. A. \& Rogers, R. W. (1990). Coping with threats to health: Effects of persuasive appeals on depressed, normal, and ancisocial personalities. Journal of Behavioral Medicine, 13, 343-357. 
Shelton, M. L, \& Rogers, R. W. (198I). Fear-arousing and empathy-arousing appeals to help: The pathos of persuasion. Journal of Applied Social Psychology, 11, 366-378.

Sherr, L. (1990). Fear arousal and AIDS: do shock tactics work. AIDS, 4, 361-364.

Spielberger, C. D. (1980). Test anxiety inventory, preliminary professional manual for the Test Anxiety Inventory (Test Attitude Inventory) TAI. Palo Alto, CA: Consulting Psychologists Press.

Spielberger, C. D., Gorsuch, R. L, \& Lushene, R. E. (1970). STAl manual for the State-Troit Anxiety Inventory. Palo Alto, CA: Consulting Psychologists Press.

Stivoro. (1997). "...Maar ik rook niet!" [...But I don't smoke!]. The Hague: Stivoro.

Strecher, V. J., \& Rosenstock, I. M. (1997). The health belief model. In K. Glanz, F. M. Lewis, \& B.

K. RImer (Eds.), Health behovior and health education: Theory, research, and practice (2nd ed., Pp. 41-59). San Francisco: Jossey-Bass.

Sutton, S. R. (1982). Fear-arousing communications: A critical examination of theory and research.

In J. R. Eiser (Ed.), Social psychology and behavioral medicine (pp. 303-337). Chichester, England: Wiley.

Sutton, S. (1992). Shock tactics and the myth of the inverted U. British Journol of Addiction, 87, 517 519.

Taubman Ben-Ari, O., Florian, V., \& Mikulincer, M. (2000). Does a threat appeal moderate reckless driving? A terror management theory perspective. Accident Analysis and Prevention, 32, 1-10. Trafimow, D., \& Finlay, K. (1996). The Importance of subjective norms for a minority of people: Between subjects and within-subjects analysis. Personality and Social Psychology Bulletin, 22, 820-828. Trafimow, D., \& Fishbein, M. (1995). Do people really distinguish between behavioural andi normative beliefs?' British Journal of Social Psychology, 34, 257-266.

Van Dalen, W. E. (1999). "Drank maakt meer kapot dan je lief is.": Een beschrijving van het 12,5 jarig bestaan van een unieke campagne ["Alcohol is ruining more than you wish": A description of the 12.5 years existence of an unique campaign]. Hondbook verslaving.

Van der Ploeg. H. M., Defares, P. B., \& Spielberger, C. D. (1979). Zelf-Beorrdelings-Vrogenlijst STAI versie DY-1 en versie DY-2 [Self-Judgment-Questionnaire. STAI version DY-I and version DY-2]. Lisse: Swets en Zeitlinger.

Verplanken, B., Hofstee, G., \& Janssen, H. J. W. (1998). Accessibility of affective versus cognitive components of attitudes. European Journal of Social Psychology, 28, 23-35.

Vinokur, A., \& Burnstein, E. (1978). Novel argumentation and attitude change: The case of polarization following group discussion. European Journal of Social Psychology, 8, 335-3.48.

Wegner, D. M., \& Bargh, J. A. (1998), Control and automaticity in social life. In D. T. Gilbert, S. T. Fiske, \& G. Lindzey (Eds.), The handbook of social psychology (4th ed., Vol. I, pp. 446-496). Boston: McGraw-Hill.

Weinstein, N. D. (1988). The precaution adoption process. Health Psychology, 7, 355-386.

Weinstein, N. D. (1992). Unrealistic optimism about susceptibility to health problems. Journal of Behovioral Medicine, 5, 441-460.

Witte, K. (1992a). Putting the fear back into fear appeals: The extended parallel process model. Communicotion Monographs, 59, 329-349.

Witte, K. (1992b). The role of threat and efficacy in AIDS prevention. International Quarterly of Community Health Educotion, 12, 225-249. 
Witte, K. (1994). Fear control and danger control: A test of the extended parallel process model (EPPM). Communication Monographs, 61, 113-134.

Witte, K. \& Allen, M. (in press). A meta-analysis of fear appeals: Implications for effective public health campaigns. Health Educotion and Behovior.

Witte, K., Berkowitz, J. M., Cameron, K. A. \& McKeon, J. K. (1998). Preventing the spread of genital warts: Using fear appeals to promote self-protective behaviors. Health Educotion and Behavior, 25, 571-585.

Wolf, S., Gregory, W. L. \& Stephan, W. G. (1986). Protection motivation theory: Prediction of intentions to engage in anti-nuclear war behaviors. Journol of Applied Social Psychology, 16, 310. 321.

Wurtele, S. K., \& Maddux, J. E. (1987). Relative contributions of protection motivation theory components in predicting exercise intentions and behavior. Health Psychology, 6, 453-466.

Zajonc, R. B. (1980). Feeling and thinking: Preferences need no inferences. American Psychologist, $35,151-175$.

Zajonc, R. B. (1984). On the primacy of affect. Americon Psychologist, 39, 117-123. 


\section{SUMMARY}

The doctoral thesis summarised here describes a research project into the effects of fear appeals on the motivation to perform a recommended behaviour. A fear appeal is a persuasive communication that attempts to motivate people into safer behaviour by arousing fear. Fear is a common emotion in people that is characterised by unpleasant feelings and the urge to create a situation that is perceived as safe. As a motivator to action, fear could thus serve an important role in increasing the effectiveness of health campaigns. However, the effects of fear appeals on self-protective motivation and behaviour are unclear, which warranted the present research.

The current thesis describes one theoretical and six empirical studies into the effects of fear-arousing information on precautionary motivation. The findings and conclusions of these studies are discussed in chapter 1 . This general overview of these studies concludes with implications for future research and the use of fear appeals in health education practice. The most important theoretical implications that were identified focus on (i) the relationship between fear arousal and threat perception and their influence on attention for persuasive messages, (ii) the automatic versus conscious nature of affective and cognitive control processes that result from fear-arousing information, (iii) the structure of both control processes and their combined effects on motivation and action, and (iv) the persuasive impact of fear appeals by linking fear appeal research with recent innovations in attitude and behaviour change research.

The empirical studies in the present thesis were all laboratory studies that used randomised experimental designs. Threatening information about breast cancer was varied between fear conditions to arouse different levels of fear, and the recommended behaviour of interest was the early detection of breast cancer by performing breast self-examination (BSE). Consequently, only women (female first-year undergraduates) participated in the experiments. Therefore, it is suggested that future research should extend the studies presented here to other risk behaviours and populations.

For health education practice, cautious use of fear appeals in health education practice is recommended because their effects are not well known yet. It is suggested that campaigns may profit more from highlighting the personal relevance of health threats and the feasibility of preventive action than from frightening people about the severity of outcomes following risk behaviour by showing images of death and injury. The latter may easily result in processes of avoidance and denial.

Chapter 2 provides an extensive review of the fear appeal literature. The main theoretical frameworks from which the effects of fear appeals have been studied are introduced and discussed. It is concluded that underlying 
processes that are supposed to mediate the effects of fear appeals have not received sufficient empirical support. A process model is proposed that has implications for future research and health education practice. The model builds on current research that argues for a better understanding of fearinstigated processes, because they may interfere with threat perception and intention formation processes. The model suggests that risk information may prompt two distinct processes: an automatic, emotional process that results in maladaptive responses such as denial and a conscious, cognitive process that may result in acceptance of the recommended action. The proposed relationships need extensive testing in which sequential measurement of fear arousal, other than by self-report, may be necessary. In a final paragraph attention is directed to the presentation of precautionary information. Links are suggested to research on valence of wording and postdecisional processes (e.g., action planning) to increase the persuasive impact of fear appeals.

In chapter 3 the first empirical study is described. It examined the effect of fear arousal on attitude towards participating in early detection activities (i.e., breast self-examination) from an information processing perspective. It was hypothesised that fear arousal motivates respondents into more argument-based processing of fear-relevant persuasive information. Respondents first read information about breast cancer in which fear was manipulated. After measuring fear arousal, respondents read a persuasive message about performing BSE in which the quality of arguments was manipulated. The results showed that reading a high threat message did not result in more argument-based processing of information about BSE performance than reading a low threat message. Instead, analyses with reported fear gave support for the hypothesis. Respondents who reported mild fear based their attitude toward BSE more on the provided arguments than respondents who reported low fear. These findings thus suggest that not perceptions of threat but specific emotional feelings of fear result in more careful reading of fearrelevant persuasive information. It is argued, however, that this conclusion could be premature. Since threat manipulations were used to generate fear but fear arousal and not threat perceptions appeared to influence argumentbased processing, it is possible that a third variable affected fear of breast cancer. Individual differences such as chronic anxiety relating to breast cancer (e.g., induced by experience of breast cancer in the family) and general responsiveness to threatening information (e.g., trait anxiety) may thus account for the effect of reported fear on argument-based processing.

The second empirical study is reported in chapter 4 . It examined the independent effects of severity and susceptibility information about breast cancer on the cognitive processing of a persuasive message about performing BSE. Three hypotheses were formulated. First, high susceptibility information 
would result in more systematic processing (i.e., careful reading of the arguments), due to heightened perceived personal relevance of breast cancer, than low susceptibility information. Second, high severity information would result in more systematic processing than low severity information, but only if recipient's susceptibility to breast cancer was described as low. Thirdly, it was expected that high severity and high susceptibility information would result in more systematic processing than the low severity and low susceptibility information. Despite successful manipulations, no empirical support was found for any of the three hypotheses. These findings thus seem to support the findings of the first empirical study that emotional feelings of fear motivate systematic processing, rather than the more cognitive perceptions of threat. This relationship between fear arousal and systematic processing could not be replicated in the second study because fear level was measured after the dependent variables. This leaves it unclear what level of fear was measured and makes causal interpretation about the effects of fear impossible. Furthermore, the manipulations did not affect BSE performance during three months after the study. The chapter concludes with recommendations for future research into the effects of threatening information on information processing. It is specifically suggested that more implicit measures are needed to assess the extent of systematic information processing (e.g., reaction time procedures), especially when topics that are studied are well known to the audience.

The third and fourth empirical study are reported in chapter 5 . They investigated the moderating influence of individual differences in efficacy beliefs regarding BSE performance in processes of fear control and danger control. It was hypothesised that in response to frightening information about breast cancer, fear control responses (i.e., defensive avoidance, message derogation, perceived manipulation) would be less influenced by efficacy perceptions than danger control responses (i.e., attitude and intention toward BSE performance). Two experiments were carried out that tested this hypothesis. The first measured efficacy perceptions directly after the dependent variables while the second measured efficacy beliefs four to six weeks in advance of the actual study. The findings strongly supported the hypothesis that in response to frightening information existing efficacy beliefs do not influence fear control responses. The findings were less consistent with regard to the postulated moderating role of efficacy beliefs in processes of danger control. The first experiment supported the hypothesis that greater fear results in more motivation to perform the recommended action among respondents with high efficacy perceptions but not among respondents with low efficacy beliefs. However, this hypothesis was not supported in the second experiment. Furthermore, correlational findings indicated that both control processes may be negatively related to each other, but that they do 
not seem to be strongly influencing each other. This may suggest that both control processes largely run independently of each other. The chapter ends with a discussion of the lack of empirical consistency regarding the interaction of threat and efficacy variables on precautionary motivation. There may be many more empirical studies that do not find significant support for this interaction effect and are subsequently not reported, which may easily result in a wrongfully understood "state-of-the-art" concerning the effects of fear appeals.

The fifth study is reported in chapter 6. It examined how wording of precautionary information may influence the effects of fear-arousing information on self-protective motivation. Based on recent persuasion research into the effects of action framing, it was hypothesised that in response to mild fear-arousing information about breast cancer BSE performance would be evaluated more positively after reading information about the negative consequences of not performing BSE (i.e., loss frame) than after reading information about the positive consequences of performing BSE (i.e." gain frame). The main dependent variables were attitude toward BSE and a relative measure of BSE importance, which asked respondents to rank BSE performance and five other health behaviours (e.g., conclom use) in order of importance. No support was found for the hypothesis with manipulated fear. That is, respondents who read mild fear-arousing information did not evaluate BSE more positively after reading the loss frame than after reading the gain frame. An effect of framing was also not found in the low feararousing conditions. Like in chapter 3, however, support was found for the hypothesis with reported fear, but only on the measure of relative importance: respondents who reported mild fear evaluated BSE performance as more important for themselves after reading the loss frame than after reading the gain frame. No effects of framing were found among respondents who reported low fear arousal. The findings carefully suggest that appropriate action framing may strengthen the persuasive impact of fear appeals, but that the findings are by far not conclusive. Future research should further examine these effects with special attention for identifying relevant mediating processes and variables.

The sixth and final study is reported in chapter 7 . Based on the recent interest in social psychology in postdecisional processes to bridge the oftenidentified gap between intention and behaviour, it examined the effects of threatening information and fear arousal on action planning. It was hypothesised that fear-arousing information may motivate people to plan recommended action to avert the presented threat, especially among those respondents that are highly motivated (i.e., intention) to perform the recommended action. Respondents first read mild or low threatening information about breast cancer. After measuring fear and intention to perform 
BSE, action planning was measured by asking respondents whether they had thought about when and where to perform BSE. Analyses with manipulated fear and reported fear partially supported the hypothesis. Respondents in the mild fear condition planned BSE performance more than respondents in the low fear condition. However, this effect of fear on action planning was found among both high and low intenders. This finding supports the importance of linking fear appeal research to research into the effects of postdecisional processes such as action planning and implementation intentions on self-protective action. Fear arousal may be positively related to action planning. It is suggested that future research should extend these findings by using samples from other populations than young females with a high educational background, covering different health topics and behaviours, and including measures of actual performance without ignoring ethical guidelines regarding long-term effects of fear-arousing information outside the laboratory. 


\section{SAMENVATTING}

Het huidige proefschrift beschrijft een onderzoeksproject naar de effecten van angstaanjagende persuasieve boodschappen op de motivatie tot gezonder gedrag. Een angstaanjagende persuasieve boodschap is een overtuigende voorlichtingsboodschap die mensen tracht te motiveren tot gezonder gedrag door angstgevoelens op te wekken. Angst is een veel voorkomende emotie die wordt gekenmerkt door onplezierige gevoelens en de neiging een situatie te creëren die als veilig wordt ervaren'. Omdat angst motiveert tot actie kan deze emotie een belangrijke rol spelen bij pogingen de effectiviteit van voorlichtingsboodschappen te verhogen. De effecten van angstaanjagende persuasieve boodschappen op (de motivatie tot) het ondernemen van veiliger gedrag zijn echter onduidelijk, hetgeen de aanleiding vormt voor het hier beschreven onderzoek.

Het proefschrift dat hier wordt samengevat beschrijft een theoretische en zes empirische studies naar de effecten van angstaanjagende informatie op de motivatie zich te beschermen tegen het gepresenteerde gevaar. In hoofdstuk 1 wordt een algemeen overzicht gegeven van de bevindingen en conclusies van deze studies. Het hoofdstuk sluit af met aanbevelingen voor toekomstig onderzoek en het gebruik van angstaanjagende persuasieve boodschappen in de praktijk van gezondheidsvoorlichting. De belangrijkste aanbevelingen voor toekomstig onderzoek zijn dat meer aandacht besteed moet worden aan: (i) de relatie tussen angstgevoelens en de cognitieve waarneming van dreiging en de invloed die beiden hebben op de aandacht voor persuasieve boodschappen, (ii) de automatische versus bewuste aard van affectieve en cognitieve controleprocessen die het gevolg zijn van het aanbieden van angstaanjagende informatie, (iii) de structuur van beide controleprocessen en hun gecombineerde effect op motivatie en gedrag, en (iv) de persuasieve impact van angstaanjagende persuasieve boodschappen door verbindingen te leggen met recente innovaties op het terrein van attitude- en gedragsverandering.

De empirische studies in dit proefschrift betreffen laboratoriumstudies waarbij gebruik wordt gemaakt van gerandomiseerde experimentele onderzoeksdesigns. Om verschillende niveaus van angst op te wekken hebben we hoog en laag bedreigende informatie over borstkanker aangeboden. Het aanbevolen 'gezonde' gedrag is het vroegtijdig ontdekken van borstkanker door

\footnotetext{
I In deze samenvatting wordt de Engelse term "fear" vertald met de Nederlandse term "angst". Een meer specifieke vertaling wordt verkregen door het gebruik van de term "vrees". Echter in de praktijk van gezondheidsvoorlichting is angstaanjagende voorlichting een algemeen gebruikt begrip.
} 
het doen van borstzelfonderzoek. Dit heeft tot gevolg gehad dat alleen vrouwen (eerstejaars vrouwelijke studenten) aan de experimenten deelnamen. Toekomstig onderzoek dient zich dan ook te richten op andere risicogedragingen (bijvoorbeeld onveilig rijden) en -populaties.

Voor de praktijk van gezondheidsvoorlichting wordt geconcludeerd dat voorzichtig moet worden omgegaan met het gebruik van angstaanjagende informatie in voorlichtingscampagnes. Campagnes zullen meer profiteren van het aanbieden van informatie die als persoonlijk relevant wordt ervaren en de effectiviteit en uitvoerbaarheid van het aanbevolen gedrag benadrukken dan van informatie die de ernstige gevolgen van het risicogedrag laat zien door middel van beelden die verwijzen naar letsel en dood. Dit laatste kan gemakkelijk leiden tot processen van vermijding en ontkenning.

Hoofdstuk 2 biedt een uitgebreid literatuuroverzicht van het onderzoek naar de effecten van angstaanjagende persuasieve boodschappen. De belangrijkste theoretische modellen in het onderzoek naar de effecten van angstaanjagende boodschappen worden geïntroduceerd en bekritiseerd. Er wordt geconcludeerd dat de onderliggende processen die de effecten van angstaanjagende boodschappen zouden moeten medieren niet voldoende gesteund worden door empirisch onderzoek. Een procesmodel wordt opgesteld dat belangrijke implicaties heeft voor toekomstig onderzoek en de praktijk van gezondheidsvoorlichting. Het model bouwt voort op hedendaags onderzoek dat pleit voor hernieuwde aandacht voor angstgerelateerde processen, aangezien die een storende invloed kunnen op processen die moeten leiden tot veiliger gedrag. Het model suggereert dat risico-informatie twee afzonderlijke processen kan aansturen: een automatisch, emotioneel proces dat resulteert in maladaptieve responsen zoals ontkenning en een bewust, cognitief proces dat kan resulteren in acceptatie van het aanbevolen gedrag. De relaties die binnen het model worden gelegd moeten uitvoerig worden getest in experimenteel onderzoek, waarbij opeenvolgende metingen van angst, anders dan door middel van zelf-rapportage, noodzakelijk zullen zijn. Om de persuasieve impact van angstaanjagende boodschappen te vergroten stellen wij voor aansluiting te zoeken bij onderzoek naar de effecten van het presenteren van informatie in negatieve versus positieve bewoordingen en de rol van post-intentionele processen zoals het plannen van toekomstig gedrag.

In hoofdstuk 3 staat de eerste empirische studie beschreven. Hierin worden de effecten van angstaanjagende informatie op de attitude ten aanzien van het doen van borstzeifonderzoek bestudeerd vanuit het perspectief van informatieverwerking. De hypothese is dat angst motiveert tot het nauwkeurig bestuderen van de argumenten in de persuasieve boodschap. De respondenten lezen eerst informatie over borstkanker waarin angst is gemanipuleerd. $\mathrm{Na}$ het meten van de mate waarin angst wordt ervaren lezen de responden- 
ten een persuasieve boodschap over het doen van borstzelfonderzoek waarin de kwaliteit van argumenten is gemanipuleerd. De resultaten laten zien dat het lezen van hoog-bedreigende informatie niet leidt tot een betere cognitieve verwerking van argumenten dan het lezen van een laag-bedreigende boodschap. In plaats daarvan wordt met analyses waarin de gerapporteerde, in plaats van gemanipuleerde, angst is opgenomen steun gevonden voor de hypothese. Respondenten die matige angst rapporteerden na het lezen van de informatie over borstkanker baseerden hun attitude ten aanzien van het doen van borstzelfonderzoek meer op de aangedragen argumenten om borstzelfonderzoek te doen dan respondenten die een lage angst rapporteerden. Deze bevindingen suggereren dat niet percepties van dreiging maar specifieke gevoelens van angst bepalen of angstrelevante persuasieve informatie nauwkeurig wordt gelezen. Deze conclusie is mogelijk echter wat voorbarig omdat de manipulatie van bedreigende informatie wel succesvol was in het oproepen van verschillende niveaus van angst maar niet van invloed bleek te zijn op het nauwkeurig lezen van de persuasieve informatie. Het zou dus kunnen zijn dat een derde variabele die ons niet bekend was de angst voor borstkanker heeft beinvloed, bijvoorbeeld chronische angst voor kanker, die vervolgens verantwoordelijk is geweest voor de effecten die werden gevonden met gerapporteerde angst.

De tweede empirische studie staat beschreven in hoofdstuk 4. De onafhankelijke effecten van ernst- en kansinformatie over borstkanker op de mate van cognitieve verwerkingen een persuasieve boodschap over het doen van borstzelfonderzoek worden bestudeerd. Drie hypothesen worden opgesteld. Ten eerste, hoge kansinformatie leidt als gevolg van een hogere inschatting van persoonlijke relevantie tot meer systematische informatieverwerking (ofwel nauwkeurig lezen) dan lage kansinformatie. Ten tweede, hoge ernstinformatie leidt tot meer systematische informatieverwerking dan lage ernstinformatie, maar alleen als de kans op de dreiging als laag wordt gepresenteerd. Ten derde wordt verwacht dat hoge ernst- en hoge kansinformatie tot meer systematische verwerking zal leiden dan lage ernst- en lage kansinformatie. Ondanks succesvolle manipulaties wordt voor deze hypothesen geen steun gevonden. De bevindingen van deze studie lijken dus die van de eerste empirische studie te bevestigen, namelijk dat emotionele gevoelens van angst verantwoordelijk zijn voor de effecten op informatieverwerking en niet zozeer de cognitieve waarnemingen van dreiging. De relatie tussen angst en informatieverwerking kan niet worden gerepliceerd in deze tweede studie omdat angst pas na de afhankelijke variabelen werd gemeten. Hierdoor is het onduidelijk welk niveau van angst wordt gemeten. Tevens is het onmogelijk causale conclusies te trekken over de effecten van angst. Een vervolgmeting drie maanden na het experiment laat zien dat de manipulaties geen invloed hebben gehad op het doen van borstzelfonder- 
zoek. Het hoofdstuk eindigt met aanbevelingen voor toekomstig onderzoek naar de effecten van bedreigende informatie op informatieverwerking. Een suggestie die wordt gedaan is dat impliciete metingen mogelijk beter de mate van systematische informatieverwerking (bijvoorbeeld reactietijden procedures) vast kunnen stellen, met name wanneer de te bestuderen onderwerpen uitgebreid bekend zijn bij het algemene publiek.

De derde en vierde empirische studie staan beschreven in hoofdstuk 5 . In deze studies wordt de modererende invloed van individuele verschillen in effectiviteitverwachtingen in processen van angstcontrole en gevaarcontrole onderzocht. Fr wordt verondersteld dat na het lezen van angstaanjagende informatie over borstkanker angstcontrole responsen (defensieve vermijding, afkraken van de boodschap, vermoeden van manipulatie) minder worden beïnvloed door effectiviteitverwachtingen ten aanzien van het doen van borstzelfonderzoek dan gevaarcontrole responsen (attitude, intentie). Twee experimenten worden gerapporteerd. In het eerste experiment worden effectiviteitverwachtingen direct na de afhankelijke variabelen gemeten, in het tweede experiment worden die vier tot zes weken voor aanvang van het experiment gemeten. De bevindingen bieden sterke steun voor de hypothese dat na het lezen van angstaanjagende informatie angstcontrole processen niet worden beînvloed door bestaande effectiviteitverwachtingen. De bevindingen zijn minder consistent voor de veronderstelde modererende rol van effectiviteitverwachtingen in processen van gevaarcontrole. Het eerste experiment biedt steun voor de hypothese dat bij respondenten met hoge effectiviteitverwachtingen meer angst leidt tot meer motivatie om borstzelfonderzoek uit te voeren en dat dit effect van angst op motivatie niet optreedt bij respondenten met lage effectiviteitverwachtingen. Het tweede experiment vindt echter geen steun voor deze hypothese. Daarnaast laten correlatie-analyses zien dat beide controleprocessen negatief aan elkaar gerelateerd zijin, maar dat deze relatie niet sterk is. Dit suggereert dat in reactie op angstaanjagende informatie beide controleprocessen grotendeels onafhankelijk van elkaar opereren. Het hoofdstuk eindigt met een discussie over het gebrek aan consistente bevindingen aangaande de interactie van dreiging- en effectiviteitvariabelen op de motivatie zichzelf te beschermen tegen bet gepresenteerde gevaar. Fr zijn waarschijnlijk veel meer empirische studies die geen significante steun hebben gevonden voor dit interactie-effect en vervolgens, niet zijn gepubliceerd. Dit kan gemakkelijk resulteren in een verkeerde opvatting over de "stand-van-zaken" met betrekking tot de effecten van angstaanjagende persuasieve boodschappen.

De vijfde empirische studie staat beschreven in hoofdstuk 6. Deze studie onderzoekt hoe het formuleren van boodschappen in negatieve of positieve termen de persuasieve effecten van angstaanjagende informatie kan beïnvloeden. Er wordt verondersteld dat in reactie op angstaanjagende informat- 
tie over borstkanker borstzelfonderzoek positiever geêvalueerd zal worden na het lezen van informatie over de negatieve gevolgen van het niet doen van borstzelfonderzoek (verliesinformatie) dan na het lezen van informatie over de positieve gevolgen van het wel doen van borstzelfonderzoek (winstinformatie). De belangrijkste afhankelijke variabelen zijn attitude ten aanzien van het doen van borstzelfonderzoek en het relatieve belang van het doen van borstzelfonderzoek ten opzichte van vijf andere gezondheidsgedragingen (bijvoorbeeld condoomgebruik). Analyses met gemanipuleerde angst vinden geen steun voor de hypothese: respondenten die matig angstaanjagende informatie kregen evalueerden borstzelfonderzoek niet positiever na het lezen van verliesinformatie dan na het lezen van winstinformatie. Een effect van soort informatie (negatief versus positief) wordt ook niet gevonden bij de respondenten die laag angstaanjagende informatie kregen. Evenals in hoofdstuk 3 wordt na opname van gerapporteerde angst in de analyses wel steun gevonden voor de hypothese: respondenten met matige angst waren na het lezen van verliesinformatie positiever over het belang van borstzelfonderzoek in vergelijking tot de vijf andere gezondheidsgedragingen dan na het lezen van winstinformatie. Dit effect van soort informatie wordt niet gevonden bij respondenten die lage angst rapporteerden. De bevindingen suggereren dan ook dat de wijze waarop persuasieve informatie wordt gepresenteerd (negatief of positief) van invloed kan zijn op de effectiviteit van angstaanjagende persuasieve boodschappen. Toekomstig onderzoek moet uitwijzen welke processen en variabelen voor deze effecten verantwoordelijk zijn.

De zesde en laatste empirische studie staat beschreven in hoofdstuk 7. Deze studie onderzoekt de effecten van angstaanjagende informatie en gevoelens van angst op het plannen van toekomstig gedrag. Er wordt verondersteld dat angstaanjagende informatie mensen zal motiveren het aanbevolen gedrag te plannen in termen van waar en wanneer het zal worden uitgevoerd, en dat dit met name het geval zal zijn bij respondenten die gemotiveerd zijn om het aanbevolen gedrag uit te voeren. Respondenten lezen eerst matige of lage bedreigende informatie. $\mathrm{Na}$ het meten van angst en intentie tot het doen van borstzelfonderzoek wordt het plannen van toekomstig gedrag gemeten door aan respondenten te vragen in hoeverre zij hebben nagedacht over waar en wanneer zij een borstzelfonderzoek zullen uitvoeren. Analyses met gemanipuleerde en gerapporteerde angst bieden gedeeltelijk steun voor de hypothese. Respondenten in de matige angstconditie planden het doen van borstzelfonderzoek meer dan respondenten in de lage angstconditie, maar dit effect van angst wordt gevonden onder zowel respondenten met hoge intentie tot het doen van borstzelfonderzoek als onder respondenten met lage intentie tot het doen van borstzelfonderzoek. Deze bevinding ondersteunt het belang om onderzoek naar de effecten van angstaanjagende 
persuasieve boodschappen te combineren met onderzoek naar de effecten van postintentionele processen zoals het plannen van aanbevolen gedrag. In dit kader wordt aanbevolen toekomstig onderzoek te laten plaatsvinden onder andere populaties dan eerstejaars vrouwelijke studenten, waarbij een ander gezondheidsprobleem dan borstkanker en het doen van borstzelfonderzoek als onderwerp dient en de uitvoering van het aanbevolen gedrag daadwerkelijk wordt gemeten zonder daarbij ethische richtlijnen aangaande mogelijke negatieve lange termijn effecten van het geven van angstaanjagende informatie te negeren. 


\section{CURRICULUM VITAE}

Rob Ruiter was born on November 21, 1969 in Haaksbergen, Twente. In 1988 he graduated at De Scholengemeenschap "De Bouwmeester" in Haaksbergen and received a VWO diploma. That same year he started his university training at Rijksuniversiteit Limburg in Maastricht (now Universiteit Maastricht). He received his Master of Public Health degree at the Faculty of Health Sciences in March 1995. In April 1995, he started as Assistent in Opleiding (AIO) at the Department of Health Education and Promotion to work on the $\mathrm{PhD}$ project entitled "The effects of fear appeals". The outcome of this work has been written down in the present thesis. Since 1999 he has been employed as lecturer at the Department of Experimental Psychology at the Faculty of Psychology, Universiteit Maastricht. 
Vraag willekeurige leden uit de doelgroep hoe voorlichtingsmateriaal verbeterd zou moeten worden om gezond gedrag te bevorderen, dan is vaak het antwoord: het moet harder, met name door het op indringende en angstaanjagende wijze tonen van de negatieve gevolgen van het ongezonde gedrag (bijvoorbeeld onveilig vrijen en AIDS). Vijftig jaar sociaalpsychologisch onderzoek is echter niet in staat geweest een eenduidig antwoord te geven op de vraag of angstaanjagende voorlichting inderdaad effectief is. In dit proefschrift wordt een hernieuwde poging ondernomen om deze vraag te beantwoorden, met wisselend succes: geen eenduidig inzicht in de effectiviteit van angstaanjagende voorlichting, wel meer duidelijkheid over mogelijke averechtse effecten van deze vorm van voorlichting en daarom het advies voorzichtig te zijn met het gebruik ervan. 